\title{
Annual Report, Basic Sciences Branch, FY 1991
}

Basic Sciences Branch

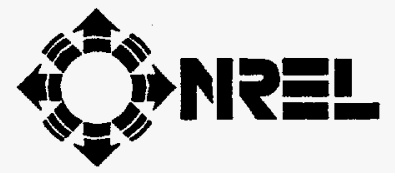

National Renewable Energy Laboratory 1617 Cole Boulevard Golden, Colorado 80401-3393 Operated by Midwest Research Institute for the U.S. Department of Energy under Contract No. DE-ACO2-83CH10093

Prepared under Task No. PV314001

April 1993

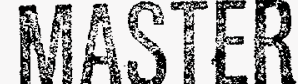




\section{NOTICE}

This-report was prepared as an account of work sponsored by an agency of the United States government. Neither the United States government nor any agency thereof, nor any of their employees, makes any warranty, express or implied, or assumes any legal liability or responsibility for the accuracy, completeness, or usefulness of any information, apparatus, product, or process disclosed, or represents that its use would not infringe privately owned rights. Reference herein to any specific commercial product, process, or senvice by trade name, trademark, manufacturer, or othenwise does not necessarily constitute or imply its endorsement, recommendation, or favoring by the United States government or any agency thereof. The views and opinions of authors expressed herein do not necessarily state or reflect those of the United States government or any agency thereof.

Printed in the United States of America

Available from:

National Technical Information Service

U.S. Department of Commerce

5285 Port Royal Road

Springfield, VA 22161

Price: Microfiche A01

Printed Copy A04

Codes are used for pricing all publications. The code is determined by the number of pages in the publication. Information pertaining to the pricing codes can be found in the current issue of the following publications which are generally available in most libraries: Energy Research Abstracts (ERA); Government Reports Announcements and Index (GRA and I); Scientific and Technical Abstract Reports (STAR); and publication NTIS-PR-360 available from NTIS at the above address. 


\section{DISCLAIMER}

Portions of this document may be illegible electronic image products. Images are produced from the best available original document. 


\section{Preface}

This report summarizes the accomplishments of the Basic Sciences Branch of the National Renewable Energy Laboratory (NREL) from October 1, 1990, through September 30, 1991. (In December 1991, the branch became the Materials Science Branch.) Seven technical sections of this report cover the following areas of NREL research: Crystal Growth Research, Amorphous Silicon Research, Polycrystalline Thin Films (involving group II-VI compounds and their analogues), III-V HighEfficiency Photovoltaic Cells, Solid-State Theory, Solid-State Spectroscopy, and Superconductivity.

Each section of the report was written by the group leader principally in charge of the work. The task in each case was to explain the purpose and major accomplishments of the work in the context of the U.S. Department of Energy's National Photovoltaic Research Program plans.

Included at the end of each section is a list of publications produced from October 1 , 1990, through September 30, 1991. 


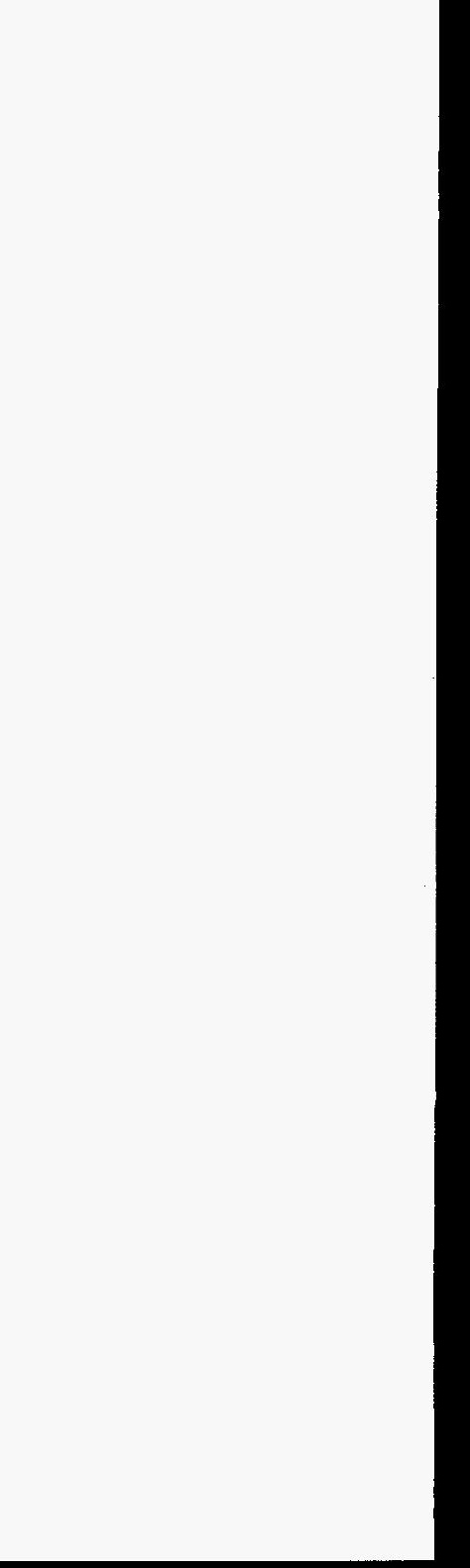




\section{Contents}

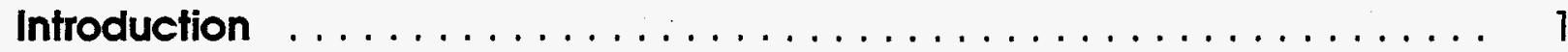

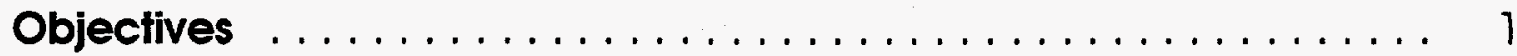

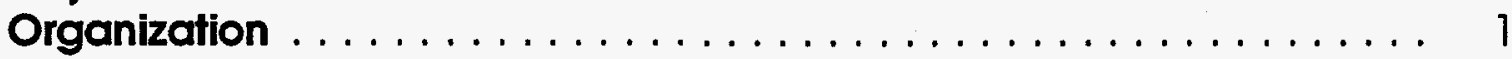

Key Accomplishments $\ldots \ldots \ldots \ldots \ldots \ldots \ldots \ldots \ldots \ldots \ldots$ I

Crystal Growth Research . . . . . . . . . . . ........... I

Amorphous Silicon Research $\ldots \ldots \ldots \ldots \ldots \ldots \ldots \ldots \ldots \ldots$ I

Polycrystalline Thin Films ..................... 2

III-V High-Efficiency Photovoltaic Cells $\ldots \ldots \ldots \ldots \ldots \ldots \ldots, 2$

Solid-State Theory . .......................... 3

Solid-State Spectroscopy $\ldots \ldots \ldots \ldots \ldots \ldots \ldots \ldots \ldots \ldots \ldots$

Superconductivity $\ldots \ldots \ldots \ldots \ldots \ldots \ldots \ldots \ldots \ldots \ldots \ldots \ldots$

1. Crystal Growth Research $\ldots \ldots \ldots \ldots \ldots \ldots \ldots \ldots \ldots$

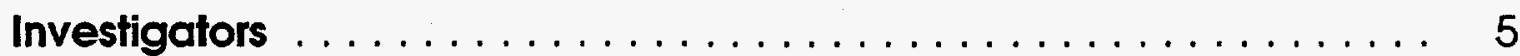

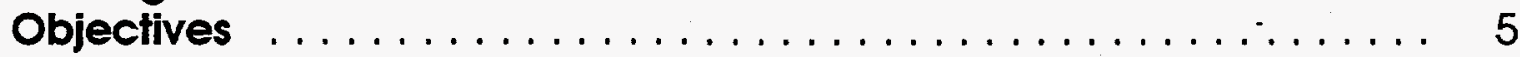

Major Accomplishments ....................... 5

Thin-Layer Silicon Crystal Growth . . . . . . . . . . . . . . . . . . 5

Material Quality Requirements for Thin-Layer Silicon . . . . . . . . . 7

Polishing Thin Silicon . . . . . . . . . . . . . . . . . . . . . 7

Silicon Photovoltaic Device Fabrication $\ldots \ldots \ldots \ldots \ldots \ldots \ldots$

CulnSe ${ }_{2}$ Crystal Growth . ...................... 8

Environment, Safety, and Health Activities ........... 8

Publications and Presentations . . . . . . . . . . . . . . . 9

References ................................ 10

2. Amorphous Silicon Research $\ldots \ldots \ldots \ldots \ldots \ldots \ldots \ldots$

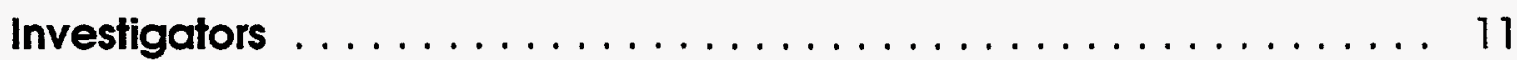

Objectives $\ldots \ldots \ldots \ldots \ldots \ldots \ldots \ldots \ldots \ldots \ldots \ldots \ldots \ldots$

Major Accomplishments . . . . . . . . . . . . . . . . . . . . 11

Material and Device Deposition and Characterization . . . . . . . 11

Metastability ......................... 14

Publications $\ldots \ldots \ldots \ldots \ldots \ldots \ldots \ldots \ldots \ldots \ldots \ldots \ldots \ldots$

3. Polycrystalline Thin Films $\ldots \ldots \ldots \ldots \ldots \ldots \ldots \ldots \ldots$

Investigators . . . . . . . . . . . . . . . . . . . . . 19

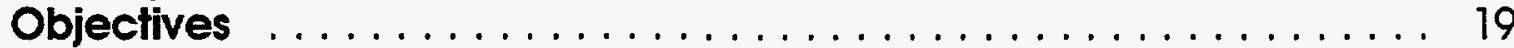


Major Accomplishments

The Effect of Microstructure and Strain in In/Cu/Mo/Glass

Precursors on CdS/CulnSe ${ }_{2}$ Photovoltaic Device Fabrication

by Selenization .

The Effect of Copper Vacancies on the Optical Bowing of

Chalcopyrite $\mathrm{Cu}(\mathrm{In}, \mathrm{Ga}) \mathrm{Se}_{2}$ Alloys

Modifications to the Interfacial and Bulk Region of

CulnSe ${ }_{2}$-Based Photovoltaic Devices: Alloys, Windows, and Grain Size Enhancement

Physical, Chemical, and Structural Modification to Thin-Film

CulnSe ${ }_{2}$-Based Photovoltaic Devices

Optical Band Gap and Lattice Constant of $\mathrm{Zn}_{1-x} \mathrm{Cd}_{x} \mathrm{~S}_{7-y} \mathrm{Se}_{y}$

Thin Film Alloys Used as Window Materials for Photovoltaic

Cells

Publications

References

4. III-V High-Efficiency Photovoltaic Cells

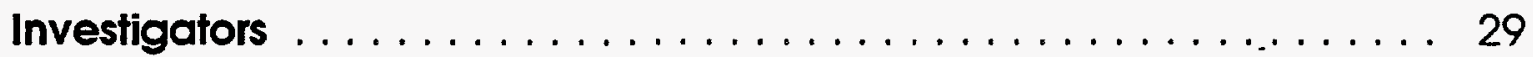

Objectives ............................. 29

Major Accomplishments . . . . . . . . . . . . . . . . . . . . 29

Back Surface Fields for GalnP 2 Solar Cells . . . . . . . . . . . . . . 29

Cation Site Ordering and Conduction Electron Scattering

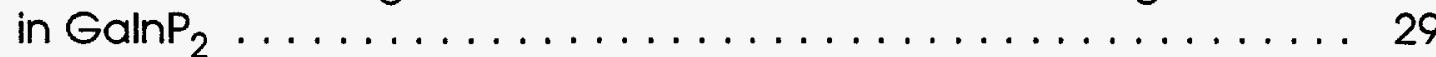

GalnP $P_{2}$ GaAs Tandem Solar Cells for Space Applications . . . . . 30

Quantitative Study of Atomic Ordering in $\mathrm{Ga}_{0.5} \ln _{0.5} \mathrm{P}$

Thin Films by ${ }^{31} \mathrm{P}$ Nuclear Magnetic Resonance ... . . . . . . . 31

Effect of Base Doping on Radiation Damage in GaAs

Single-Junction Solar Cells . . . . . . . . . . . . . . . . . . 31

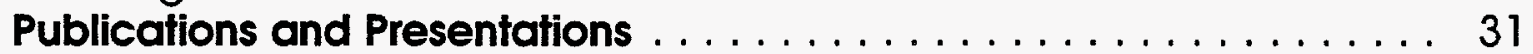

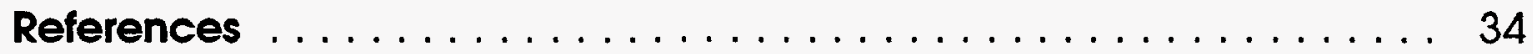

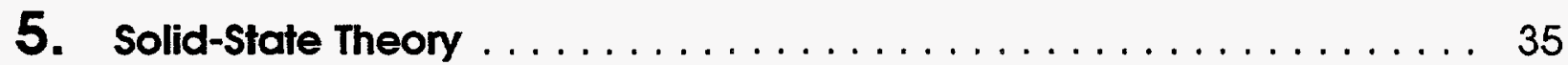

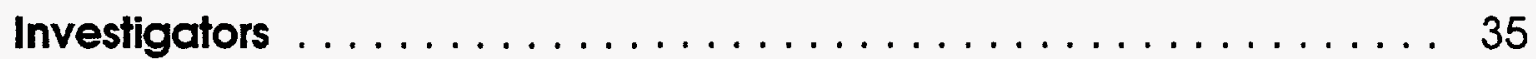

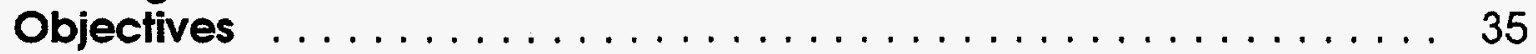

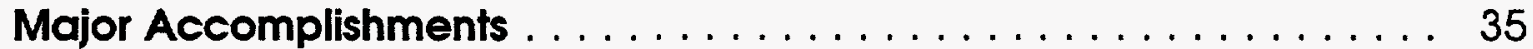

Density of States of Disordered Transition Metal Alloys . . . . . . . 35

First-Principles Calculation of the Order-Disorder

Transition in Chalcopyrite Semiconductors . . . . . . . . . . 36

Consequences of Interfacial Roughness in Semiconductor

Superlattices on Stability and Optical Properties ............

Ordering Thermodynamics of Surface and Subsurface

Layers in GalnP Alloys 
Comparisons of Ab-Initio Charge Densities of Semiconductors with Experiment .................. 38

An Efficient Method for Performing Large-Scale

Pseudopotential Calculations on Complex Solids . . . . . . . . . 38

Diamond-Like Order in Zinc-Blende Compounds . . . . . . . . . . . . . . 39

A New Method for Predicting Band Gaps of Arbitrary Substitutional Structures . . . . . . . . . . . . . . . . . . . . . . . . 39

Strain Energy and Stability of Si-Ge Compounds, Alloys, and Superlattices . . . . . . . . . . . . . . . . . . . . . . . . 40

Theory of Defects, Impurities, and Doping in ZnSe . . . . . . . 41

Publications $\ldots \ldots \ldots \ldots \ldots \ldots \ldots \ldots \ldots \ldots \ldots \ldots \ldots \ldots \ldots \ldots$

6. Solid-State Spectroscopy $\ldots \ldots \ldots \ldots \ldots \ldots \ldots \ldots \ldots \ldots \ldots$. . . . 43

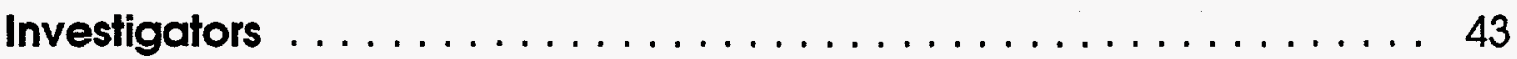

Objective $\ldots \ldots \ldots \ldots \ldots \ldots \ldots \ldots \ldots \ldots \ldots \ldots \ldots \ldots \ldots$

Major Accomplishments ....................... 43

Spectroscopic Studies on Spontaneously Generated

Lateral Superlattices . . . . . . . . . . . . . . . . . . 43

Publications $\ldots \ldots \ldots \ldots \ldots \ldots \ldots \ldots \ldots \ldots \ldots \ldots \ldots$

7. Superconductivity $\ldots \ldots \ldots \ldots \ldots \ldots \ldots \ldots \ldots \ldots \ldots \ldots$

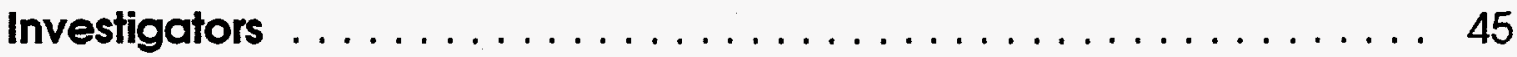

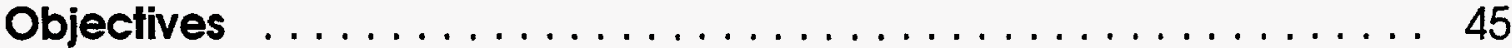

Major Accomplishments $\ldots \ldots \ldots \ldots \ldots \ldots \ldots \ldots \ldots \ldots \ldots \ldots 45$

Technical Highlights . . . . . . . . . . . . . . . . 45

Subcontracts and Collaborations .................. 45

Development of Electrodeposition Processing ........... 46

Heat Treatment of Electrodeposited Films . . . . . . . . . . . 46

Microstructural Analysis . . . . . . . . . . . . . . . . . . . 47

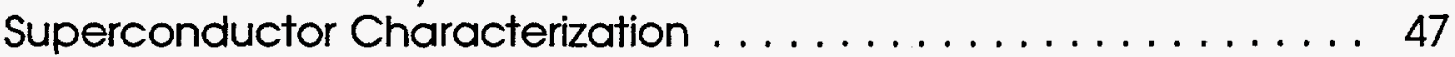

Publications and Presentations . . . . . . . . . . . . . . . . 49 


\section{Figures}

1-1 Silicon layers grown from copper solution on a (111) singlecrystal substrate

1-2 Composition versus position along ingot showing composition change in type conversion region $\ldots \ldots \ldots \ldots \ldots \ldots \ldots$

2-1 FWHM measurement of the Raman Si-Si TO mode . . . . . . . . . . 12

2-2 DOS versus energy $\ldots \ldots \ldots \ldots \ldots \ldots \ldots \ldots \ldots \ldots \ldots \ldots$

2-3 Defect density as measured by CPM for the HW and GD films, both in the as-grown and saturated-light-soaked states, and plotted as a function of the bonded hydrogen content . . . . . . 14

2-4 The DOS for dangling-bond optical transitions before and after light soaking according to Reaction 1 and Reaction 2 of the Adler model

3-1 The effect of strain on X-ray diffraction line position $\left(d_{110}\right)$ and width (FWHM), both theoretically and as observed, for In/Cu/Mo/glass precursors . . . . . . . . . . . . . . . . . .

3-2 Molybdenum (110) peak distortion (FWHM and $\varepsilon(110)$ strain) for as-fabricated, as-annealed, and as-selenized (SLS substrates only) precursors A, B, and C

3-3 A simple mechanistic model for explaining the difference in film strain (qualitatively) measured for points 1 and 2 in Figure 3-2

3-4 Optical band gap of Culn ${ }_{1-y} \mathrm{Ga}_{y} \mathrm{Se}_{2}$ alloys, including the effect of copper

3-5 Correlation of lattice shrinkage with the increased band gap of copper-poor alloys

3-6 SIMS depth profile of two CulnSe ${ }_{2}$ device structures. One contains $1000 \AA$ of Culn ${ }_{0.88} \mathrm{Al}_{0.12} \mathrm{Se}_{2}$, while the other contains $1000 \AA$ of $\mathrm{Zn}_{0.4}$ (Culn $)_{1.6} \mathrm{Se}_{2}$ 
3-7 Relative spectral response of a standard $\mathrm{CdS} / \mathrm{CulnSe_{2 }}$ device and three alloy device structures; $1000 \AA$ (Culn) ${ }_{1.6} \mathrm{Zn}_{0.4} \mathrm{Se}_{2}$ at the interface; $1000 \AA$ Culn $0.76 \mathrm{Al}_{0.24} \mathrm{Se}_{2}$ buried layer; and $2000 \AA$ Culn $_{0.88} \mathrm{Al}_{0.12} \mathrm{Se}_{2}$ at the interface

3-8 Scanning electron micrograph of the surface morphology of large-grain, thin-film CulnSe ${ }_{2} \ldots \ldots \ldots \ldots \ldots \ldots \ldots \ldots \ldots \ldots$

3-9 Auger compositional analysis of the sample depicted in

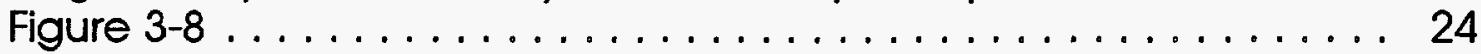

3-10 Auger compositional depth profile of the bulk grain region of the thin-film sample depicted in Figure 3-8

3-11 Experimentally obtained optical band gap and lattice constant for various $Z n_{1-x} C d_{x} S_{1-y} S e_{y}$ thin-film alloys superimposed on contours of the calculated values

4-1 $\quad V_{\text {oc }}$ versus band gap for a number of different cells $\ldots \ldots \ldots . . .30$

4-2 Room temperature Hall mobilities and carrier concentrations for ordered (growth temperature $\mathrm{T}_{g}=670^{\circ} \mathrm{C}$ ) and disordered $\tau_{g}=600^{\circ}$ and $\left.750^{\circ} \mathrm{C}\right)$ samples

4-3 Effects of magic-angle spinning to resolve NMR lines from ${ }^{3 i} P$ nuclei in the five possible $G a_{n} \ln _{4-n} P$ clusters

4-4 Damage coefficient values derived from modeling the external quantum efficiency of the cells.

6-1 PR Spectra of the sample at room temperature with the polarization of the incident light $E$ along (110) and (110)

6-2 Photoluminescence excitation spectrum of the buffer layer . . . . . 44

7-1 Cyclic voltammogram for a solution mixture of $\mathrm{TINO}_{3}$. $\mathrm{Ca}\left(\mathrm{NO}_{3}\right)_{2} 4 \mathrm{H}_{2} \mathrm{O}, \mathrm{Ba}\left(\mathrm{NO}_{3}\right)_{2}$, and $\mathrm{Cu}\left(\mathrm{NO}_{3}\right)_{2}$ dissolved in dimethyl sulfoxide

7-2 The electrodeposition schematic $\ldots \ldots \ldots \ldots \ldots \ldots \ldots$

7-3 The two-zone furnace schematic $\ldots \ldots \ldots \ldots \ldots \ldots \ldots \ldots$

7-4 Typical current versus voltage for a YBCO film . . . . . . . . . . 49

7-5 Schematic of the mutual inductance measurement setup . . . . . 50 


\section{Tables}

3-1 Summary of Modifications to CulnSe ${ }_{2} /$ CdS Device Structure . . . . 23

3-2 List of Potential Alloy Partners to CulnSe $2 \ldots \ldots \ldots 23$ 


\section{Introduction}

This report covers the research and development in the Basic Sciences Branch at the National Renewable Energy Laboratory (NREL) during the period from October 1, 1990, to September 30, 1991.

\section{Objectives}

The objectives of the branch are threefold: (1) to define and carry out fundamental and applied research on state-of-the-art photovoltaic materials and devices that are consistent with the Department of Energy's (DOE) five-year research plans, (2) to complement subcontract research activities, and (3) to identify research needs and develop, evaluate, and transfer a coherent base of scientific knowledge and technology to the public and private sectors, so that rational decisions can be made on the relevance of different technologies for cost-effective power generation.

\section{Organization}

To meet these objectives, research activities within the branch are structured into the following program areas:

- Crystal Growth Research

- Amorphous Silicon Research

- Polycrystalline Thin Films (involving group II-VI compounds and their analogues)

- III-V High-Efficiency Photovoltaic Cells

- Solid-State Theory

- Solid-State Spectroscopy

- Superconductivity

The scope of each of these program areas was carefully chosen to ensure a close integration with one another and with related activities in other branches. They are funded through DOE programs from both the Office of Conservation and Renewable Energy, through the Office of Utility Technologies (the Photovoltaics Program) and the Office of Energy Research, Basic Energy Sciences (OER/BES) through the Division of Material Sciences.

In addition to its mainstream activities, the branch also conducted research on high-critical-temperature superconducting thin films and bulk materials. The superconductivity work is funded by DOE's Office of Energy Storage and Distribution. In fiscal year (FY) 1991, the branch staff was composed of 32 full-time and 15 visiting scientists and students.

\section{Key Accomplishments}

During FY 1991, the members of the branch made major contributions to various technologies through fundamental studies and applied research and development. A brief overview of the key accomplishments is given here. More extensive discussions and lists of publications are given in Sections 1-7.

\section{Crystal Growth Research}

The main objectives of the Crystal Growth Research Group were to (1) initiate investigations of alternative approaches for thin-layer silicon growth that could be used in multi-light-pass photovoltaic (PV) device structures; (2) reestablish a baseline silicon PV cell fabrication process to complement and support our experimental silicon materials work; and (3) develop procedures and an apparatus for growing stoichiometric CuInSe ${ }_{2}$ crystals with $1-\mathrm{cm}$ grain sizes that are of suitable quality for basic characterization and use by other researchers. Key accomplishments of the Crystal Growth Research Group follow:

- We began demonstrating the use of copper as a solvent for growing high-quality thin films of silicon. This metal solvent has not been reported in previous literature on silicon growth from solution, presumably because of concerns regarding the degradation of minority carrier lifetime.

However, both electrowinning and the chemical vapor deposition of silicon from Cu-Si alloy sources have indicated that the alloy has beneficial gettering or impurity-filtering properties.

- We explored other techniques of preparing thin films, including plasma deposition and electrodeposition. However, neither technique looked promising.

- We studied the effects of grain size and silicon thickness on solar cell efficiency. We used a unique technique of growing ingots with continuously widening grain sizes and processed different sections into cells.

- We finished expanding and setting up an improved growth system for preparing high-quality $\mathrm{CuInSe}_{2}$ single crystals.

\section{Amorphous Silicon Research}

During FY 1991, the Amorphous Silicon Research Group emphasized two areas of research: 
(1) improving deposition methods of hydrogenated amorphous silicon $(\mathrm{a}-\mathrm{Si}: \mathrm{H})$ and its alloys, and (2) reducing the light-induced degradation of a-Si:H. Advances in these areas are necessary for developing more efficient, stable solar cells. The group made significant contributions in both areas, as well as in solar cell processing, photoconductivity theory, and in determining the density of deep defects induced by doping.

It is significant that, during FY 1991, our deposition operations were suspended and we concentrated on meeting new safety regulations at NREL regarding how we deal with hazardous gases.

Key accomplishments of the Amorphous Silicon Research Group follow:

- We achieved a significant improvement in material quality by decomposing process gas on a hot filament. (This technique is referred to as the "hot wire" $[\mathrm{HW}]$ process). The technique produces both a-Si:H and a-SiGe:H materials that are superior to those produced by the standard glow discharge (GD) deposition method.

- We characterized GD-deposited a-SiGe:H films made with diluted silane. Helium dilution improved film quality slightly, but hydrogen dilution produced less of an effect and tended to depend more on the deposition system. This is in contrast to the widespread belief that hydrogen dilution produces significantly improved alloys.

- We improved our understanding of light-induced metastable defects. Although we found the phenomenon to be more complex than previously thought, we are refining our models and experiments to restrict the number of possible causes of the degradation.

\section{Polycrystalline Thin Films}

The objective of the Polycrystalline Thin Films Group is to fabricate and test promising thin-film solar-cell materials and devices. The primary goals of this research are to (1) develop a selenization process to fabricate $\mathrm{Cu}(\mathrm{In}, \mathrm{Ga}) \mathrm{Se}_{2}$ thin films and devices and identify issues pertinent to this process in support of industry and CuInSe ${ }_{2}$ technology, (2) execute a comprehensive plan to improve the performance of $\mathrm{Cu}(\mathrm{In}, \mathrm{Ga}) \mathrm{Se}_{2}$ absorber-based PV structures by optimizing the standard CulnSe ${ }_{2}$ device design and developing novel device structures, and (3) investigate alternative window semiconductor compounds that are compatible with $\mathrm{Cu}(\mathrm{In}, \mathrm{Ga}) \mathrm{Se}_{2}$ films. To achieve these goals, we focused on three closely related areas: fabricating materials, characterizing materials, and correlating device performance with material properties and fabrication parameters.

Key accomplishments of the Polycrystalline Thin Films Group follow:

- We discovered a correlation between $\mathrm{CuInSe}_{2} \mathrm{PV}$ device performance and the initial state of the $\mathrm{In} / \mathrm{Cu} / \mathrm{Mo} /$ glass precursor used to produce the device. A notable result of this study, and one of significance to the technology as a whole, was the direct observation that molybdenum film strain was a function of the thermal history of the precursor. No single factor is more important to the viability of this technology than film adhesion, and film strain is extremely important in this adhesion.

- We improved the interface and bulk regions of CuInSe ${ }_{2}$-based photovoltaic devices by enhancing alloys, windows, and grain sizes.

- We explored physical, chemical, and structural modifications to $\mathrm{CuInSe}_{2}$-based cells.

- We began to study quaternary alloys for improved window materials.

\section{III-V High-Efficiency Photovoltaic Cells}

The objective of III-V high-efficiency PV cell research is to develop an understanding of, and solutions to, the problems inherent in fabricating high-efficiency, multijunction cascade solar cells using III-V semiconductor materials such as GaAs, GaP, InP, GaInP, and AlGaAs. Our major areas of research include metal-organic chemical vapor deposition (MOCVD), material analysis, and device fabrication and characterization.

Because MOCVD operations were suspended for the purpose of conducting a safety review, most of our work in FY 1991 was devoted to materials and device studies on samples grown prior to the suspension. Nevertheless, we performed a number of studies that resulted in significant findings and conclusions. Some key accomplishments follow:

- We used a unique ordering-related band-gap reduction to produce a back surface field in $\mathrm{GaIIP}_{2}$ solar cells. We took advantage of the dependence of the band-gap reduction on growth conditions and produced a significant improvement in open-circuit voltage.

- We studied the ordering phenomenon in $\mathrm{GaInP}_{2}$ through conduction electron scattering and by ${ }^{31} \mathrm{P}$ nuclear magnetic resonance. 
- We developed $\mathrm{GaInP}_{2} / \mathrm{GaAs}$ tandem solar cells for space applications.

- We studied the effect of base doping on radiation damage in GaAs single-junction solar cells.

\section{Solid-State Theory}

The Solid-State Theory Group's primary mission is to capitalize on recent developments to (1) bring the state-of-the-art methods and ideas of condensedmatter theory into the realm of PV materials, (2) develop a fundamental understanding of the elements that constitute and enhance solar cell performance, and (3) use this knowledge to design novel PV materials that could be grown and tested in the laboratory by modern crystal-growth techniques.

A second mission of the group is to analyze the properties of existing materials. A goal of this research is to ensure that PV technology continuously benefits from breakthroughs achieved in other areas of condensed-matter physics. This approach supplements the more conventional trial-and-error approaches to designing PV systems. These missions are funded by the PV program and by the Materials Science Division of OER-BES.

Key accomplishments of the Solid-State Theory Group follow:

- We developed an efficient method of calculating the density of states of disordered transition metal alloys (OER-BES work):

- We carried out a first-principles calculation of the order-disorder transition in chalcopyrite semiconductors.

- We determined the consequences that interfacial roughness in semiconductor superlattices has on stability and optical properties (OER-BES work).

- We explored the ordering thermodynamics of surface and subsurface layers in GaInP alloys. An understanding of this phenomenon could help us define the growth conditions that optimize it.

- We compared $A b$-Initio charge densities with experimental data for $\mathrm{Si}$ and $\mathrm{NiAl}$ (OER/BES work).

- We designed and implemented an efficient method for performing large-scale pseudopotential calculations on complex solids.

- We predicted regions of diamond-like order in zinc-blende compounds. These regions could affect the material's electronic and optical properties (OER-BES work).

- We developed a new method for predicting the band gaps of arbitrary substitutional structures (OER-BES work).

- We developed models relating the stability of Si-Ge compounds, alloys, and superlattices with the built-in strain energy.

- We developed a theory of defects, impurities, and doping in $\mathrm{ZnSe}$, an important wide-band-gap semiconductor.

\section{Solid-State Spectroscopy}

The goal of solid-state spectroscopy research is to obtain an understanding of the fundamental optoelectronic properties of solid-state materials used for PV applications. We hope that this will provide information on the intrinsic performance limitations of $P V$ devices. In addition to investigating traditional PV semiconductor materials, an important aspect of this research is directed toward exploring the optical properties of novel semiconductor architectures that have potential for PV applications.

Key accomplishments of our solid-state spectroscopy research follow:

- We set up new experiments to characterize the opto-electronic properties of an alloy system exhibiting the phenomenon of spontaneous lateral compositional modulation.

- We used the results to confirm that this spontaneous lateral compositional modulation produces a lateral superlattice effect.

\section{Superconductivity}

The electric power industry requires the highly efficient conversion, storage, and transmission of energy. Installing superconducting devices into existing electrical generation and transmission grids would yield significant energy savings with respect to fuel costs and overall electrical losses.

Our superconductivity research focuses on thalliumoxide superconductors, which currently offer the highest critical temperatures observed to date $(125 \mathrm{~K})$. NREL is studying a novel electrodeposition process that offers low cost and scalability to long-length conductor configurations like wires or tapes.

Key accomplishments of our superconductivity research follow: 
- We awarded two subcontracts, one to General Electric Corporate Research and Development, and the other to Rutgers University.

- We developed critical conditions for the electrodeposition and heat treatment of superconducting films.

- We performed microstructural analyses and superconductor characterizations of these films. 


\section{Section 1 Crystal Growth Research}

\section{Investigators}

\author{
T.F. Ciszek, Principal Scientist \\ Y.S. Tsuo, Senior Scientist \\ (from May 1991) \\ C.R. Schwerdtfeger, Associate Scientist \\ R. Burrows, Master Technician \\ J. Alleman, Research Technician \\ (from May 1991) \\ C. Sarris, Part-Time Temporary
}

\section{Objectives}

The main objectives of the Crystal Growth Research Group were to (1) initiate investigations of alternative approaches for thin-layer silicon growth that could be used in multi-light-pass photovoltaic (PV) device structures; (2) reestablish a baseline silicon PV cell fabrication process to complement and support our experimental silicon materials work; and (3) develop procedures and an apparatus for growing stoichiometric CuInSe $e_{2}$ crystals with 1-cm grain sizes that are of suitable quality for basic characterization and use by other researchers. Along with these main objectives, we had a number of minor ancillary objectives. The group also had the objective of improving the environment, safety, and health (ES\&H) aspects of our research laboratories and operating procedures.

\section{Major Accomplishments}

\section{Thin-Layer Silicon Crystal Growth}

Thin layers of reasonably large-grain crystalline silicon offer an opportunity to develop silicon PV device structures that use less active material than that used in conventional cells $(10-50 \mu \mathrm{m}$ thicknesses versus $100-400 \mu \mathrm{m}$ ). These device structures would also have less stringent requirements on minority charge carrier lifetime $\tau$ or diffusion length $L$ (light-generated electrons and holes have a shorter path length to reach grid contacts on the surfaces). Because the optical absorption coefficient of silicon dictates a $\geq 100-\mu \mathrm{m}$ thickness to absorb essentially all incident photons, multiple passes of light are necessary for thin silicon layers to function efficiently. Textured surfaces and a good back surface reflector may be required to achieve an adequately long optical path through the silicon.

The use of thin-layer silicon is hampered by several technological barriers, which are the subject of the research in this task. The group's goals in this research include (1) developing an effective method to form or grow thin layers with large grains; (2) determining the grain size and material quality requirements for thin-layer silicon; (3) developing adequate substrates for the thin layers (or, alternatively, evaluating the problems of handling and transferring free-standing thin layers); (4) modifying device processing procedures to accommodate substrates, back surface reflectors, and texturing; and (5) effectively integrating the silicon growth and processing steps to optimize the device performance. Our initial work in the first four areas is reported below.

Experimental work was begun to evaluate copper as a solvent for growing thin crystalline silicon layers from high-temperature solution. This metal solvent has not been reported in previous literature on silicon growth from solution, presumably because of concerns over minority carrier lifetime degradation. However, both electrowinning [1] and chemical vapor deposition [2] of silicon from $\mathrm{Cu}-\mathrm{Si}$ alloy sources have indicated that the alloy has a beneficial gettering or impurityfiltering effect. This information, along with characteristics of the $\mathrm{Cu}-\mathrm{Si}$ phase diagram, prompted us to evaluate copper as a solvent.

We are working with $\mathrm{Cu}-\mathrm{Si}$ solutions of approximately $78 \mathrm{wt} \% \mathrm{Cu} / 22 \mathrm{wt} \% \mathrm{Si}$ and temperatures in the vicinity of $950^{\circ} \mathrm{C}$. A vertical induction-heated hot zone is used in an argon ambient atmosphere. A quartz crucible inside a graphite susceptor holds the Cu-Si solution. Substrates (either vertical or 
horizontal) are vertically lowered into the solution; the solution's temperature is then reduced slightly to provide supersaturation. After a growth period of 5-10 minutes, the substrate is raised out of the solution. While this vertical dipping technique offers simplicity, the floating silicon particulates that can arise when the melt is supersaturated may be disruptive to epitaxial growth. A capping layer of calcium chloride has been helpful for stabilizing the surface temperature and for cleanliness, as has a thermal gradient in which the top of the solution is slightly hotter than the bottom.

Problems we have encountered with multiple nucleation sites and morphological instability of the leading edges of growing layers are related to the thermal geometry and control of our growth system. These problems are particularly pronounced in thicker growth layers (e.g., $35 \mu \mathrm{m}$ ) and can lead to solvent entrapment. By improving the thermal control of our radio frequency $(R F)$ growth system, and tailoring the vertical temperature profile of the hot zone, we have been able to grow textured, near-(111) epitaxial silicon layers several millimeters in width that are free of $\mathrm{Cu}$-Si solution entrapment (see Figure 1-1a). By contrast, earlier layers grown with poorer thermal control show considerable morphological instability and $\mathrm{Cu}-\mathrm{Si}$ solution entrapment (see Figure 1-1b). Both Figures 1-1a and 1-1b show a 1.5-mm-wide region.

In collaboration with other NREL researchers, we established that our thin-layer silicon films grown from copper solution can maintain a whole-wafer epitaxial relationship on a (111) single-crystal substrate (via electron channeling patterns). We also learned that when unstable morphology occurs, the second-phase material interlaced with the epitaxial silicon is rich in copper and is probably $\mathrm{Cu}_{3} \mathrm{Si}$ (via energy dispersion spectroscopy [EDS]). Copper content in the clean growth regions (as in Figure 1-1a) was analyzed using secondary ion mass spectroscopy (SIMS) to obtain values in the bulk of the layers. We found that copper was not present above the approximate level of $2 \times 10^{16}$ atoms-cm ${ }^{-3}$. That amount of copper, if maintained throughout the layer volume, should cause no degradation of measurable lifetime or solar cell efficiency because the degradation threshold is $1 \times 10^{17}$ atoms-cm ${ }^{-3}$ for $\mathrm{p}$-base devices [3].

We also began to evaluate additional solvents for growing thin-layer silicon sheets from hightemperature solution: tin and gallium. In the case of tin, a solution of $97.7 \mathrm{wt} \% \mathrm{Sn}$ and $2.3 \mathrm{wt} \% \mathrm{Si}$ was used at a growth temperature of $1120^{\circ}-1130^{\circ} \mathrm{C}$. For gallium, a solution of $91 \mathrm{wt} \% \mathrm{Ga}$ and $9 \mathrm{wt} \% \mathrm{Si}$ was used at a growth temperature of $1020^{\circ}-1030^{\circ} \mathrm{C}$. Both
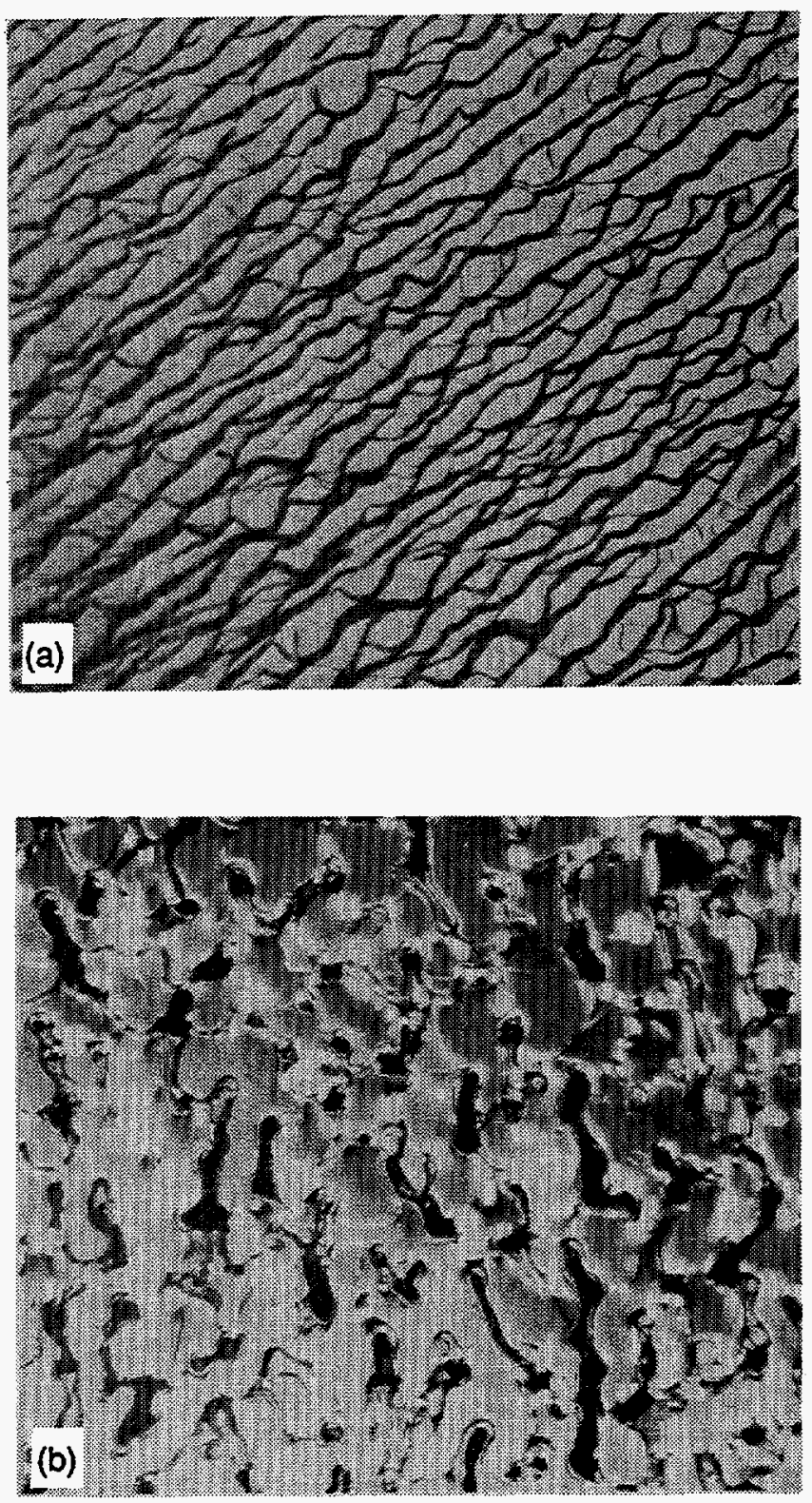

Figure 1-1. Silicon layers grown from copper solution on a (111) single-crystal substrate: (a) a clean, textured growth layer; (b) a growth layer with morphological instability and solvent entrapment.

solvents produced epitaxial growth, but some solvent was observed in the grown layer. The solvent entrapment was similar to that described for copper. Neither tin nor gallium appeared to offer any substantial improvement over copper in terms of growth morphology. A disadvantage of tin and gallium relative to copper is that their lower solubilities lead to a larger change in melt composition (and hence saturation temperature) as silicon is removed by growth on the substrate. 
Our group performed exploratory experiments on inductively coupled plasma deposition of thin silicon layers. To do this, we designed and built a silicon powder feed system and used it to plasma-deposit thin silicon layers on graphite substrates held $15 \mathrm{~mm}$ beneath the tip of the plasma at a temperature of approximately $1300^{\circ} \mathrm{C}$. The grain sizes obtained were $\leq 60 \mu \mathrm{m}$. We feel that larger grains are required, and are therefore not pursuing this approach.

Because electrodeposition of silicon involves potentially low process temperatures, it may be an attractive way to form thin layers. We made a silicon analogue of a tin plating system (sodium silicate: $9 \mathrm{~g}$; sodium acetate: $1.5 \mathrm{~g}$; sodium hydroxide: $0.74 \mathrm{~g}$; water: $100 \mathrm{ml}$ ). Silicon sheet electrodes were formed from strips scribed out of single-crystal wafers. Operating the plating bath for 14 hours at $\sim 60^{\circ} \mathrm{C}$ with a 3-7 V DC potential (5 $\mathrm{mA}$ current) between cathode and anode resulted in a thin $(270 \mathrm{~nm})$ deposit which peeled off the electrode. EDS analysis showed the deposit to be silicon with heavy copper and zinc contamination from the brass fixture used to hold the electrodes.

\section{Material Quality Requirements for Thin-Layer Silicon}

The Crystal Growth Research Group began an experiment to determine the effects of grain size and silicon thickness on the performance of thin-layer solar cells. Seeds $20 \mathrm{~mm}$ in diameter and $100 \mathrm{~mm}$ long were core drilled along diameters of a large chemical-vapordeposited polycrystalline silicon log. In a standard, high-purity float zone configuration, these seeds were used to initiate small-grained ingot growth. As growth progressed, the grains widened. Wafers of different thickness then can be cut and polished at different positions along the ingot and used to fabricate solar cells or measure lifetime. Based on these experiments, we established ingot growth procedures and developed thin-wafer polishing techniques (these are discussed in the next section). In collaboration with the Georgia Institute of Technology, we achieved a $14.5 \%$ solar cell efficiency on a 94-mm-thick wafer from one ingot (open-circuit voltage $\left[\mathrm{V}_{\mathrm{oc}}\right]=600 \mathrm{mV}$, short-circuit current density $\left.\mathrm{D}_{\mathrm{sc}}\right]=30.7 \mathrm{mAcm}^{-2}$, and fill factor $\left.[\mathrm{FF}]=0.786\right)$. We will use our recently reestablished device processing capability to aid in completing the study.

\section{Polishing Thin Silicon}

Our group has also begun experiments with polishing thin multicrystalline silicon wafers to study grain size, thickness, and diffusion length interdependencies. A very firm polishing pad and relatively more mechanical than chemical polishing action have minimized the problem of different rates of attack on different crystallographic grain orientations. We have been able to polish multigrain wafers $20 \mathrm{~mm}$ in diameter to a thickness that is transparent to red visible light (that is, a light bulb filament can be readily seen through the wafers).

\section{Silicon Photovoltaic Device Fabrication}

In May 1991, the Crystal Growth Research Group and the Device Development Group initiated a joint program to reestablish NREL's ability to fabricate diagnostic silicon devices. The in-house fabrication capability is important in the research of thin-layer crystalline silicon and other experimental crystalline silicon materials. Integral development of the material and device aspects of thin-layer cells is necessary because of the interplay between substrate, back-surface reflector, thin silicon layer, and textured layer surface for optimized light-trapping.

Using commercially available Czochralski (CZ) crystal growth wafers, we can now routinely fabricate solar cells with air mass (AM) 1.5 efficiencies of $15 \%-16 \%$ and areas of $0.04-4 \mathrm{~cm}^{2}$. A summary of the silicon device fabrication activities at NREL during FY 1991 is provided below.

Wafer Quality Testing. We used four-point probe, Hall mobility, surface photovoltage, and photoconductive decay measurements.

Wafer Cleaning and Etching. We rebuilt a wet chemical bench that contains deionized water baths, a hot plate, and a spinner.

Texture Etching. We studied texture-etching methods using heated $\mathrm{KOH}$, isopropyl alcohol (IPA), and $\mathrm{H}_{2} \mathrm{O}$ mixtures.

Junction Diffusion. We established the capabilities for three different phosphorus diffusion methods for junction formation: $\mathrm{POCl}_{3}$ liquid bubbler, phosphorofilm spin-on liquid dopant, and discshaped solid sources. To date, $\mathrm{POCl}_{3}$ doping has given us the best results. We used an automated spreading resistance probe for characterizing junction depth, set up a computer control system to operate four tubes of a diffusion furnace, and rebuilt a highflux tube etcher for cleaning quartz diffusion tubes.

Front and Back Metalizations. We used an electron-beam evaporation system to evaporate aluminum for the back contact and $\mathrm{Ti} / \mathrm{Pd} / \mathrm{Ag}$ for the front metalization. We used a lift-off photolithographic technique for pattern definition of the front contacts. We used only one photolithography mask in our cell fabrication sequence. 
Oxidation and Surface Passivation. We studied dry oxygen oxidation and $\mathrm{HCl}+\mathrm{O}_{2}$ oxidation processes and found that $\mathrm{HCl}+\mathrm{O}_{2}$ gives better quality thin (e.g., 34-nm thick) oxides.

Antireflection Coatings. We used electron-beamevaporated $\mathrm{SiO}_{2}$ antireflective (AR) coatings and thermally evaporated $\mathrm{ZnS} / \mathrm{MgF}_{2}$ double-layer $\mathrm{AR}$ coatings on both textured and flat substrates.

\section{CuInSe $_{2}$ Crystal Growth}

Last year, our group reported on the development of a high-pressure growth chamber to be used for liquidencapsulated directional solidification (LEDS) of chalcopyrite semiconductors. This growth system has been developed to address several problems typically associated with $\mathrm{CuInSe_{2 }}$ crystal growth, including a high density of ingot cracks in the material. One way to decrease the cracking problem is to use very slow cooling rates $\left(-1^{\circ} \mathrm{C} / \mathrm{h}\right)$. A computer-controlled system is used to maintain stable temperature control with $+0.5^{\circ} \mathrm{C}$ precision over the time period required for slow cooling (typically two to eight weeks). High-pressure (70-80 bar) argon is used in conjunction with a liquid encapsulant $\left(\mathrm{B}_{2} \mathrm{O}_{3}\right)$ to contain volatile selenium in the open-top ampoule at the standard $1100^{\circ} \mathrm{C}$ operating temperature. This method eliminates the risk of explosion often encountered with sealed ampoules of selenium. The focus of this year's work was on expanding the system to have three chambers running simultaneously.

Each of the six subsystems-electrical, heating, cooling, pressure, mechanical, and computer controlwere modified to improve safety and system reliability. An uninterruptible power supply (UPS) was installed to provide continuous power over long periods of time. The UPS is connected to an emergency generator, so there should be no down time 365 days per year. The temperature profiles in which solidification of the CuInSe ${ }_{2}$ ingots occur were modified by designing, building, and profiling different heating coils. Of the ten designs investigated, two were selected for use: one for directional solidification in a steep $\left(60^{\circ}-90^{\circ} \mathrm{C} / \mathrm{cm}\right)$ temperature gradient, and one for gradient freezing in a shallow $\left(5^{\circ}-15^{\circ} \mathrm{C} / \mathrm{cm}\right)$ temperature gradient. The cooling water system was fitted with flow switches and relays so the power to any furnace will shut off if the water flow is disrupted. Separate gas pressure regulators were installed on each chamber. All three chambers now have identical stepper-motor motion-control systems with end-of-travel limit switches. A projectile safety screen was installed in front of the system. Lastly, the computer control subsystem was improved with the latest version of software which allows better PID temperature control and simplified modification.

We made two runs with the improved growth system. We obtained a CuInSe 2 ingot with several large grains, but with severe cracking in the lower $80 \%$. A cross-section slice of the ingot at a point about one centimeter from the last-to-freeze end, where the cracks nearly completely disappeared, revealed a single grain of CulnSe $\mathrm{C}_{2}$ over $1.5 \mathrm{~cm}$ wide. All material up to that point was n-type with resistivities between 0.3 and $130 \Omega-\mathrm{cm}$. From the middle of this slice to the last-to-freeze end, the material was p-type with resistivities between 25 and $90 \Omega-\mathrm{cm}$. Electron microprobe compositional analysis revealed a decrease in selenium and an increase in copper across the type conversion region (see Figure 1-2).

The first set of experiments was designed to determine the optimal cooling rate for crystal growth, and whether or not crystal quality depends on the temperature gradient in which the ingot is solidified. These experiments are ongoing.

\section{Environment, Safety, and Health Activities}

Several tasks were performed to improve the safety of the crystal growth laboratories. One project was to create, revise, or update standard operating procedures (SOPs) for all laboratory activities. Eighteen SOPs were revised or written. Another project was to clean, sort, and rearrange laboratory space and equipment. Some of the equipment was modified to upgrade safety shields and identification labels. Equipment that exhibited an immediate hazard was tagged "out of operation" until appropriate modifications could be made. The entire chemical inventory of our group was put into a computer data base, and will be updated whenever new chemicals arrive or old chemicals are consumed. All chemicals were labeled according to hazard potential, and a complete set of material safety data sheets was accumulated. Training requirements were updated so each employee knows which classes are required (based mainly on the training requirements outlined in each SOP). Approximately 15 man-days were contributed to a review and critique of sitewide NREL management practices related to ES\&H.

Perhaps the biggest safety-related problem for the Crystal Growth Research Group is the fact that we are doing research in a building designed as an office building. To solve that problem, plans are under way for construction of a new facility. Members of our group contributed more than 30 man-days to planning and drawing laboratory layouts for the new building and attending interactive meetings with the 


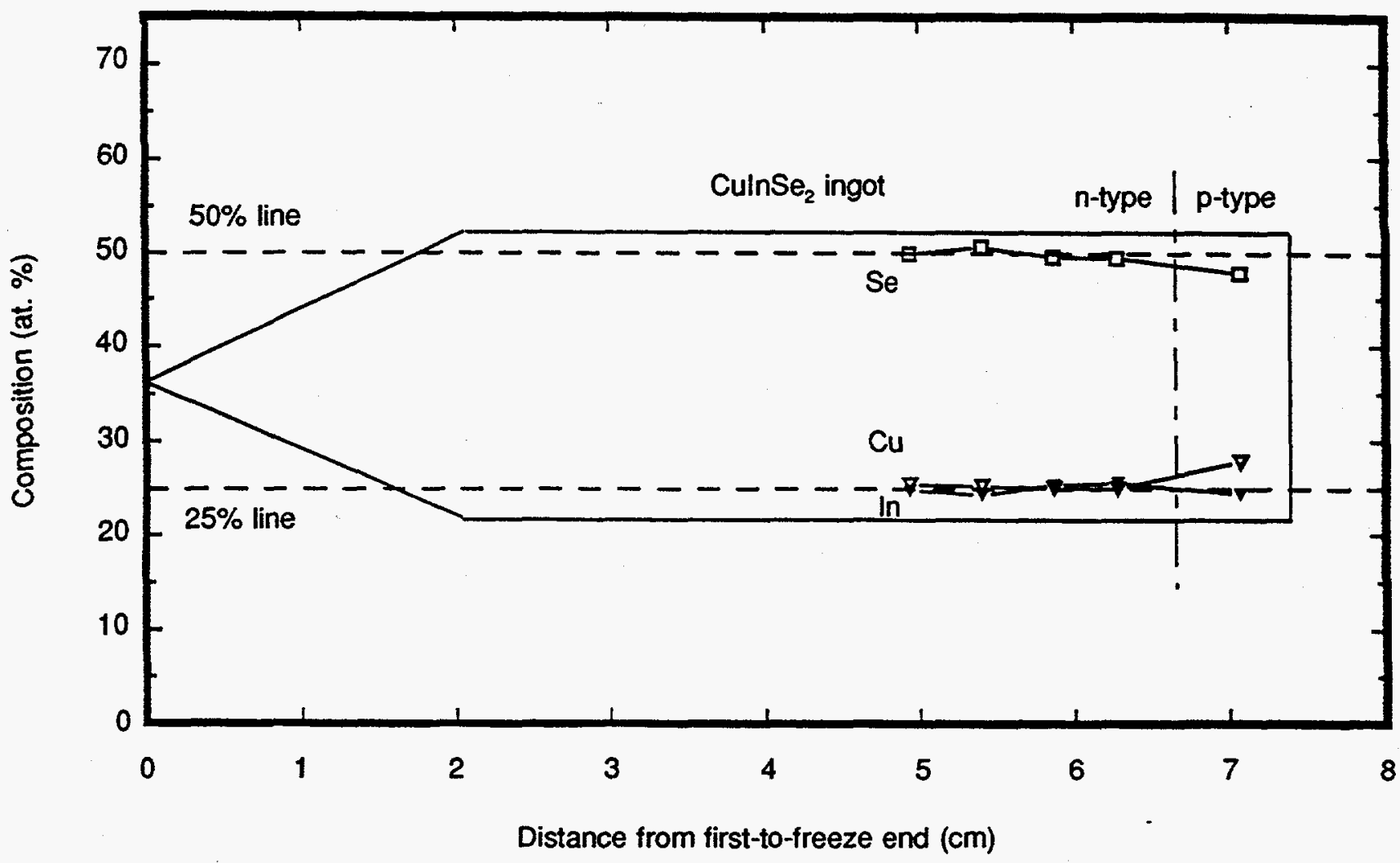

Figure 1-2. Composition versus position along ingot showing composition change in type conversion region. Note: dotted lines represent stoichiometric compositions.

architects and the project manager. The result is a plan for a somewhat undersized, but functional, facility for crystal growth research activities.

\section{Publications and Presentations}

\section{Publications}

R. Bacewicz and T. F. Ciszek, "Liquid-Encapsulated Crystal Growth and Electrical Properties of $\mathrm{Sb}_{2} \mathrm{Se}_{3}$ and $\mathrm{Bi}_{2} \mathrm{~S}_{3}, "$ J. Crystal Growth 109, 1991, p. 133.

L. A. Boatner, T. F. Ciszek, and T. Surek (editors), "American Crystal Growth 1990," J. Crystal Growth special issue 109, 1991.

T. F. Ciszek and C. D. Evans, "Single-Crystal Growth and Low-Field AC Magnetic Susceptometry of $\mathrm{YBa}_{2} \mathrm{Cu}_{3} \mathrm{O}_{7-\delta}, \mathrm{ErBa}_{2} \mathrm{Cu}_{3} \mathrm{O}_{7-\delta}$ and $\mathrm{Bi}_{2} \mathrm{Sr}_{2} \mathrm{Ca}_{0.8} \mathrm{Cu}_{2} \mathrm{O}_{8}$ Superconductors," J. Crystal Growth 109, 1991, p. 418.

T. F. Ciszek, "Silicon Float-Zoned Crystal Growth for High Minority Charge Carrier Lifetime Material Applications," Solar Cells 30, 1991, p. 5.
T. F. Ciszek, "Method for the Melt-Growth of Ternary III-V Crystals Which are Uniform in Composition," U.S. Patent \#5,047,112, 1991.

G. Dagan, T. F. Ciszek, and D. Cahen, "Ionic Mobility in Chalcopyrite Semiconductors: II. The Quaternary Materials $\mathrm{Cu}_{x} \mathrm{Ag}_{1-x}$ InSe $2^{\prime \prime}$ in progress.

C. H. Qiu, S. P. Ahrenkiel, N. Wada, and T. F. Ciszek, "X-Ray Diffraction and High-Pressure Raman Scattering Study of Iodine-Intercalated $\mathrm{Bi}_{2} \mathrm{Sr}_{2} \mathrm{CaCu}_{2} \mathrm{O}_{8+x}$ " Proceedings of the International Conference on Materials and Mechanisms of Superconductivity in High-Temperature Superconductors (M²S-HTSC III), July 22-26, 1991, Kanazawa, Japan.

Y. Simon Tsuo, "Oxygen Ion-Beam Microlithography," U.S. Patent $\# 5,041,361,1991$.

T. H. Wang, T. F. Ciszek, and T. Schuyler, "Charge Carrier Recombination Centers in High-Purity, Dislocation-Free, Float-Zoned Silicon Due to Growth-Induced Microdefects," J. Crystal Growth 109, 1991, p. 155. 


\section{Presentations}

S. P. Ahrenkiel, C. H. Qiu, N. Wada, and T. F. Ciszek, "Pressure-Induced Oxygen Intercalation in

$\mathrm{YBa}_{2} \mathrm{Cu}_{3} \mathrm{O}_{7-\mathrm{x}}:$ Raman Scattering and X-Ray

Diffraction Studies," presented at the American

Physical Society Meeting, Cincinnati, Ohio, March

1991.

T. F. Ciszek, "Silicon Float-Zone Crystal Growth for High Minority Charge Carrier Lifetime Applications," presented at the SERI PVAR\&D 10th Review Meeting, Denver, Colorado, October 1990.

T. F. Ciszek, "Microdefects and Their Effect on Minority Charge Carrier Lifetime in Dislocation-Free Float-Zoned Silicon," presented at the 3rd European Conference on Crystal Growth, Budapest, Hungary, May 1991.

C. H. Qiu, S. P. Ahrenkiel, N. Wada, and T. F. Ciszek, "High-Pressure Raman Scattering and X-Ray Scattering Study of Iodine-Intercalated $\mathrm{Bi}_{2} \mathrm{Sr}_{2} \mathrm{CaCu}_{2} \mathrm{O}_{8+\mathrm{x}}$ " presented at the American Physical Society Meeting, Cincinnati, Ohio, March 1991.
C. H. Qiu, S. P. Ahrenkiel, N. Wada, and T. F. Ciszek, "X-Ray Diffraction and High-Pressure Raman Scattering Study of Iodine-Intercalated $\mathrm{Bi}_{2} \mathrm{Sr}_{2} \mathrm{CaCu}_{2} \mathrm{O}_{8+x^{\prime}}$ " presented at the International Conference on Materials and Mechanisms of Superconductivity in High-Temperature Superconductors ( $\mathrm{M}^{2} \mathrm{~S}-\mathrm{HTSC}$ III), Kanazawa, Japan, July 1991.

\section{References}

1. J. M. Olson and K. L. Carleton, "A Semipermeable Anode for Silicon Electrorefining," $J$. Electrochem. Soc. 128, 1981, p. 2698.

2. P. Tejedor and J. M. Olson, "Silicon Purification by the Van Arkel-de Boer Technique Using a $\mathrm{Cu}_{3} \mathrm{Si}$ Si Composite Alloy Source," J. Crystal Growth 89, 1988, p. 220.

3. J. R Davis, Jr., A. Rohatgi, R. H. Hopkins, P. D. Blais, P. Rai-Choudhury, J. R. McCormick, and H. C. Mollenkopf, "Impurities in Silicon Solar Cells," IEEE Trans. on Electron. Derices ED-27, $1980,677$. 


\section{Section 2}

\section{Amorphous Silicon Research}

\section{Investigators}

\author{
R. Crandall, Principal Investigator \\ and Group Leader \\ H. Branz, Staff Scientist \\ H. Mahan, Senior Scientist \\ T. McMahon, Senior Scientist \\ B. Nelson, Associate Scientist \\ S. Tsuo, Senior Scientist \\ E. Molenbroek, Visiting Scientist \\ I. Balberg, Visiting Scientist \\ S. Salamon, Visiting Scientist \\ E. Iwaniczko, Research Technician \\ D. Tanenbaum, Visiting Scientist \\ Y. Xu, Associate Scientist
}

\section{Objectives}

During FY 1991, the Amorphous Silicon Research Group emphasized two areas of research:

(1) improving deposition methods of hydrogenated amorphous silicon (a-Si:H) and its alloys, and

(2) reducing the light-induced degradation of a-Si:H. Advances in these areas are necessary for the development of more efficient, stable solar cells. Our group made significant contributions in both these areas, as well as in solar cell processing, photoconductivity theory, and determining the density of deep defects induced by doping.

We achieved a significant improvement in material quality by decomposing process gas on a hot filament (i.e., the "hot wire" [HW] process). Our technique produces both a-Si:H and a-SiGe:H materials that are superior to those produced by the standard glow discharge (GD) method. In addition, films of a-Si:H are more resistant to light-induced defect production. Of special note is our demonstration of the lowest stabilized defect density attained in a-Si:H. We are developing methods to incorporate these films in devices. There is a widespread belief that hydrogen dilution of the source gases leads to improved a-SiGe:H alloys produced by GD deposition. We systematically investigated this theory through both transport and structure characterizations and concluded that any improvements are marginal and depend more on the deposition system. However, we did observe slight improvements in film quality by using helium dilution.
Our understanding of light-induced metastable defects continues to improve. With more understanding, we find the phenomenon to be more complex. However, we are refining our models and experiments to restrict the number of possible causes of the degradation.

\section{Major Accomplishments}

\section{Material and Device Deposition and Characterization}

Deposition of Device-Quality, Low-H Content a-Si:H by the Hot Wire Technique. For the first time, we produced device-quality a-Si:H that contains as little as 1 at. \% $\mathrm{H}$. Based on experiments where we varied the substrate deposition temperature $\left(T_{S}\right)$ to vary hydrogen content $\left(\mathrm{C}_{\mathrm{H}}\right)$ in both $\mathrm{HW}$ - and $\mathrm{GD}$ deposited films, we reported on the electronic properties of the HW films (particularly in the low$\mathrm{C}_{\mathrm{H}}$, high- $\mathrm{T}_{\mathrm{S}}$ regime) and contrasted these with the properties of GD films.

Most of our work in this area focuses on possible structural differences between the two types of a-Si:H films as the reason for material improvement. Three different measurements support the assertion that the HW lattice is more ordered. First, narrower Urbach edges $(E \mu)$ traditionally translate into more ordered material, and the $E \mu$ values of the low $-C_{H} H W$ films are significantly narrower than those of the low- $C_{H}$ GD films. In addition, different band gap $\left(\mathrm{E}_{\mathrm{g}}\right)$ values were measured for $\mathrm{C}_{\mathrm{H}}<10$ at. $\%$ in the two sets of 
material. Changes in $\mathrm{E}_{\mathrm{g}}$ for a $\mathrm{HW}$ film, from the value observed for zero $\mathrm{C}_{\mathrm{H}^{\prime}}$ are divided into two components. The first component is attributed to the amount of alloying with hydrogen and the second to the amount of ordering. Because the changes in $E_{g}$ due to hydrogen alloying are identical for $H W$ and GD films containing identical $C_{H}$, the $H W$ films, exhibiting higher $\mathrm{E}_{\mathrm{g}}$ values, should be more ordered.

The third measurement supporting a more ordered HW lattice is the full width at half maximum (FWHM) measurement of the Raman Si-Si transverse optical (TO) mode (see Figure 2-1), which has been shown to be a measure of the average bond-angle deviation (structural disorder) in a-Si:H. We found that the narrowest values for GD films are about $70 \mathrm{~cm}^{-1}$, in agreement with values in previously published literature, and these values rise slightly as $\mathrm{C}_{\mathrm{H}}$ deviates significantly from its device-quality value. A similar behavior is seen for the HW films, except that the HW FWHMs are typically $4-5 \mathrm{~cm}^{-1}$ narrower than those of the GD samples. This again suggests better ordering of the HW lattice.

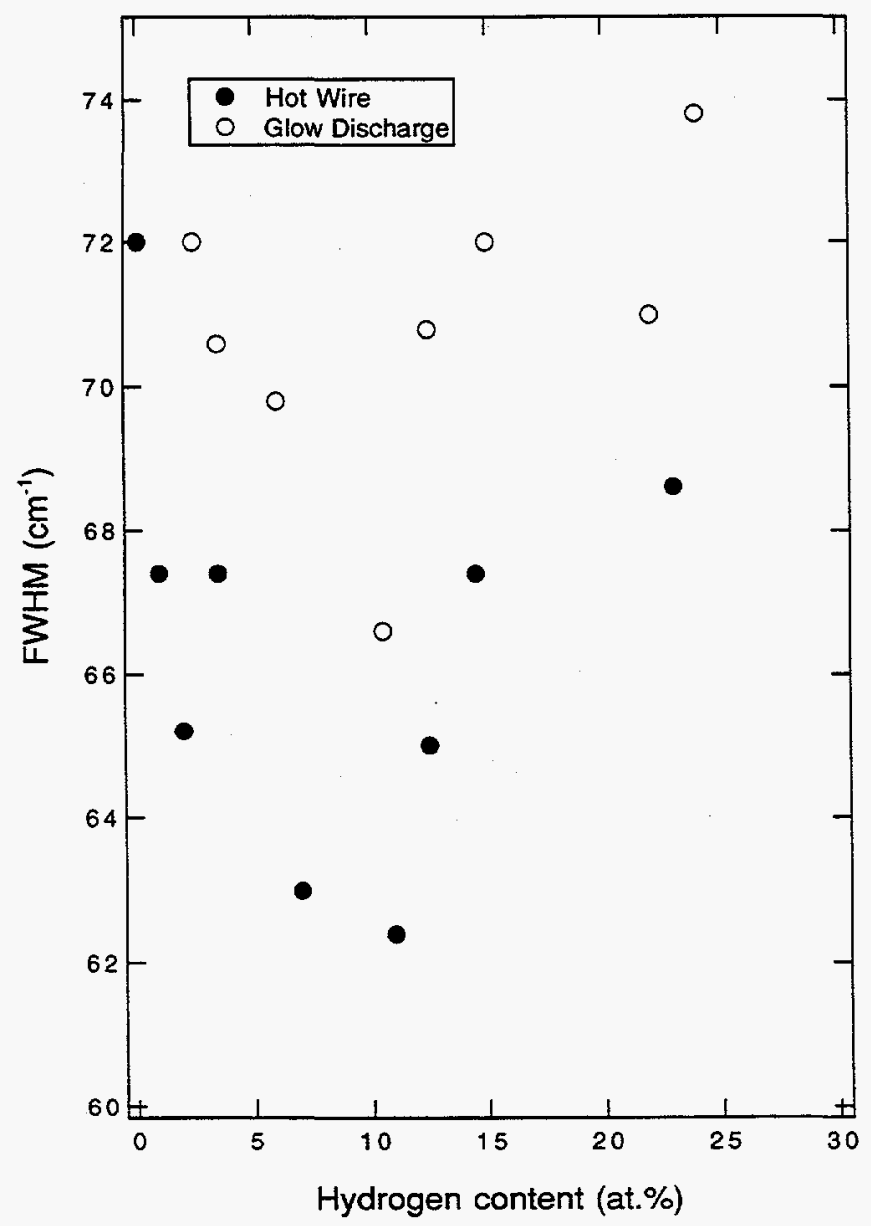

Figure 2-1. FWHM measurement of the Raman Si-Si To mode
Effects of Helium Dilution on Glow Disharge Depositions of a-Si ${ }_{1-x} G: \mathbf{H}$ Alloys. The development of multijunction solar cells is necessary to improve the conversion efficiency and stability of a-Si:H-based PV modules. Although the same-bandgap a-Si:H/a-Si:H tandem cell approach has achieved high efficiency and stability, these cells have limited potential for further improvements in efficiency because of insufficient light absorption. To further improve the efficiency of a-Si:H-based multijunction cells, we need to develop high-quality, low-band gap alloy materials such as $\mathrm{a}-\mathrm{Si}_{1-\mathrm{x}} \mathrm{Ge}_{\mathrm{x}}: \mathrm{H}$.

We studied the effects of helium dilution of the feed gas on the properties of a-Si $i_{1-x} \mathrm{Ge}_{\mathbf{x}}: \mathrm{H}$ alloys deposited using radio-frequency (RF) GD decomposition of silane and germane gas mixtures. Comparing a-Si ${ }_{1-x} \mathrm{Ge}_{x}: \mathrm{H}$ films deposited using $65 \%$ helium dilution with films deposited using $65 \%$ hydrogen dilution, we found that films deposited with helium dilution have higher quantum efficiency-mobilitylifetime product values and a longer charge-carrier diffusion length. We also found that the incorporation of germanium atoms in the $a-\mathrm{Si}_{1-\mathrm{x}} \mathrm{Ge}_{\mathbf{x}}: \mathrm{H}$ film is more efficient with helium dilution than with hydrogen dilution. For example, to obtain 50 at. \% Ge content in a film, we need a $\mathrm{GeH}_{4} /\left(\mathrm{GeH}_{4}+\mathrm{SiH}_{4}\right)$ gas flow ratio of $23 \%$ for $65 \% \mathrm{H}_{2}$ dilution and a ratio of $18 \%$ for $65 \% \mathrm{He}_{2}$ dilution.

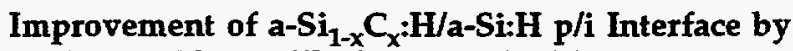
Hydrogen-Plasma Flushing Studied by

Photoluminescence. The material interfaces in $\mathrm{a}-\mathrm{Si}: \mathrm{H}$ $\mathrm{p}-\mathrm{i}-\mathrm{n}$ cells play an important role in determining their conversion efficiency and stability. For $p-i-n$ cells deposited in a single-chamber reactor, it is important to reduce the boron cross contamination of the i-layer after depositing the boron-doped a-SiC:H p-layer. We have shown that a $\mathrm{H}$-plasma reactive flush of the reactor after the $\mathrm{p}$-layer deposition is more effective in reducing boron cross contamination at the $p / i$ interface than are the conventional reactor-cleaning procedures of silane gas flush and high-vacuum pumping. The H-plasma flush was found to improve the $V_{o c}$ and PV conversion efficiency of the solar cell.

Photoluminescence studies of $\mathrm{p}-\mathrm{i}$ structures in a-Si:H show that the H-plasma process increases both the luminescence efficiency and the activation energy for the competing non-radiative recombination.

Etching Properties of Hydrogenated Amorphous Silicon. We have studied dry and wet-chemical etching properties of doped and undoped a-Si:H films with bonded-hydrogen content varying from 0 to 20 at. \%. Etching studies include (1) wet-chemical etching using solutions of $\mathrm{KOH}, \mathrm{IPA}$, and $\mathrm{H}_{2} \mathrm{O}$, 
(2) $\mathrm{H}$-plasma etching, (3) $\mathrm{XeF}_{2}$ vapor etching, and

(4) hydrogen ion-beam sputtering.

Factors that may affect the etching properties of a-Si-based alloys include alloy composition, hydrogen content and bonding configurations, optical band gap, and the Fermi level position. We have found that the wet-chemical etch rate of undoped a-Si:H in a $\mathrm{KOH}$-based etchant depends very strongly on both the $\mathrm{KOH}$ concentration in the solution and on the hydrogen content of the film. For plasma etching, we found that the etch rate of a-Si:H in an RF H-plasma decreases slightly as bonded-hydrogen content increases in the a-Si:H. This etch rate increases with the RF power density. It is important to note that the RF H-plasma etching of a-Si:H is very sensitive to oxides on the film surface. We also found that $\mathrm{H}$-plasma either does not etch or very weakly etches $\mathrm{a}-\mathrm{Ge}: \mathrm{H}$. We believe this may be one of the reasons that GD-deposited a-SiGe:H and a-Ge:H alloys have poor electronic properties.

The etch rate of semiconductors often depends on the Fermi level position. N-type and undoped semiconductors have more filled states in the band gap and thus are chemically more reactive and have higher etch rates than p-type semiconductors. We found that, for our $\mathrm{KOH}$-based wet-chemical etching of a-Si:H, phosphorus-doped a-Si:H has similar etching properties to undoped a-Si:H. However, boron-doped films have much smaller wet-chemical and H-plasma etch rates (the etch rate is less than $0.1 \mathrm{~nm} / \mathrm{min}$ for both wet-chemical and H-plasma etching) than do undoped and n-type films.

\section{Density of States Spectroscopy in Amorphous}

Silicon. We use capacitance spectroscopy to measure the density of states, $\mathrm{N}(\mathrm{E})$, in $\mathrm{p}$ - and n-type a-Si:H. If $N(E)$ is of the form $N(E)=N_{0} \exp \left(E / k_{B} T_{0}\right)$ over a region of a few $k_{B} T$, we show that the capacitance, $C$, has the high-temperature closed form solution

$$
C=\frac{\varepsilon}{4 L s} \exp \left[\frac{T \ln (v / 2 \pi f)}{2 T_{0}}\right]
$$

Here, $\mathrm{E}$ is the energy measured from the band edge, $N_{0}$ is a constant, $k_{B}$ is Boltzmann's constant, $T$ is the absolute temperature, $T_{0}$ is the characteristic temperature, $\varepsilon$ is the dielectric constant, $\gamma$ is the "attempt-to-escape" frequency, $f$ is the measuring frequency, and $L_{S}$ is the characteristic screening length of the band tail states. Equation (1) is in agreement with $C$ versus $T$ measurements at various frequencies.
The results of this study are shown in Figure 2-2, which displays the density of states (DOS) measured for various $n$-type samples versus energy. Both $P$ and $B$ doping lead to states that increase rapidly away from $E_{F}$ toward midgap. In the absence of $C$ or at low doping, the DOS shows one slope. However, samples containing large amounts of $C$ and $B$ show a two-slope DOS. This suggests a change in the type of states contributing to the DOS as the slope changes. The best supporting evidence for this idea is the two orders of magnitude decrease in $v$ in the region farther above $E_{\mathrm{F}}$. This decrease in $v$ means that the hole-capture cross section decreases by this amount in this region-good evidence that a change to a defect has taken place, with different native charge states dominating different regions of the DOS. This phenomenon might represent a different bonding of $B$ in the presence of $C$.

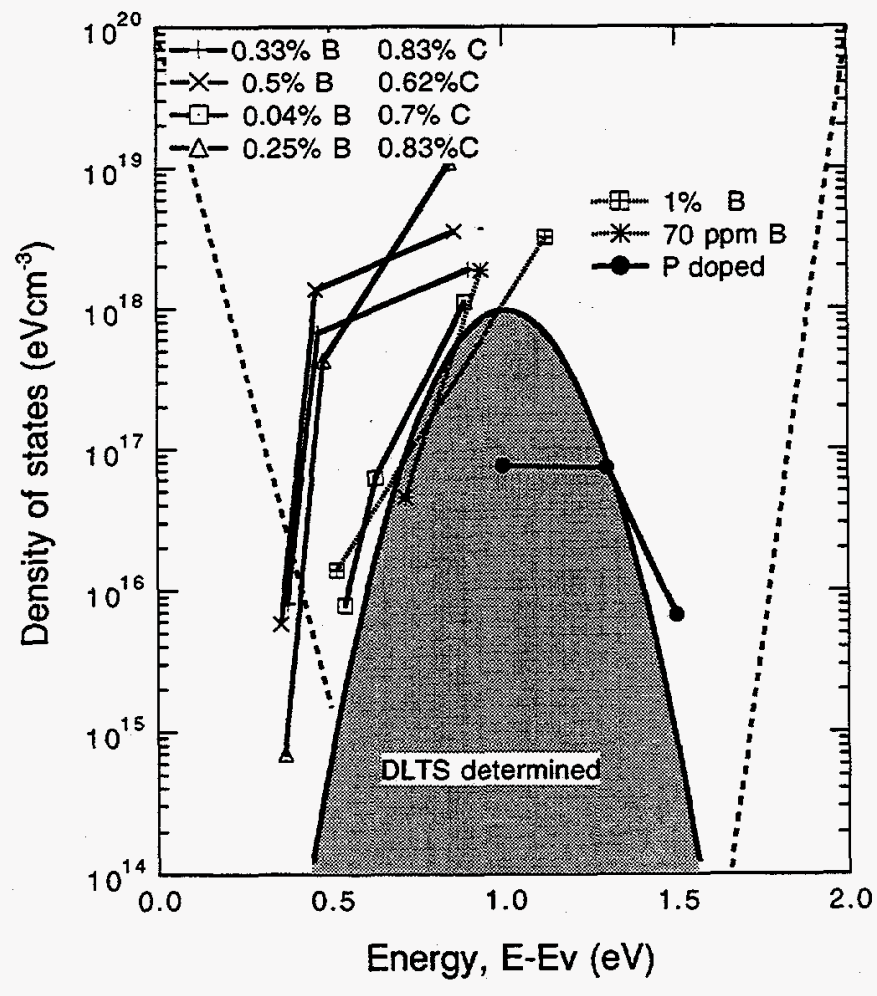

Figure 2-2. DOS versus energy. Curves are labeled by sample parameters. The figure also shows values for a lightly P-doped sample and those determined by deep-level transient spectroscopy (DLTS).

Mobility-Lifetime Products in a-Si:H. The most important parameters characterizing the photoelectronic quality of a semiconductor are its charge-carrier mobility lifetime, $\mu \tau$, products. The two common experimental methods used to determine these parameters in a-Si:H are the steadystate photoconductivity measurement and the 
time-of-flight charge-collection measurement. The fact that the two methods yield quite different results is a puzzle. We show that this puzzle can be solved by an understanding of the physics involved in each of the measurements. In fact, we show that the steady state $\mu \tau$ is expected to be up to three orders of magnitude larger than the time-of-flight $\mu \tau$ in undoped a-Si:H. This prediction agrees with the corresponding experimental results.

\section{Metastability}

\section{A Reduction in the Staebler-Wronski Effect} Observed in Low Hydrogen-content HW-Deposited a-Si:H Films. Since Staebler and Wronski showed that reversible changes occur in the electronic properties of a-Si:H when the films are exposed to light, this phenomenon has been studied extensively. We made a detailed, systematic study of the effects of saturation light soaking on these samples, using the constant photocurrent method (CPM) and steady-state photograting technique (SSPG) to probe changes in the material. Data for a series of GD films, also deposited at different substrate temperatures, are included for comparison purposes.

Figure 2-3 shows the defect density as measured by CPM for the HW and GD films, both in the as-grown and saturated-light soaked states, plotted as a function of the bonded-hydrogen content. While the as-grown CPM values for the GD samples exhibit a minimum hydrogen content of about 10 at. \% (i.e., deposited at the device-quality deposition temperature of $250^{\circ} \mathrm{C}$ ), which is in agreement with previous measurements, the HW samples exhibit low CPM as-grown values for hydrogen content down to about 1 at. $\%$, before the values finally increase above $1 \times 10^{16} \mathrm{~cm}^{-3}$. At the same time, in this region of low hydrogen content, the saturated CPM defect densities for the HW samples are considerably lower than the saturated values for the GD films, and the lowest values occur at low hydrogen contents (1-4 at. \%). The same trends are evident in measurements of the ambipolar diffusion length for the same films, also as a function of hydrogen content. While the GD diffusion lengths for the samples in the as-grown state peak around the hydrogen content contained in device-quality a-Si:H and decrease on either side of this peak, the HW samples exhibit their highest asgrown values at the lower hydrogen contents mentioned previously. The highest saturated SSPG values for the HW samples occur in a similar range and are higher than any of the saturated values for the GD samples.

To further illustrate differences between the HW and GD samples, we also examined the excess defect density obtained by light soaking. We showed that

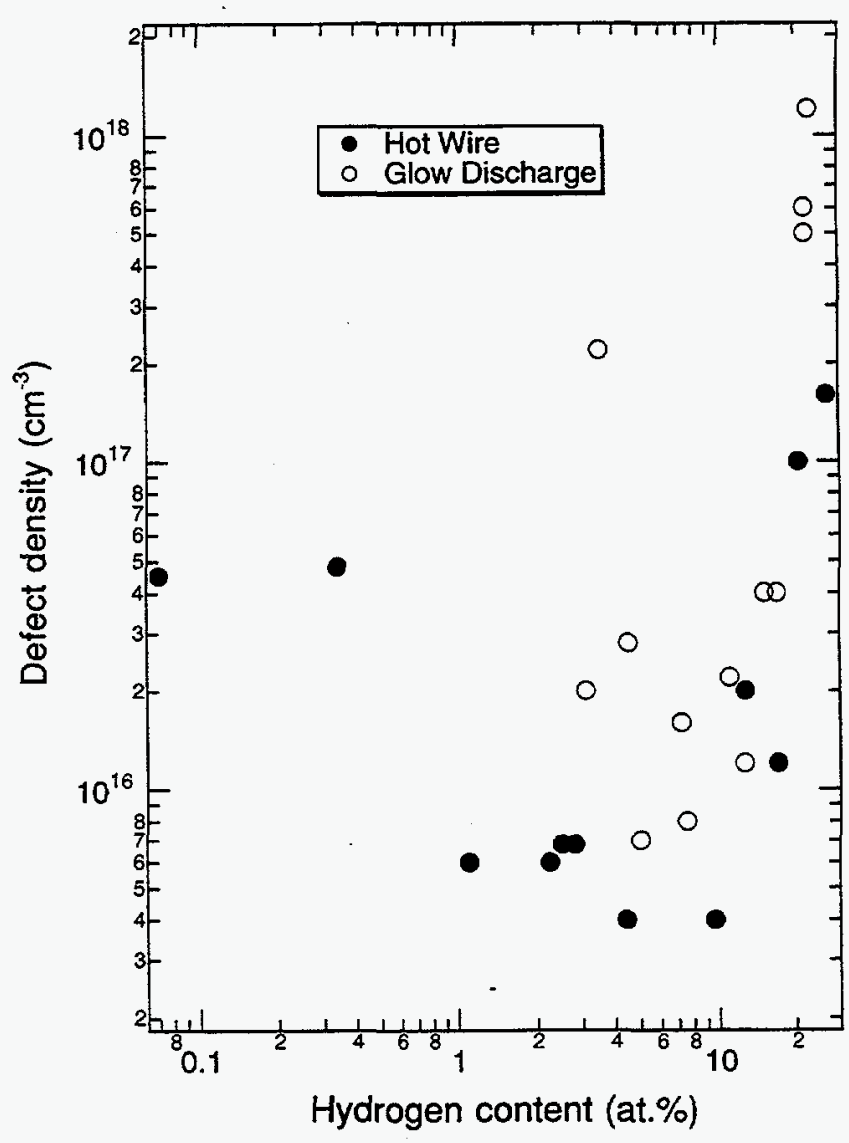

Figure 2-3. Defect density as measured by CPM for the HW and GD films, both in the as-grown and saturated-light-soaked states, and plotted as a function of the bonded hydrogen content.

this excess spin density decreased dramatically as the hydrogen content was reduced for both series of samples, even in the (very) low-hydrogen-content regime where the initial spin density is seen to increase. However, we showed that, once again, the data for the HW and GD samples fall on different curves. That is, for a given bonded-hydrogen content, the HW samples exhibit a smaller excess defect density than the GD samples.

Several points can be drawn from these data. First, if we assume that the Staebler-Wronski effect is reduced purely because of the decreased number of hydrogen atoms, then our results suggest that hydrogen bonded in the monohydride state may contribute to the metastability, in contrast to earlier measurements linking the light-induced effect primarily to dihydride bonding. Because our HW and GD samples deposited at substrate temperatures $>250^{\circ} \mathrm{C}$ (containing less that 10 at. \% hydrogen) contain no discernible dihydride bonding from infrared measurements and still exhibit significant changes in defect density upon light soaking, hydrogen bonding in the 
dihydride mode may not be the sole contributor. Put another way, if these low-hydrogen-content films do contain dihydride bonding, the results described here show that the lower dihydride films exhibit a smaller light-induced effect. These arguments suggest that the microscopic models presented in the literature, involving hydrogen in the monohydride bonding configuration, may be applicable in a specific as well as a generic sense. However, the data also suggest that the hydrogen content alone does not govern the amount of the Staebler-Wronski effect because the data for the HW and GD samples fall on different curves. That is, in the regions where the two sets of films have identical bonded-hydrogen contents, the HW films exhibit a consistently lower metastability.

We suggested that the differences in ordering of the HW and GD lattices, described earlier, can also affect the values of the saturated Staebler-Wronski effect. We have already shown that the initial state densities of the HW and GD films, when plotted against the Urbach edge, are quite similar. Following thermodynamic models relating the number of weak bonds to the width of the Urbach edge, the number of weak bonds susceptible to being broken by recombination processes should also be similar for the two sets of films. If the weak-bond model is correct, then the light-induced saturation changes, i.e., $N(B)-N(A)$, for the two sets of samples should also exhibit identical behavior when plotted against either the hydrogen content or the optical band gap; clearly, they do not. Thus, we assert that the microscopic nature of the lattice may play a role in the Staebler-Wronski effect, and that the HW films exhibit a lower saturation because the HW a-Si lattice is more ordered.

\section{Capacitance Studies of Bias-Induced Metastability}

in p-Type a-Si:H. The stability of a-Si:H against changes in structure caused by non-equilibrium carrier densities is one of the most important research topics in amorphous solids. Deleterious carrierinduced metastabilities are observed in solar cells, thin-film transistors (TFT), and other a-Si:H devices. Consequently, the problem has technological as well as intellectual interest.

There is considerable evidence that metastable effects in undoped a-Si:H are caused by defects that trap charge and metastably reconfigure. Junction capacitance experiments in both p-i-n and undoped Schottky barrier solar cells have been an important technique in these studies. The capacitance changes can be produced either by illumination or by bias treatment above about $440 \mathrm{~K}$.

We conducted the first detailed capacitance study of metastable changes in a-Si:H p-layers. We produced the metastable change by reverse-bias annealing $p / n$ junction devices having thin, heavily doped n-layers. After cooling under applied reverse bias, we observed a significant increase in the capacitance. This metastable change anneals out at zero bias above about $380 \mathrm{~K}$. We measured the characteristic times and activation energies for both production and annealing of these metastable changes. Our measurements show that charge trapping is an integral part of the metastability in p-type a-Si:H. It is clear that reverse-bias annealing removes holes from a metastable defect which can only anneal by hole capture over a barrier.

Capacitance measurements on a-Si:H $\mathrm{p} / \mathrm{n}$ junctions clearly show that activated hole trapping and emission cause metastability in p-type a-Si:H. This supports a bistable charge-trapping defect model of the metastability. The capacitance changes observed by reverse-bias annealing of p-type a-Si:H are qualitatively similar to the metastabilities observed in n-type and undoped a-Si:H. We suggest that bistable charge-trapping defect models explain most light- and bias-induced metastability in a-Si:H.

Defect Relaxation in Amorphous Silicon: Stretched Exponentials, Meyer-Neldel Rule, and StaeblerWronski Effect. Annealing and production of metastable defects in disordered solids is explained quantitatively with a model in which defect relaxation is a local phenomenon. The stretchedexponential time dependence of defect relaxation and the MeyerNeldel rule for the relaxation time constant are natural consequences of this model. We obtained these results by using an exponential distribution of activation barriers for transitions between the two states of the local defect. The model, applied to a-Si:H data, gives an exponential distribution of barriers with a characteristic temperature of $220^{\circ} \mathrm{C}$, roughly equal to the accepted freeze-in temperature for defect distributions in a-Si:H. The model explains that long degradation times convert defects with higher barriers and this results in longer annealing times. The microscopic models of the metastable defects in a-Si:H, weak-bond breaking and carrier trapping by charged dangling bonds, are discussed in the framework of this defect relaxation model.

The Adler Model Revisited. The metastable degradation of a-Si:H material and devices due to light exposure has been an important research topic. The degradation of a-Si: $\mathrm{H}$ films involves increased carrier recombination, decreased photoconductivity, a shifted Fermi level, and increased neutral dangling bond $\left(\mathrm{T}_{3}{ }^{0}\right)$ spin density. In a-Si:H solar cells, light soaking reduces nearly all parameters that determine the energy conversion efficiency. Several models of the Staebler-Wronski effect have been proposed, but none is universally accepted. 
Adler proposed that because amorphous silicon is inhomogeneous it includes regions where the effective correlation energy $\left(\mathrm{U}_{\text {eff }}\right.$ ) of the dangling-bond defect is negative. In these regions, spinless charged dangling-bond defects form. The $\mathrm{T}_{3}{ }^{+}\left(\mathrm{T}_{3}{ }^{-}\right)$defects are in their equilibrium $\mathrm{sp}^{2}\left(\mathrm{~s}^{2} \mathrm{p}^{3}\right)$ hybridizations and form $120^{\circ}\left(90^{\circ}\right)$ bond angles. The defects capture photogenerated carriers and reconfigure according to

$$
\mathrm{T}_{3}{ }^{+}\left(\mathrm{sp}^{2}\right)+\mathrm{e}^{-} \rightarrow \mathrm{T}_{3}{ }^{0}\left(\mathrm{sp}^{3}\right)
$$

and

$$
\mathrm{T}_{3}{ }^{-}\left(\mathrm{s}^{2} \mathrm{p}^{3}\right)+\mathrm{h}^{+} \rightarrow \mathrm{T}_{3}^{0}\left(\mathrm{sp}^{3}\right) .
$$

Reconfiguration into the $\mathrm{sp}^{3}$ hybridization involves bond-angle shifts of 10 to 20 degrees and an accommodation by the surrounding atoms. The resulting $\mathrm{T}_{3}{ }^{0}$ defects are indistinguishable from the native $T_{3}{ }^{0}$ defects, but are metastable. To return to equilibrium during annealing, they must reconfigure over a barrier. This may be an enthalpy barrier or simply the requirement that neighboring atoms cooperate to enable reconfiguration.

Figure 2-4 is a schematic diagram of the density of states for dangling-bond optical transitions in the Adler model of metastability. Photons excite electrons from states below Fermi level $\left(E_{F}\right)$ to extended states above the conduction-band mobility edge $\left(E_{c}\right)$ and holes from states above $E_{F}$ to extended states below the valence-band mobility edge $\left(\mathrm{E}_{\mathrm{v}}\right)$. In both films and solar cells, the equilibrium $\mathrm{T}_{3}{ }^{+}$defects have their $(0 /+)$ electronic transition levels above $E_{F}$, and the equilibrium $\mathrm{T}_{3}{ }^{-}$defects have $(-/ 0)$ levels below $E_{\mathrm{F}}$. Because structural relaxation does not occur on the time scale of optical excitation, the optical levels are deeper than the thermodynamic transition levels that govern equilibrium occupation. As shown in Figure 2-4(a), Reaction 1 produces $\mathrm{T}_{3}{ }^{0}\left(\mathrm{sp}^{3}\right)$ defects that are stable against emitting an electron to $E_{F}$ without reconfiguration, but metastable against emitting the electron and reconfiguring to $\mathrm{sp}^{2}$. The optical transition of the metastable $\mathrm{T}_{3}{ }^{0}$ defect is the vertical transition shown in Figure 2-4. This means that the $(0 /+)$ thermodynamic transition levels are actually filled above $\mathrm{E}_{\mathrm{F}}$. Similarly, Reaction 2 produces $\mathrm{T}_{3}{ }^{0}\left(\mathrm{sp}^{3}\right)$ defects that are stable against emitting a hole to $\mathrm{E}_{\mathrm{F}}$ without reconfiguration, but metastable against emitting the hole and reconfiguring to $s^{2} \mathrm{p}^{3}$.

A signature of the Adler metastability is chargetrapping at the defect during creation and emission of charge during annealing. To metastably trap a carrier, the defect must surmount the barrier to reconfiguration before the trapped carrier escapes. This results in the low observed efficiency of

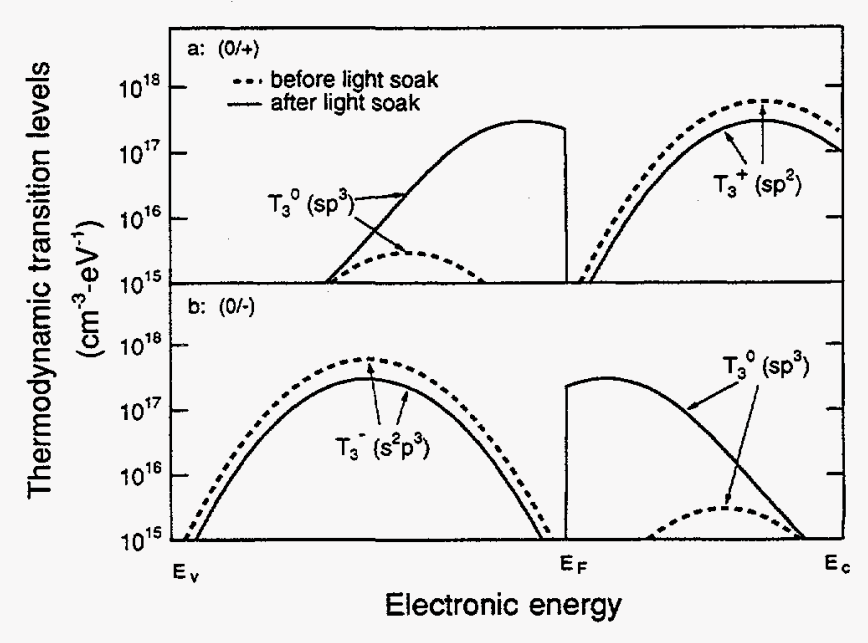

Figure 2-4. The DOS for dangling-bond optical transitions before and after light soaking according to (a) Reaction 1 and (b) Reaction 2 of the Adler model. For simplicity, the predicted shifts of $E_{F}$ are not shown.

metastable defect production. Both the energy released by the photoexcited carrier upon trapping and thermal phonons may contribute energy needed to surmount the barrier.

The Adler model suggests that one-carrier injection, in the absence of recombination, will cause the Staebler-Wronski metastability by carrier trapping. Despite the problem of space-charge limitation, single-carrier-defect creation has been observed by many workers.

The observed change in $E_{\mathrm{F}}$ during light soaking strongly suggests there are defect reactions that trap and stabilize charge. One carrier is removed from the Fermi sea by charge-trapping and reconfiguration, changing $E_{F}$. In the Adler model, Reaction 1 lowers the electron Fermi level and Reaction 2 raises it, as described above. Of course, charge-trapping in a-Si:H could be due to defects different than those proposed by Adler.

The evidence for charge-trapping metastable defect reactions in $\mathrm{a}-\mathrm{Si}: \mathrm{H}$ analogous to those found in crystalline semiconductors is strong. It is possible that several metastability mechanisms are active in a material as complex and as far from its equilibrium structure as a-Si:H. More charge-sensitive measurements are needed to study the charge-trapping metastabilities and determine whether they dominate the Staebler-Wronski effect. 
The only well-developed model of charge-trapping metastability in undoped a-Si:H is the Adler model, which suggests that charged dangling-bond defects trap carriers and reconfigure into metastable $\mathrm{T}_{3}{ }^{0}$ defects. Inhomogeneity in a-Si:H films and proximity to the doped layers of devices cause the equilibrium $\mathrm{T}_{3}{ }^{+}$and $\mathrm{T}_{3}{ }^{-}$defects that are the source of the metastability. Further study of charged defects in undoped a-Si:H and of charge-trapping metastability are needed.

Efforts to reduce the impact of the Staebler-Wronski effect in a-Si:H should focus on reducing the densities of charged dangling-bond defects by improving material homogeneity. In solar cells, charged impurity-related defects could be introduced near the interfaces to reduce the harmful effects of the electric field collapse that results from metastable neutralization of charged dangling bonds.

\section{Publications}

H. M. Branz, R. S. Crandall, and M. Silver, "Capacitance Studies of Bias-Induced Metastability in p-type Hydrogenated Amorphous Silicon," Proceedings of the Amorphous Silicon Materials and Solar Cells, ed. by B. L. Stafford, Denver: American Institute of Physics, 1991, P. 29.

H. M. Branz, R. S. Crandall, and M. Silver, "Metastability in Hydrogenated Amorphous Silicon: the Adler Model Revisited," Stability of Amorphous Silicon Alloy Materials and Devices, ed. by B. L. Stafford, New York: American Institute of Physics, 1991, pp. 29-36.

R. S. Crandall, "Capacitance studies of bias-induced metastability in p-type hydrogenated amorphous silicon," Phys. Reo. B 43, 1991, p. 4057.

R. S. Crandall and I. Balberg, "Capacitance studies of bias-induced metastability in p-type hydrogenated amorphous silicon," Appl. Phys. Lett. 58, 1991, p. 508.

R. S. Crandall, K. Sadlon, S. J. Salamon, and H. M. Branz, "Capacitance Studies of Bias-Induced Metastability in p-type Hydrogenated Amorphous Silicon," Proceedings of the Amorphous Silicon Materials and Solar Cells, ed. by B. L. Stafford, Denver: American Institute of Physics, 1991, p. 154.
R. S. Crandall, S. J. Salamon, and H. M. Branz, "Capacitance Studies of Bias-Induced Metastability in p-type Hydrogenated Amorphous Silicon," Stability of Amorphous Silicon Alloy Materials and Devices, ed. by B. L. Stafford, New York: American Institute of Physics, 1991, pp. 154-161.

R. S. Crandall, S. J. Salamon, and Y. Xu, "Capacitance Studies of Bias-Induced Metastability in p-type Hydrogenated Amorphous Silicon," Amorphous Silicon Technology-1991, ed. by A. Madan, M. J. Thompson, P. G. LeComber, Y. Hamakawa, and P. C. Taylor, Pittsburgh: Materials Research Society, 1991, p. 557.

R. S. Crandall, S. J. Salamon, and Y. Xu, "Capacitance studies of bias-induced metastability in p-type hydrogenated amorphous silicon," J. Non-Cryst. Sol. 137 \& 138, 1991, p. 311.

Daxing Han, J. I. Pankove, Y. S. Tsuo, C. H. Qiu, and $Y$. Xu, "Improvement of a-Si ${ }_{1-x} \mathrm{C}_{\mathbf{x}}: \mathrm{H} / \mathrm{a}-\mathrm{Si}: \mathrm{Hp} / \mathbf{i}$ interface by hydrogen-plasma flushing studied by photoluminescence," J. Materials Research, 6, 1991, pp. 1900-1904.

A. H. Mahan, J. Carapella, B. P. Nelson, R. S. Crandall, and I. Balberg, "Capacitance studies of bias-induced metastability in p-type hydrogenated amorphous silicon," J. Appl. Phys. 69, 1991, p. 6728.

A. H. Mahan, B. P. Nelson, S. J. Salamon, and R. S. Crandall, "Capacitance Studies of Bias-Induced Metastability in p-type Hydrogenated Amorphous Silicon," Amorphous Silicon Technology-1991, ed. by A. Madan, M. J. Thompson, P. G. LeComber, Y. Hamakawa, and P. C. Taylor, Pittsburgh: Materials Research Society, 1991, p. 673.

T. J. McMahon, "Defect equilibration in device quality a-Si:H," Int'l Conf. Proc. on the Stability of Amorphous Silicon Materials and Solar Cells, Denver: American Institute of Physics, 1991, p. 234.

T. J. McMahon, "Defect equilibration and metastability in low-spin-density amorphous hydrogenated silicon," Solar Cells 30, 1991, p. 235.

T. J. McMahon, "Defect equilibration in metastability in low-spin-density a-Si:H," Proceedings of the Materials Research Society, 219, 1991, p. 57.

G. Nobile and T. J. McMahon, "Limitations of the integrated subbandgap absorption for determining the density of defects in amorphous silicon," J. Appl. Phys. 67,1990, p. 578. 
Y. S. Tsuo, Y. Xu, D. W. Baker, and S. K. Deb, "Improvement of a-Si ${ }_{1-x} C_{x}: H / a-S i: H p / i$ interface by hydrogen-plasma flushing studied by photoluminescence," Amorphous Silicon Technology-1991, ed. by A. Madan, M. J. Thompson, P. G. LeComber, Y. Hamakawa, and P. C. Taylor, Pittsburgh: Materials Research Society, 1991, p. 679.

Y. S. Tsuo, Y. Xu, I. Balberg, and R. S. Crandall, "Effects of helium dilution on glow discharge deposition of a-Si $\mathrm{i}_{1-\mathrm{x}} \mathrm{Ge}_{\mathrm{x}}: \mathrm{H}$ alloys," Proc. of the $22 \mathrm{nd}$ IEEE PVSC, 1991.

Y. S. Tsuo, Y. Xu, E. A. Ramsay, R. S. Crandall, S. J. Salamon, I. Balberg, and B. P. Nelson, "Improvement of a-Si ${ }_{1-x} \mathrm{C}_{\mathbf{x}}: \mathrm{H} / \mathrm{a}-\mathrm{Si}: \mathrm{Hp} / \mathrm{i}$ interface by hydrogenplasma flushing studied by photoluminescence," Amorphous Silicon Technology-1991, ed. by A. Madan, J. Thompson, P. G. LeComber, Y. Hamakawa, and P. C. Taylor, Pittsburgh: Materials Research Society, 1991, p. 679.
M. Vanecek, B. P. Nelson, A. H. Mahan, and R. S. Crandall, "Capacitance studies of bias-induced metastability in p-type hydrogenated amorphous silicon," ICAS, 1991.

K. Wang, D. Han, M. Silver, and H. M. Branz, "Electroluminescence studies of recombination in hydrogenated amorphous silicon p-i-n devices," Solar Cells 30, 1991, p. 219-225.

N. Wyrsch, F. Finger, T. J. McMahon, and M. Vanecek, "Capacitance studies of bias-induced metastability in p-type hydrogenated amorphous silicon," J. Non-Cryst. Sol. 137 \& 138, 1991, p. 347.

N. Wyrsch, F. Finger, T. J. McMahon and M. Vanecek, "How to reach a more precise interpretation of subgap absorption spectra in terms of deep defect density in a-Si:H", J. Non-Cryt. Sol. XX, 1991. 


\section{Section 3}

Polycrystalline Thin Films

\section{Investigators}

R. Noufi, Principal Scientist

and Task Leader

D. S. Albin, Staff Scientist

J. Tuttle, Staff Scientist

M. Contreras, Associate Engineer

J. Dolan, Master Technician

J. Carapella, Master Technician

A. Duda, Graduate Student

A. Tennant, Graduate Student

\section{Objectives}

The objective of the Polycrystalline Thin Films Group is to fabricate and test promising thin-film solar-cell material and devices. The primary goals of this research are to (1) develop a selenization process to fabricate $\mathrm{Cu}(\mathrm{In}, \mathrm{Ga}) \mathrm{Se}_{2}$ thin films and devices and identify issues pertinent to this process in support of industry and CuInSe $\mathrm{C}_{2}$ technology, (2) execute a comprehensive plan to improve the performance of $\mathrm{Cu}(\mathrm{In}, \mathrm{Ga}) \mathrm{Se}_{2}$ absorber-based PV structures through optimization of the standard CulnSe ${ }_{2}$ device design and development of novel device structures, and (3) investigate alternative window semiconductor compounds that are compatible with $\mathrm{Cu}(\mathrm{I}, \mathrm{Ga}) \mathrm{Se}_{2}$ films. To achieve these goals, we have focused on three closely related lines of study: material fabrication, material characterization, and correlation of device performance with material properties and fabrication parameters.

\section{Major Accomplishments}

\section{The Effect of Microstructure and Strain in $\mathrm{In} / \mathrm{Cu} / \mathrm{Mo} / \mathrm{Glass}$ Precursors on CdS/CuInSe ${ }_{2}$ Photovoltaic Device Fabrication by Selenization}

We reported a definite correlation between the initial state of an In $/ \mathrm{Cu} / \mathrm{Mo} /$ Glass precursor and PV device performance after selenization of the precursor. We observed correlations between the degree of alloying in the initial as-fabricated precursor and the melting kinetics of the In/Cu layers, the air-annealing sensitivity of the final device, shifting of the spacecharge region, and, to a lesser degree, final device efficiency. Final device open-circuit voltage $\left(V_{o d}\right)$ was directly related to the grain size of the selenized precursors. A notable result of this study, and one of significance to the technology as a whole, was the direct observation of molybdenum film strain as a function of the thermal history of the precursor. No single factor is more important to the viability of this technology than film adhesion, and little is more important to adhesion than film strain.

Film strain is quantitatively measured by considering both the position (d-value) and width of molybdenum peaks in X-ray diffraction. This effect is illustrated in Figure 3-1. Molybdenum peak distortion as a function of processing is shown in Figure 3-2. The measured values of peak width (full width at half maximum [FWHM]) shown in Figure 3-2 correlate well with calculated strains based on literature values for the expansion coefficients of the representative layers. One such calculation for points 1 and 2 is shown mechanistically in Figure 3-3. The thermal history of each precursor is identical, the only difference being the glass substrate on which the precursor is fabricated. As shown in Figure 3-3, the large co-efficient of thermal expansion (CTE) mismatch of the soda lime glass (SLS) and resulting pre-tension of the molybdenum layer when heated to $200^{\circ} \mathrm{C}$ results in a lower value of compressive strain (as verified by $x$-ray defraction) when the deposited $\mathrm{Cu}-\mathrm{In}$ alloy is cooled and contracts.

With regard to the strain found in as-selenized films, there appears to be a good linear correlation between film strain (FWHM) measurements and final device efficiency. Strain will be present in any thin-film layered structure consisting of materials with different CTE values, as long as there is good adhesion between the layers; it is only in the event of poor adhesion that strain will be removed. Consequently, signs of strain in our as-selenized films are probably 


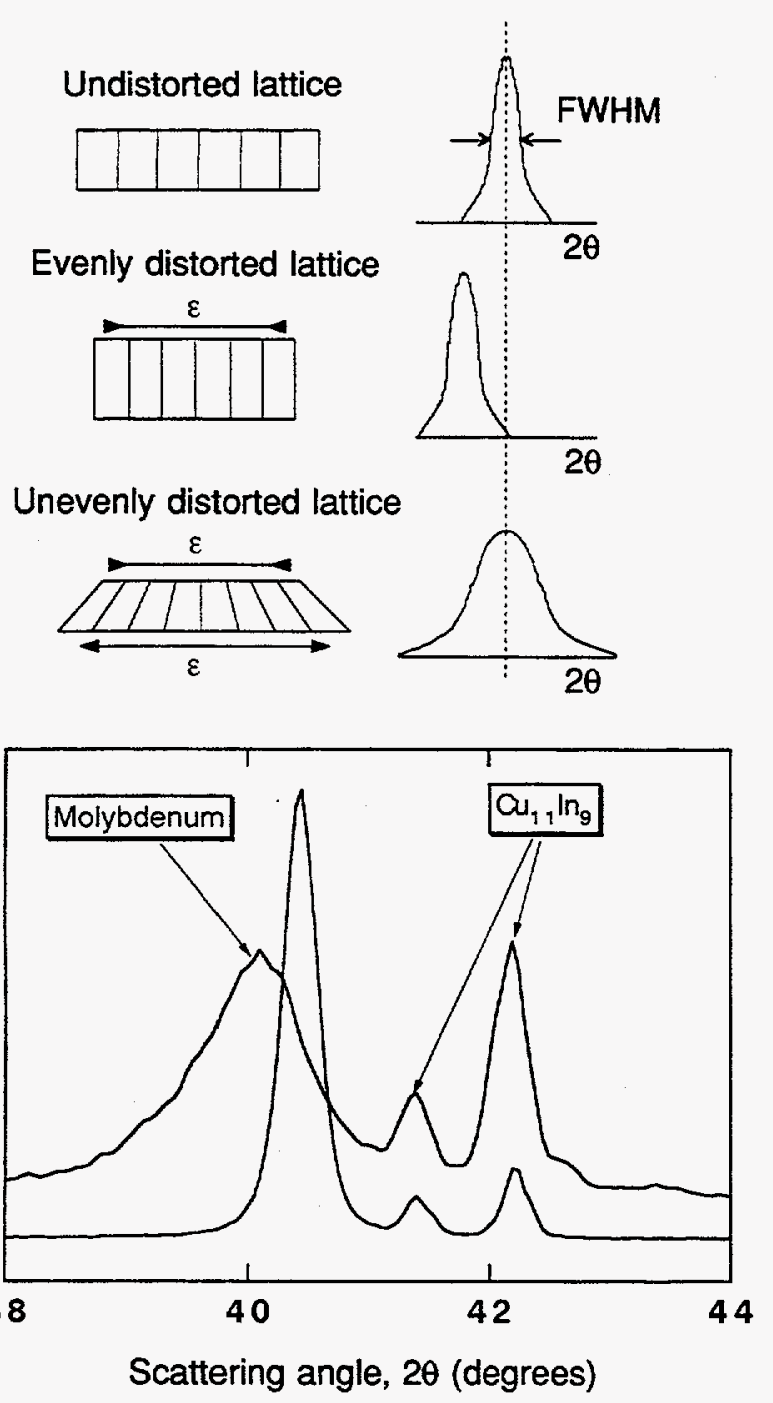

Figure 3-1. The effect of strain on X-ray diffraction line position $\left(d_{110}\right)$ and width (FWHM), both theorefically (top) and as observed (bottom), for In/Cu/Mo/glass precursors

an indication of good film adhesion, although the magnitude of the strain should be minimized to improve reliability.

\section{The Effect of Copper Vacancies on the Optical} Bowing of Chalcopyrite $\mathrm{Cu}(\mathrm{In}, \mathrm{Ga}) \mathrm{Se}_{2}$ Alloys

The optical bowing behavior of polycrystalline thinfilm CuIn ${ }_{1-y} \mathrm{Ga}_{\mathrm{y}} \mathrm{Se}_{2}$ alloys is dependent on the copper stoichiometry. The variation in optical band gap, $\mathrm{E}_{\mathbf{g}^{\prime}}$ for alloys in which copper is near stoichiometry (25 at. \%) is parabolic and follows the relationship:

$$
\mathrm{E}_{\mathrm{g}}(\mathrm{y})=1.011+0.421 \mathrm{y}+0.244 \mathrm{y}^{2}(\mathrm{eV}),
$$

where $y$ is the alloy parameter, [at. \% Ga]/ [at. $\% \mathrm{Ga}+$ at. $\%$ In]. Alternatively, films with copper-poor stoichiometries $(-19$ at. \% Cu) exhibit little alloy bowing:

$$
E_{g}(y)=1.01+0.733 y-0.046 y^{2}(e V) .
$$

This copper-dependent behavior is shown in Figure 3-4.

The increased band gap of copper-poor alloys correlates with lattice shrinkage, presumably from the presence of copper vacancies as measured by $x$-ray diffraction. However, the observed increase in $E_{g}$ could not be explained solely on the basis of this shrinkage. This was shown by plotting the change in $\mathrm{E}_{\mathrm{g}}, \Delta \mathrm{Eg}$, versus en $\left(\mathrm{V}_{\mathrm{st}} / \mathrm{V}_{\mathrm{cp}}\right)$ where st and $\mathrm{cp}$ refer to the stoichiometric and copper-poor cases at fixed gallium content. The slope of such a plot should
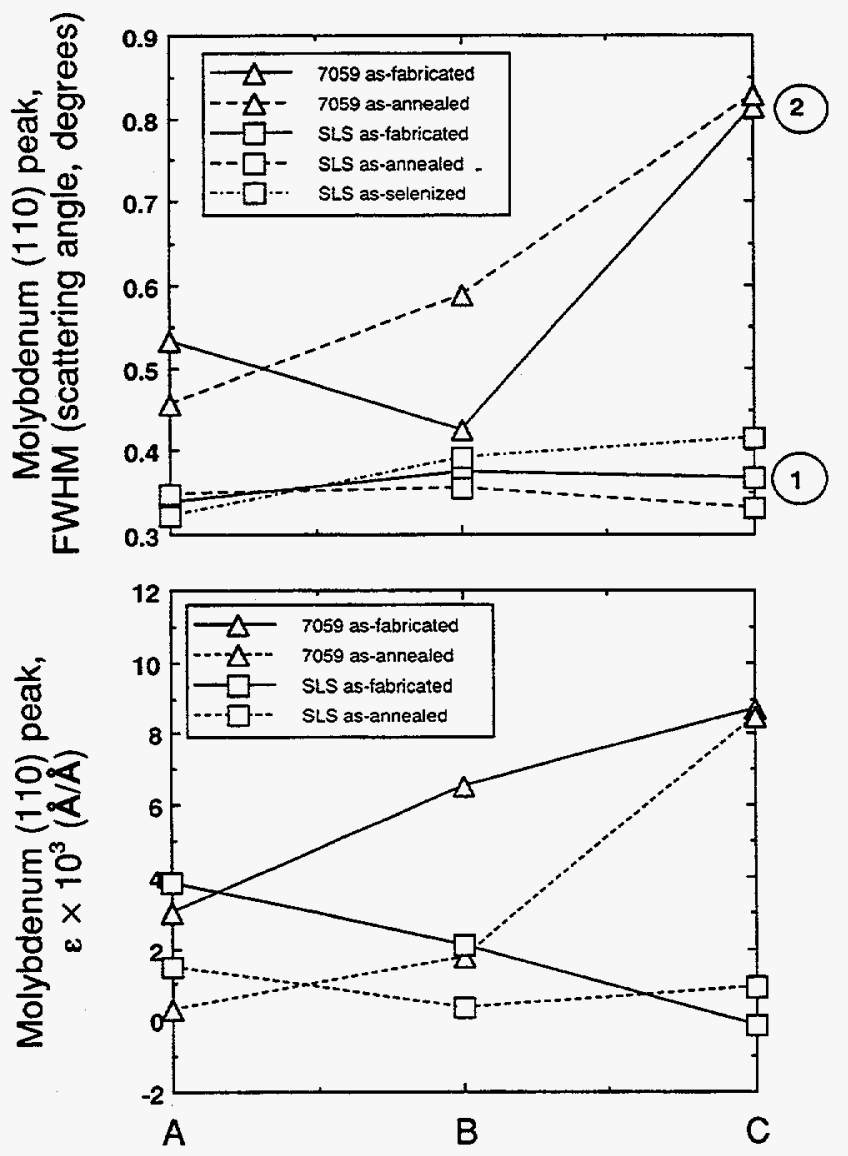

Precursor

Figure 3-2. Molybodenum (110) peak distortion (FWHM (top) and $\varepsilon(110)$ strain (bottom)) for asfabricated, as-annealed, and as-selenized (SLS substrates only) precursors A, B, and C 
Point 1

in Figure 3-2

SLS glass
$\alpha=9 \times 10^{-6}$

Point 2

in Figure 3-2
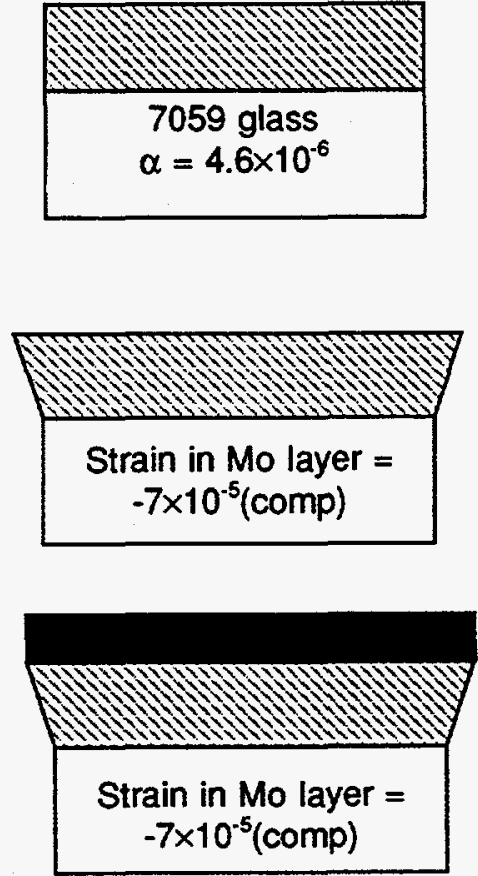

Strain in Mo layer = $+7 \times 10^{-4}$ (tension)
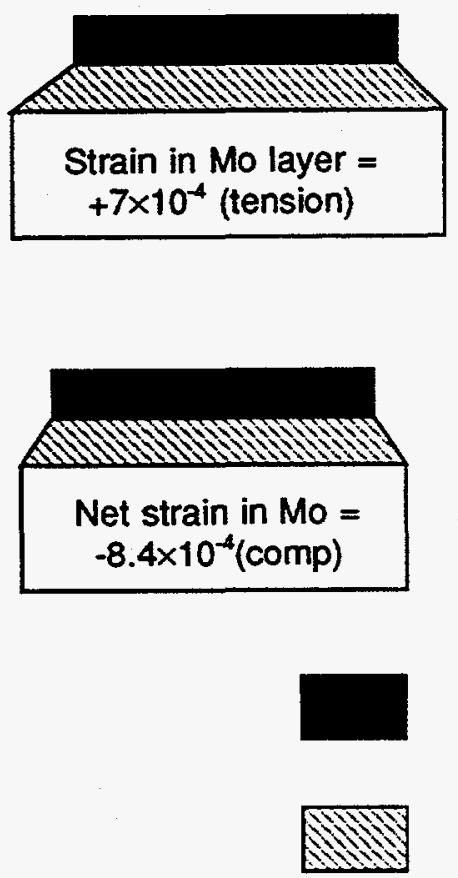

$C u_{11} \ln 9+\ln$ alloy $\left(\alpha \equiv 17 \times 10^{-6}\right)$

Molybdenum $\left(\alpha \cong 5 \times 10^{-6}\right)$
Mo deposited onto glass substrate, $\mathrm{T}=25^{\circ} \mathrm{C}$

Mo/glass heated to $200^{\circ} \mathrm{C}$

$\mathrm{Cu}_{11}, \mathrm{n}_{9}+\mathrm{In}$ alloy deposited at $200^{\circ} \mathrm{C}$

In+Cu/Mo/glass precursor cooled to $25^{\circ} \mathrm{C}$

Figure 3-3. A simple mechanistic model for explaining the difference in film strain (qualitatively) measured for points 1 and 2 in Figure 3-2

equal the constant $\gamma / \kappa$ where $\gamma$ is $\delta E_{g} / d P$ and $\kappa$ is the compressibility. As shown in Figure 3-5, a leastsquares fit of the data indicates a slope of around $-8.4 \mathrm{eV}$. Literature values for $\gamma$ and $\kappa$ predict a value of between -3.0 and $-6.0 \mathrm{eV}$. The steeper slope and non-zero intercept shown in Figure 3-5 may indicate an additional counterbalance between minimized $p-d$ repulsion (decreases $\Delta \mathrm{E}$ ) and bond relaxation (increases $\Delta \mathrm{E}$ ). Both of these mechanisms are believed to be present in copper-poor alloys.
Modifications to the Interfacial and Bulk Region of CuInSe ${ }_{2}$-Based Photovoltaic Devices: Alloys, Windows, and Grain Size Enhancement

Polycrystalline thin-film CuInSe $\mathrm{C}_{2}$ and $\mathrm{CuInSe}_{2}$-based alloy materials have emerged as front-runners in the quest for commercially viable terrestrial PV technologies, with efficiencies exceeding $14 \%$ in smallarea devices [1] and $11 \%$ in $989-\mathrm{cm}^{2}$ modules [2]. Further device and module optimization is necessary. 


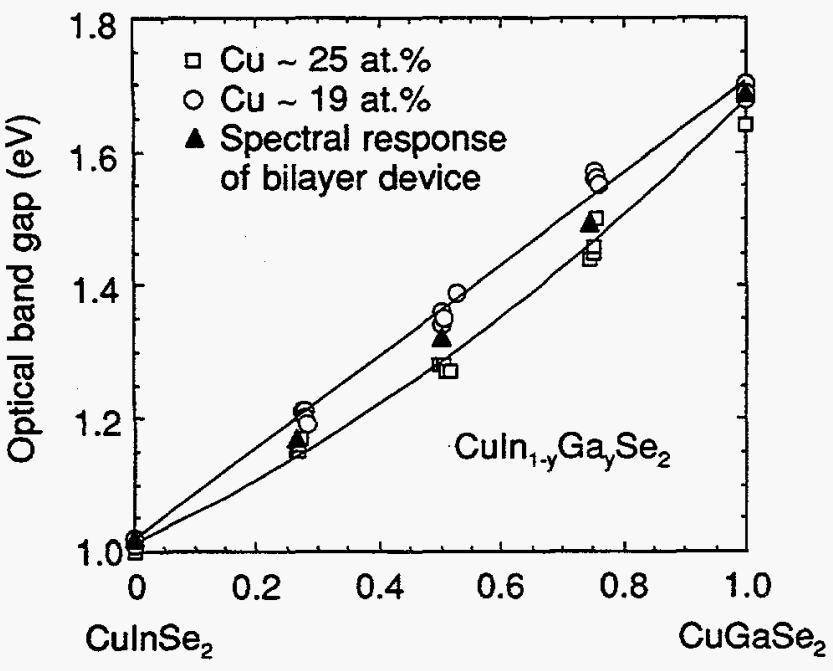

Alloy parameter y

Figure 3-4. Optical band gap of Culn ${ }_{1-y} \mathrm{Ga}_{\mathrm{y}} \mathrm{Se}_{2}$ alloys, including the effect of copper

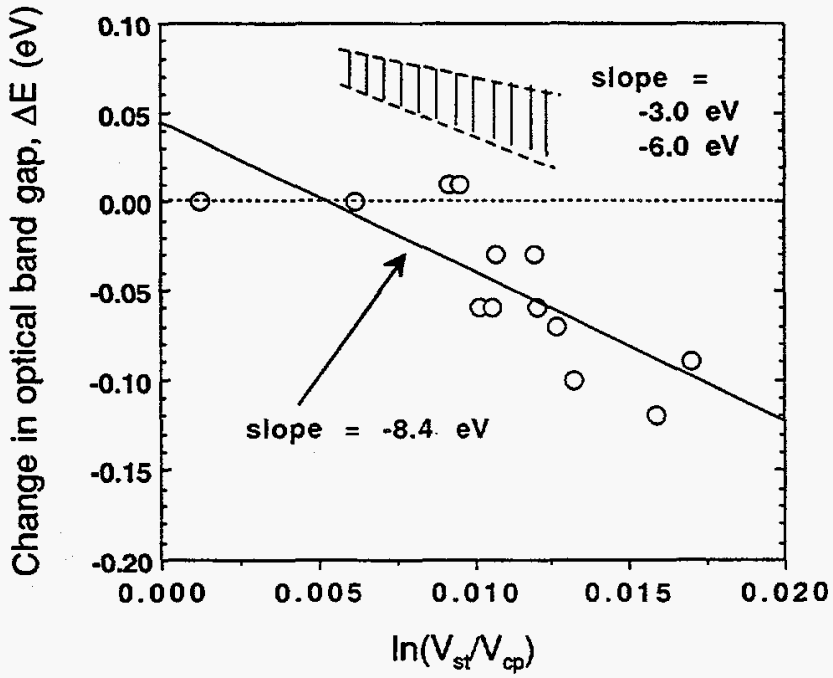

Figure 3-5. Correlation of lattice shrinkage with the increased band gap of copper-poor alloys

Our group is investigating three approaches to realizing this goal: (1) carrier lifetime enhancement by novel processing techniques, (2) band gap enhancement of the near-interface region by

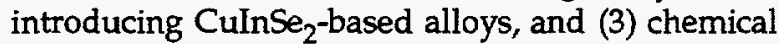
modification of the hetero-interface by introducing alternative II-VI window compounds.

The common objective in the various scenarios is to push the $V_{o c}$ parameter above present barriers, using both novel and conventional methods, while maintaining the near-optimal $\mathrm{J}_{\mathrm{sc}}$ values currently realized. In each case, we use device modeling tools to shed valuable light on the subtleties associated with complex device structures. In the end, achieving predicted improvements in polycrystalline thin-film material systems is a laborious process that depends heavily on the methodology and a little on luck!

CuInSe ${ }_{2}$ and $\mathrm{Zn}_{\mathrm{y}}\left(\mathrm{CuIn}_{1-\mathrm{x}}[\mathrm{Al}, \mathrm{Ga}]_{\mathrm{x}}\right)_{2-\mathrm{y}} \mathrm{Se}_{2}$ absorber structures, and $\mathrm{Zn}_{1-x} \mathrm{Cd}_{x} \mathrm{~S}_{1-y} \mathrm{Se}_{\mathrm{y}}$ window structures, are fabricated by physical vapor deposition (PVD) of the constituent elements under a vacuum of $10^{-6}$ torr. PVD is the fabrication technology of choice for this study because it is capable of producing layered alloy structures of a controlled composition.

Modifications to the interfacial and bulk regions of $\mathrm{CuInSe}_{2}$-based PV devices for optimization purposes are promising. Using special processing techniques, we achieved a ten-fold grain size enhancement of thin-film CuInSe, with an associated compositional gradient. We also enhanced carrier lifetime, with an associated increase in $V_{o c}$, using solution chemical treatments.

It appears that CdS plays a chemical rather than electrical role at the hetero-interface. Alternatives to $\mathrm{CdS}$ in the $\mathrm{Zn}_{1-\mathrm{x}} \mathrm{Cd}_{\mathrm{x}} \mathrm{S}_{1-\mathrm{y}} \mathrm{Se}_{\mathrm{y}}$ alloy family have been substituted in this region, with $\mathrm{ZnSe}$ exhibiting superior performance.

Finally, we accomplished modifications to the spacecharge region by inserting wide-gap CuInSe $\mathrm{C}_{2}$-based alloys. We observed an enhancement in $\mathrm{V}_{\mathrm{oc}}$, but further optimization of the alloys is required to develop high-quality device structures.

\section{Physical, Chemical, and Structural Modification to Thin-Film CuInSe ${ }_{2}$-Based Photovoltaic Devices}

We investigated two approaches to modifying and improving CuInSe $e_{2}$-based $\mathrm{PV}$ devices. One approach, the incorporation of wide-gap CulnSe ${ }_{2}$-based alloys at the interface, produced inconclusive results but suggests that the choice of alloy systems is critical. Two methods can be used to grow enhanced-grain thin-film CuInSe ${ }_{2}$, as described below. The properties of the films are consistent with those required for device fabrication.

$\mathrm{CuInSe}_{2}$-based thin-film absorber structures are fabricated by PVD of the constituent elements under a vacuum of $10^{-6}$ torr. Experimentally, the wide-gap interface layers are fabricated by alloying $\mathrm{CuInSe}_{2}$ $\left(E_{\mathrm{g}}=1.0 \mathrm{eV}\right)$ with either the binary $\mathrm{ZnSe}(2.65 \mathrm{eV})$ or the ternaries CuGaSe $2(1.64 \mathrm{eV}), \mathrm{CuAlSe}_{2}(2.65 \mathrm{eV})$, or $\mathrm{CuInS}_{2}(1.53 \mathrm{eV})$ during the final minutes of the deposition (see Table 3-2). Each alloy system may be 
Table 3-1. Summary of Modifications to CulnSe ${ }_{2} / \mathrm{CdS}$ Device Structure

\begin{tabular}{|c|c|c|c|c|c|}
\hline Modification & Description & \multicolumn{2}{|c|}{$\begin{array}{cc}\text { Control Device } \\
V_{o c} & J_{s c} \\
(m V) & \left(\mathrm{mA} / \mathrm{cm}^{2}\right)\end{array}$} & \multicolumn{2}{|c|}{$\begin{array}{c}\text { Modified Device } \\
\mathrm{V}_{o c} \mathrm{~J}_{\mathrm{sc}} \\
(\mathrm{mV}){ }^{\circ}\left(\mathrm{mA} / \mathrm{cm}^{2}\right)\end{array}$} \\
\hline $\begin{array}{l}\text { Chemical } \\
\text { Treatments }\end{array}$ & $\begin{array}{l}\text { - Iodide solution (\#1) } \\
\text { + laser irradiation } \\
\text { - Iodide solution (\#2) } \\
\text { - } 5^{\prime} \mathrm{NaCN} @ 50^{\circ} \mathrm{C}\end{array}$ & $\begin{array}{l}440 \\
425 \\
351\end{array}$ & $\begin{array}{r}34.0 \\
33.3 \\
1.0\end{array}$ & $\begin{array}{c}503 \\
\text { (unst } \\
472 \\
302\end{array}$ & $\begin{array}{r}35.0 \\
31.9 \\
34.0\end{array}$ \\
\hline ZnSe Window & $\begin{array}{l}200 \AA \mathrm{ZnSe}+\text { Std. } \\
\text { CdS window }\end{array}$ & 382 & 33.1 & 418 & 32.2 \\
\hline $\mathrm{Cu}(\mathrm{In}, \mathrm{Ga}) \mathrm{Se}_{2}$ Alloy & $\begin{array}{l}\text { - } 2000 \AA \mathrm{Ca}_{2} \mathrm{Se}_{3} \mathrm{CO}- \\
\text { evaporated with } \mathrm{Cu} \\
\text { and In on a standard } \\
\text { CuInSe } \text { bilayer. } \\
\text { - } 1000 \AA \mathrm{CuGaSe}_{2} \text { on } \\
\text { a standard } \mathrm{CuInSe}_{2} \\
\text { bilayer. }\end{array}$ & 381 & 40.5 & 500 & 22.0 \\
\hline & $\begin{array}{l}\text { - } 500 \AA \mathrm{CuGaSe}_{2} \text { on } \\
\text { a standard CuInSe } \\
\text { bilayer. } \\
\text { - } 7000 \AA \\
\mathrm{CuIn}_{0.78} \mathrm{Ga}_{0.22} \mathrm{Se}_{2} \\
\text { standard CuInSe}{ }_{2} \\
\text { 1st layer. }\end{array}$ & 381 & 40.5 & 488 & 33.7 \\
\hline $\mathrm{Cu}(\mathrm{In}, \mathrm{Al}) \mathrm{Se}_{2}$ Alloy & $\begin{array}{l}\text { - } 100 \AA \mathrm{Al} \text { on a } \\
\text { standard CuInSe } \\
\text { bilayer, followed by } \\
\text { a 2-hr anneal @ } \\
400^{\circ} \mathrm{C} \text { in Ar. }\end{array}$ & - & - & 630 & 4.0 \\
\hline
\end{tabular}

Table 3-2. List of Potential Alloy Partners to CulnSe

\begin{tabular}{|c|c|c|l||}
\hline Compound & Band Gap (eV) & Alloy Content (\%) & \multicolumn{1}{|c|}{ Concerns } \\
\hline ZnSe & 2.65 & 25 & $\begin{array}{l}\bullet \text { Alloy phase nature unknown } \\
\text { Zn doping vs. alloying }\end{array}$ \\
\hline CuAlSe $_{2}$ & 2.65 & 25 & $\begin{array}{l}\bullet \text { Al reactivity with Se } \\
\text { Unstable compound }\end{array}$ \\
\hline $\mathrm{CuGaSe}_{2}$ & 1.67 & 60 & $\begin{array}{l}\text { - Well characterized } \\
\text { 27\% Ga upper limit }\end{array}$ \\
\hline $\mathrm{CuInS}_{2}$ & 1.53 & $\begin{array}{l}\text { - Anion exchange superior } \\
\text { Good stand-alone absorber }\end{array}$ \\
\hline
\end{tabular}


examined on the basis of required alloy content, phase stability, and anion/cation exchange character.

Figures 3-6 and 3-7 present data on modified devices in which $~ 1000-2000 \AA$ of the alloys $(20 \% \mathrm{ZnSe}$, $12 \% \mathrm{CuAlSe}_{2}$ ) were introduced at the CdS/CuInSe interface. The implication is that zinc and aluminum are incorporated into the absorber in observably different manners. Secondary ion mass spectroscopy (SIMS) (see Figure 3-6) depth profiling reveals zinc diffusion well into the bulk of the absorber, while aluminum maintains the profile of the deposition recipe. Relative spectral response measurements (see Figure 3-7) suggest recipe-dependent alloying of the aluminum with $\mathrm{CuInSe}{ }_{2}$, and type conversion of the near-interface CuInSe ${ }_{2}$ to $n$-type via zinc-doping of copper vacancies.

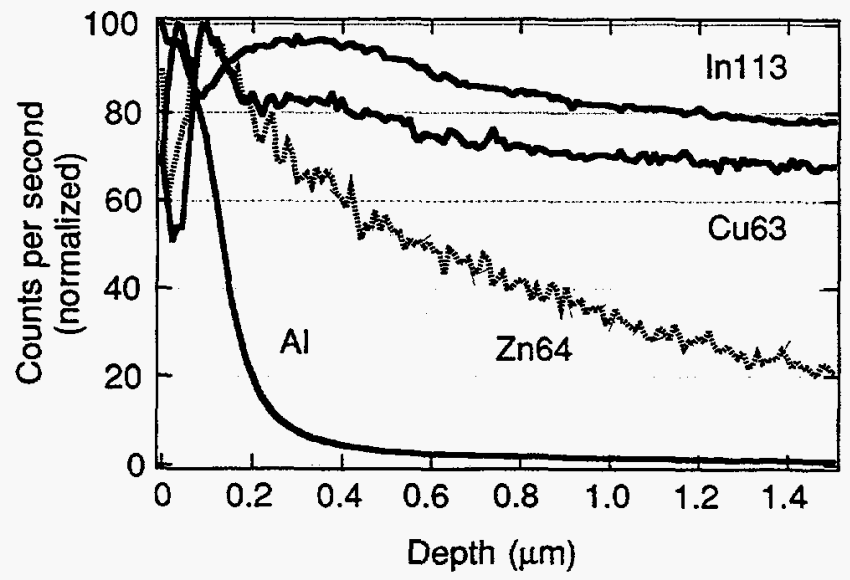

Figure 3-6. SIMS depth profile of two CulnSe ${ }_{2}$ device structures. One contains $1000 \AA$ of Culn $0.88 \mathrm{Al}_{0.12} \mathrm{Se}_{2}$, while the other contains $1000 \dot{A}$ of $Z n_{0.4}(C u l n)_{1.6} \mathrm{Se}_{2}$.

Large-grain thin-film CuInSe ${ }_{2}$ is fabricated in one of two manners: (1) using the morphology of largegrain copper-rich or $\mathrm{Cu}_{2} \mathrm{Se}$ films as a growth surface for active layers, or (2) converting the existing photoinactive copper-rich thin-film material to photo-active material by a vapor recrystallization process.

Our best effort to date in this series is shown in Figure 3-8 and exhibits the type of morphology we have targeted. Crystallite sizes are on the order of $5.0 \mu \mathrm{m}$ with a smooth surface texture. The cracking, which presents a problem for device fabrication, may result from the thermal mismatch between the $\mathrm{Cu}_{2} \mathrm{Se}$ base layer and the 7059 glass substrate. The results of Auger electron spectroscopy analysis (see Figures 3-9 and 3-10) suggest that the crystallite surfaces are either deficient in indium or rich in copper, relative to the bulk. The crystallite boundary is also copper-rich relative to the bulk. Depth profiling reveals a

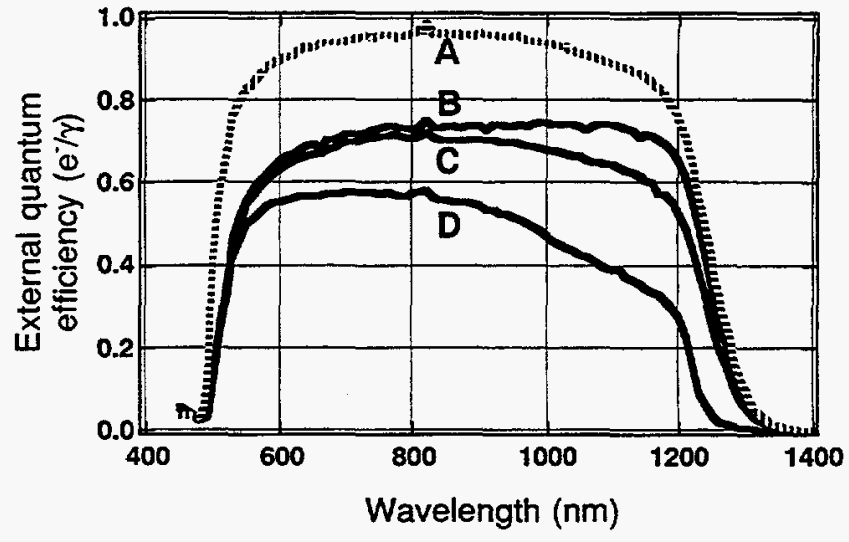

Figure 3-7. Relative spectral response of a standard $\mathrm{CdS} /$ CuInSe $_{2}$ device $(A)$ and three alloy device structures; (B) $1000 \AA$ (Culn) $1.6 \mathrm{Zn}_{0.4} \mathrm{Se}_{2}$ of the intertace; (C) $1000 \AA$ A Culn $0.76 \mathrm{Al}_{0.24} \mathrm{Se}_{2}$ buried layer; and (D) $2000 \AA$ Culn $n_{0.88} \mathrm{Al}_{0.12} \mathrm{Se}_{2}$ at the interface

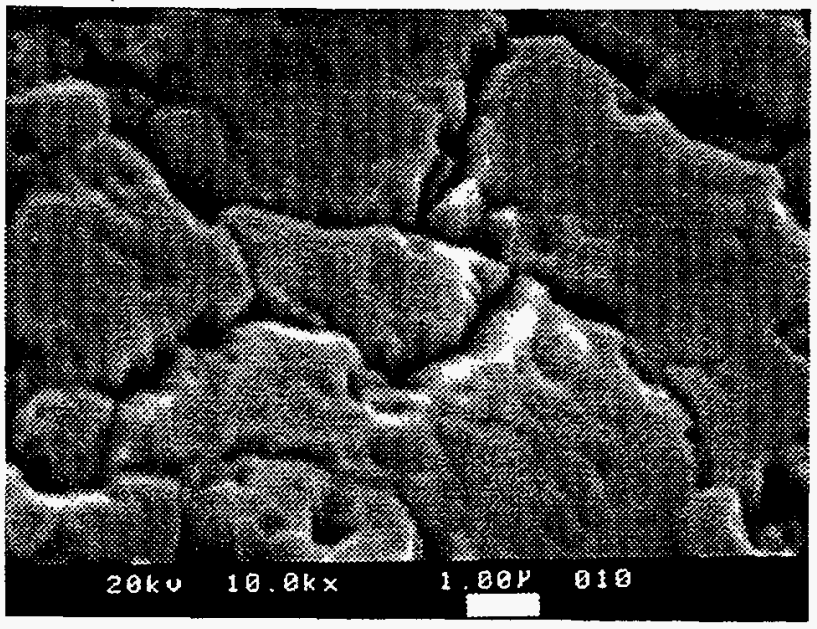

Figure 3-8. Scanning electron micrograph of the surface morphology of large-grain, thin-film $\mathrm{CulnSe}_{2}$

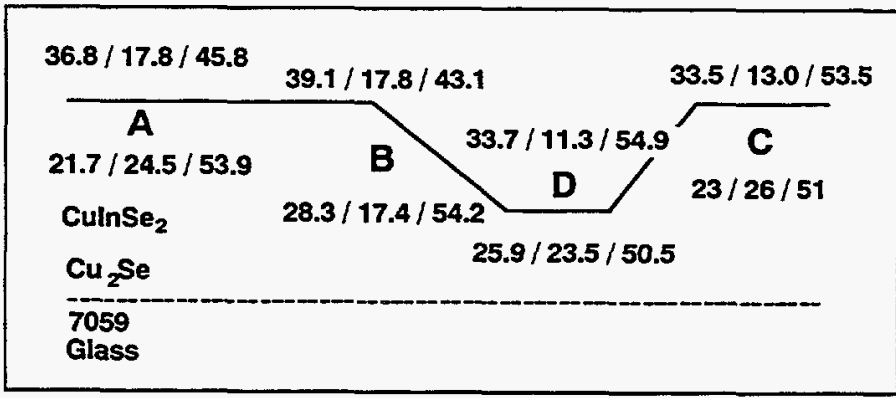

Figure 3-9. Auger compositional analysis of the sample depicted in Figure 3-8. The top number represents a surface survey and the bottom number a survey following two minutes of sputtering. (A) grain top, (B) grain edge, (C) grain top, and (D) grain crack. 


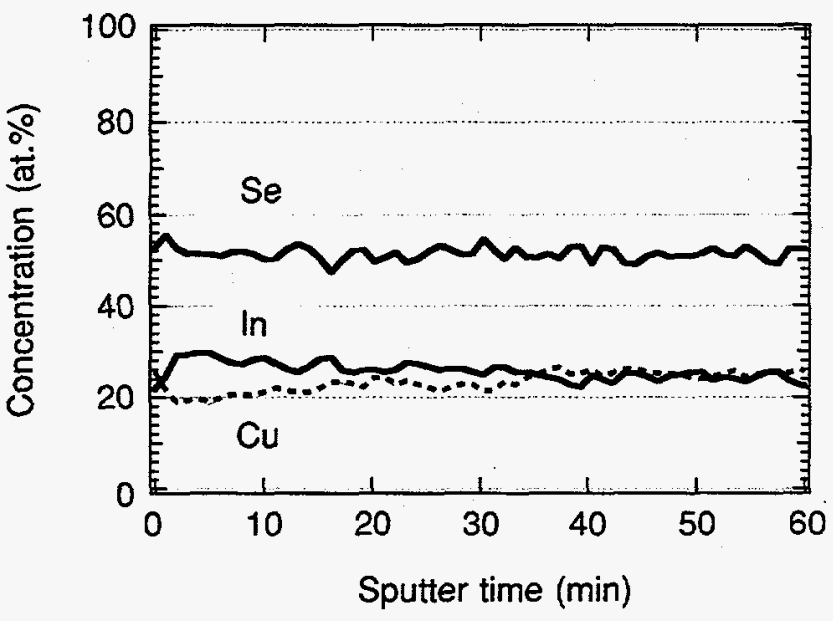

Figure 3-10. Auger compositional depth profile of the bulk grain region of the thin-film sample depicted in Figure 3-8

compositional gradient near the surface, a condition necessary for device fabrication.

\section{Optical Band Gap and Lattice Constant of $\mathrm{Zn}_{1-x} \mathrm{Cd}_{\mathbf{x}} \mathrm{S}_{1-\mathrm{y}} \mathrm{Se}_{\mathrm{y}}$ Thin Film Alloys Used as Window Materials for Photovoltaic Cells}

Several alloy compositions of the $\mathrm{Zn}_{1-x} \mathrm{Cd}_{x} \mathrm{~S}_{1-y} \mathrm{Se}_{y}$ quaternary were prepared by vacuum co-evaporation from the II-VI binaries of CdSe, CdS, ZnSe, and ZnS. Optical band gaps were measured for $5000 \AA$ thick films grown on 7059 glass. The measurements were performed with a Beckman Spectrophotometer, using an integrating sphere to measure diffuse and total reflectance and scattered and total transmission. Lattice constants were extracted from $x$-ray diffraction measurements of $2-\mu \mathrm{m}$ thick films using a Rigaku Dmax vertical goniometer and controller system with a rotating copper anode $\mathrm{x}$-ray generator.

It is important to note that we work with solid solution, which includes substitution between both anions and cations. This allows flexibility to tailor the optical band gap and the lattice constant for optimal lattice matching to the absorber.

To date, we have completed the fabrication and analysis of ten alloy compositions by vacuum coevaporation. More compositions are needed to complete a comprehensive study. We will also extend this study to films fabricated from solution growth.

Figure 3-11 shows energy band gap and lattice constant contours of the $\mathrm{Zn}_{1-x} \mathrm{Cd}_{\mathrm{x}} \mathrm{S}_{1-\mathrm{y}} \mathrm{Se}_{\mathrm{y}}$ alloys calculated using the method presented by Moon et al. [3]. On this figure, we superimposed our experimental data points, which (surprisingly) compare favorably with the calculated contour. It is evident from Figure 3-11 that, for a given lattice parameter, a range of band gaps is available and can be achieved by adjusting $x$ and $y$ in the fabrication of the alloy.

\section{Publications}

D. S. Albin, J. J. Carapella, J. R. Tuttle, and R. Noufi, "The Effect of Copper Vacancies on the Optical Bowing of Chalcopyrite $\mathrm{Cu}(\mathrm{In}, \mathrm{Ga}) \mathrm{Se}_{2}$ Alloys," Proceedings of the 1991 MRS Spring Meeting, "Materials for Optical Information Processing," vol. 228, p. 267 (1992).

D. S. Albin, J. Carapella, A. Duda, J. Tuttle, A. Tennant, R. Noufi, and B. Basol, "The Effect of Microstructure and Strain in In/Cu/Mo/Glass Precursors on CdS/CuInSe 2 Photovoltaic Device Fabrication by Selenization," 22nd IEEE PV Specialists Conference. New York: Institute of Electrical and Electronics Engineers, 1991, p. 907.

D. S. Albin, G. D. Mooney, J. Cärapella, A. Duda, J. Tuttle, R. Matson, and R. Noufi, "The Phase Behavior of Evaporated Copper and Indium Precursors for Selenization," Solar Cells Vol. 30, 1991, p. 41.

D. S. Albin, G. D. Mooney, A. Duda, J. Tuttle, R. Matson, and R. Noufi, "Enhanced Grain Growth in Polycrystalline CuInSe ${ }_{2}$ Using Rapid Thermal Processing," Solar Cells Vol. 30, 1991, p. 47.

R. Noufi, D. S. Albin, J. R. Tuttle, J. J. Carapella, M. Contreras, and A. Tennant, "Optical Band Gap and Lattice Constant of $\mathrm{Zn}_{1-x} \mathrm{Cd}_{x} \mathrm{~S}_{1-y} \mathrm{Se}_{y}$ Thin Film Alloys Used as Window Materials for Photovoltaic Cells," 22nd IEEE PV Specialists Conference. New York: Institute of Electrical and Electronics Engineers, 1991, p. 1105.

J. R. Tuttle, D. S. Albin, R. Noufi, and S. K. Deb, "The Design and Fabrication of Polycrystalline Thin-Film $\mathrm{CuInSe}_{2}$ and $\mathrm{Cu}(\mathrm{In}, \mathrm{Ga}) \mathrm{Se}_{2}$-Based Photovoltaic Materials and Devices," Proceedings of the 6th International Photovoltaic Science and Engineering Conference, New Delhi, India, 1992, p. 849.

J. R. Tuttle, D. S. Albin, and R. Noufi, "Issues Concerning the Design and Fabrication of Polycrystalline Thin-Film $\mathrm{Cu}(\mathrm{In}, \mathrm{Ga}) \mathrm{Se}_{2}$-Based Photovoltaic Materials and Devices," Proceedings of the ISES 1991 Solar World Congress, Denver, Colorado. New York: Pergamon Press, 1991, Vol. 1, p. 21. 


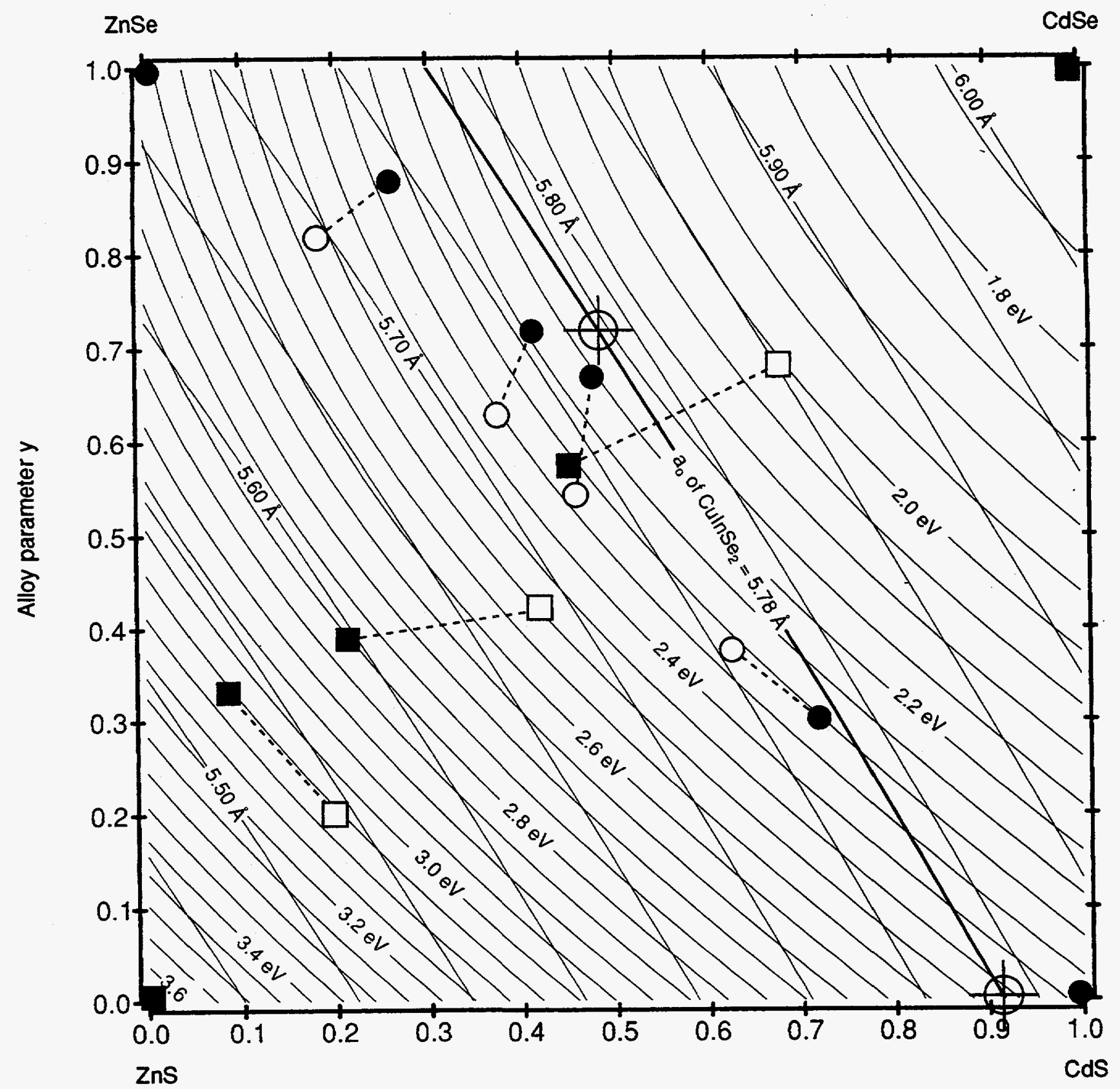

Alloy parameter $x$

Figure 3-11. Experimentally obtained optical band gap and lattice constant for various $2 n_{1-x} \mathrm{Cd}_{x} \mathrm{~S}_{1-y} \mathrm{Se}_{y}$ thin-film alloys superimposed on contours of the calculated values. Open symbols represent flux ratios and solid symbols represent actual compositions. 
J. R. Tuttle, M. Contreras, D. S. Albin, and R. Noufi, "Physical, Chemical, and Structural Modifications to Thin-film CuInSe ${ }_{2}$-based Photovoltaic Devices," 22nd IEEE PV Specialists Conference. New York: Institute of Electrical and Electronics Engineers, 1991, p. 1062.

J. R. Tuttle, M. Contreras, J. Carapella, D. S. Albin, and R. Noufi, "Modifications to the Interfacial and Bulk Region of CuInSe $\mathrm{C}_{2}$-Based Photovoltaic Devices: Alloys, Windows, and Grain-Size Enhancement," Proceedings of the 26th Intersociety Energy Conversion Engineering Conference, Boston, Massachusetts. La Grange Park, Illinois: American Nuclear Society, 1991, Vol. 5, p. 106.

\section{References}

1. K. W. Mitchell and H. I. Liu, Proceedings 20th IEEE Photovoltaic Specialists Conference, Las Vegas, Nevada. New York: Institute of Electrical and Electronics Engineers, 1989, pp. 1461-1468.

2. K. W. Mitchell, C. Eberspacher, J. Ermer, and D. Pier, Proceedings 20th IEEE Photoooltaic Specialists Conference, Las Vegas, Nevada. New York: Institute of Electrical and Electronics Engineers, 1989, pp. 1384-1389.

3. R. L. Moon, G. A. Antypas, and L. W. James, J. Electron. Mater. 3, 1974, p. 635. 


\section{Section 4 \\ III-V High-Efficiency Photovoltaic Cells}

\section{Investigators}

J. Olson, Principal Scientist

and Group Leader

S. Kurtz, Senior Scientist

C. Kramer, Research Technician

A. Kibbler, Staff Scientist

D. Friedman, Staff Scientist

K. Bertness, Staff Scientist

\section{Objectives}

The group's objective is to develop an understanding of, and solutions to, the problems inherent in the fabrication of high-efficiency, multijunction cascade solar cells using III-V semiconductor materials such as $\mathrm{GaAs}, \mathrm{GaP}$, InP, GaInP, and AlGaAs. Our major areas of research include metal-organic chemical vapor deposition (MOCVD), material analysis, and device fabrication and characterization.

Because of a suspension of MOCVD operations for the purpose of conducting a safety review, most of the effort in FY 1991 was devoted to materials and device studies on samples grown prior to the suspension. Nevertheless, we carried out a number of studies, which resulted in some significant findings and conclusions.

\section{Major Accomplishments}

\section{Back Surface Fields for GaInP 2 Solar Cells}

By using a tandem combination of an optically thin $\mathrm{Ga}_{0.51} \mathrm{In}_{0.49} \mathrm{P}$ top cell and a GaAs bottom cell, we achieved a one-sun, AM1.5 efficiency of $27.3 \%$. The $\mathrm{Ga}_{0.51} \mathrm{In}_{0.49} \mathrm{P}$ (hereafter referred to as $\mathrm{GaInP}_{2}$ ) top cell, with a band gap of $1.85 \mathrm{eV}$, must be $\sim 1 \mu \mathrm{m}$ thick in order to achieve current matching. At this thickness, the surface recombination velocity at the back of the cell significantly affects the $V_{o c}$. Hence, the $V_{o c}$ of the $27.3 \%$ device, which contained no back surface field (BSF), was about $100 \mathrm{meV}$ less than the expected value. To remedy this situation, we studied the efficacy of two BSF structures. The first was an AlGaInP alloy with a band gap of $\sim 1.95 \mathrm{eV}$. The second was GaInP 2 grown under conditions that yield a band gap of $1.88 \mathrm{eV}$. (The band gap of $\mathrm{GaInP}_{2}$, at constant composition, is a function of numerous growth conditions and can be varied from 1.8 to $1.9 \mathrm{eV}$.) We examined the differences between the two candidate materials for passivating the back surface of the $\mathrm{GaInP}_{2}$ top cell. Of the many characterization techniques applied to these cells, dark and light current-voltage (IV) electrical measurements and SIMS profiling are described here.

Figure 4-1 displays $\mathrm{V}_{\mathrm{oc}}$ against band gap for a number of cells. The figure shows that, for any given band gap, the cells with the $\mathrm{GaInP}_{2}$ BSF have higher $V_{o c}$ values than the cells with the quaternary BSF. This indicates that the improved $V_{\text {oc }}$ is due to the superiority of the GaInP $\mathrm{P}_{2}$ BSF and not just to variations in the band gap of the emitter/base.

A SIMS scan through a top cell with a quaternary BSF showed a level of oxygen contamination peaking at the location of the BSF, as might be expected from the known oxygen-gettering properties of aluminum. It seems reasonable to guess that the oxygen content of the quaternary layer is responsible for its poor performance as a BSF. (We thank Dr. S. Asher for the SIMS measurements.)

\section{Cation Site Ordering and Conduction Electron Scattering in $\mathbf{G a I n P}_{\mathbf{2}}$}

The band gap of the alloy $\mathrm{GaInP}_{2}$ has been shown to vary from about 1.8 to $1.9 \mathrm{eV}$ depending on the degree of compositional ordering. The conduction mobility $\mu$ in III- $V$ alloys depends on the degree of alloy clustering and may, therefore, be a useful probe for clustering. We presented the measured Hall mobility $\mu_{\mathrm{H}}(\mathrm{T})$ from $\mathrm{T}=300$ to $600 \mathrm{~K}$ and analyzed it using the Harrison-Hauser/Marsh (HHM) formalism 


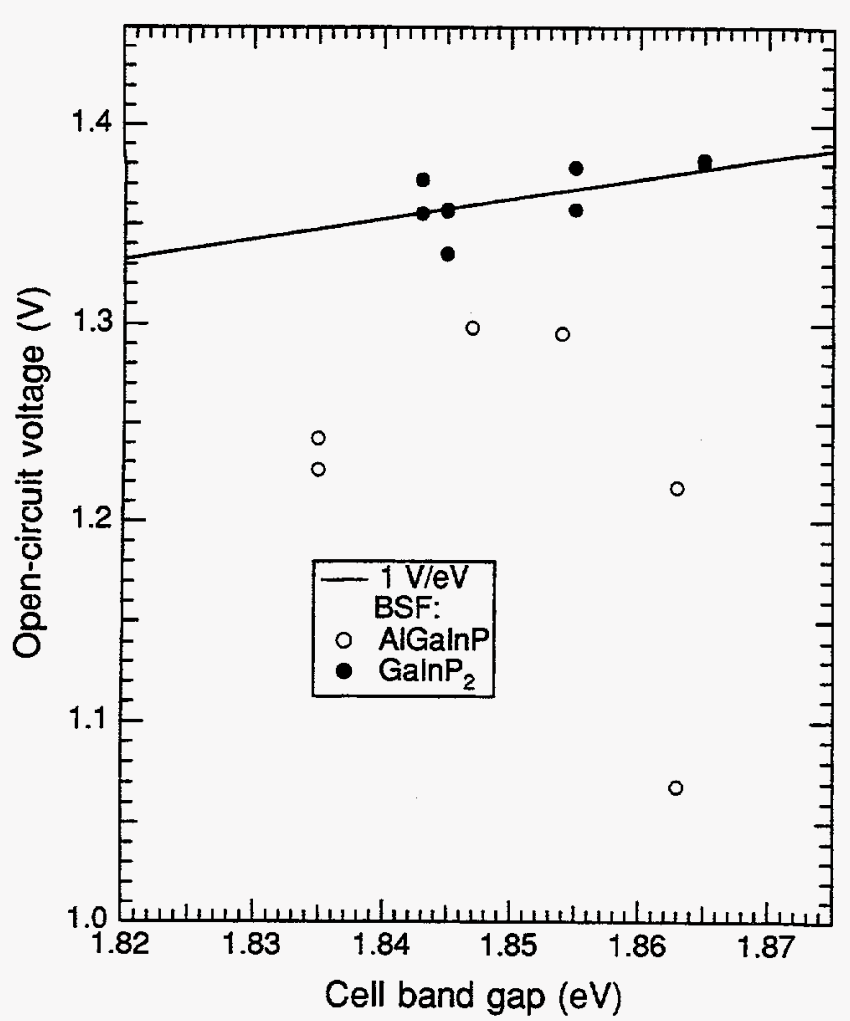

Figure 4-1. $v_{\propto}$ versus band gap for a number of different cells. The solid line shows the expected slope when all other factors are held constant.

to quantify the difference in clustering between the ordered and disordered states of $\mathrm{GaInP}_{2}$.

Figure 4-2 shows the room temperature mobilities and carrier concentrations for a number of disordered and ordered samples. The data fall into two clearly defined groups: all of the ordered samples have mobilities $\mu_{\mathrm{H}} \sim 500 \mathrm{~cm}^{2} / \mathrm{V} \bullet \mathrm{s}$, while both the $\mathrm{T}_{\mathrm{g}}=600^{\circ}$ and $750^{\circ} \mathrm{C}$ disordered samples have $\mu_{\mathrm{H}}$ roughly double this value. We concluded that the difference in mobility between the disordered and ordered samples at room temperature and above is due primarily to stronger cluster scattering in the ordered samples. To quantify this assignment, we modelled our $\mu_{H}(T)$ data (not shown) using Marsh's extension of the Harrison-Hauser theory of alloy scattering. This model treats the cluster scattering potential as a square well of energy $\left(V_{0}\right)$ and cluster radius $\left(r_{c}\right)$. The modelling allows us to estimate the relative fraction of ordered material in the more- and less-ordered samples, as well as define limits for $V_{0}$ and $r_{c}: r_{c}<\sim 20 \AA, V_{0}>\sim 40 \mathrm{meV}$.

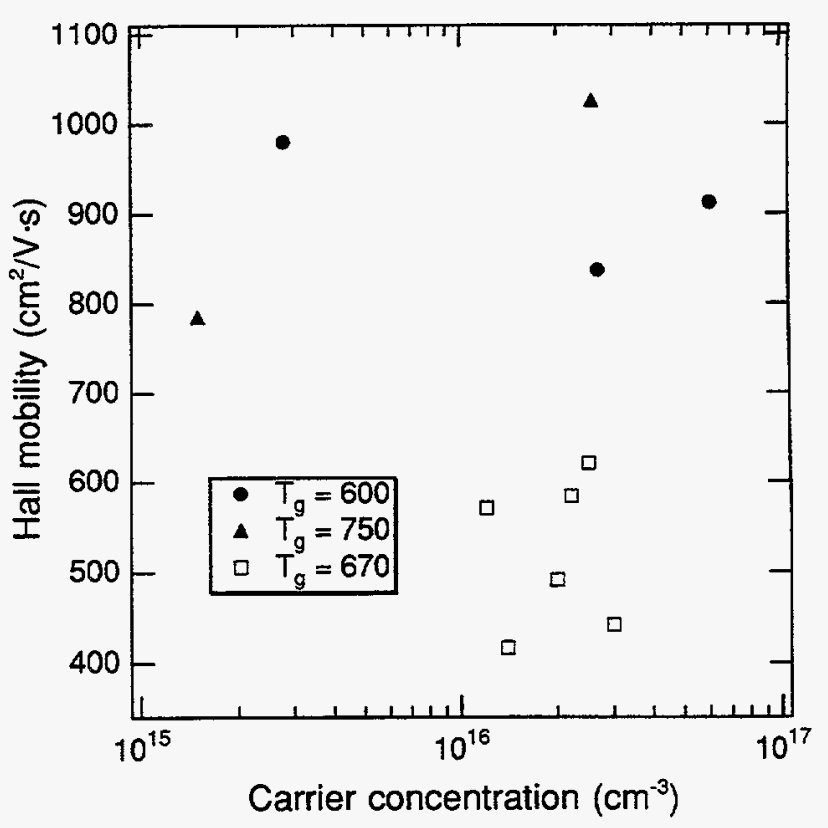

Figure 4-2. Room temperature Hall mobilities and carrier concentrations for ordered (growth temperature $\mathrm{T}_{g}=670^{\circ} \mathrm{C}$ ) and disordered $\mathrm{T}_{g}=600^{\circ}$ and $750^{\circ} \mathrm{C}$ ) samples

\section{$\mathrm{GaInP}_{2} / \mathrm{GaAs}$ Tandem Solar Cells for Space Applications (with T. Cavicchi, Spectrolab, Inc.)}

The monolithic, tunnel-junction-interconnected tandem combination of a GaIn $\mathrm{P}_{2}$ top cell and a GaAs bottom cell has a predicted air mass zero (AMO) efficiency greater than $26 \%$. The advantage of this device relative to other space solar-cell candidates include high-voltage, low-current, two-terminal operation for simple panel fabrication, and high conversion efficiency with a low-temperature coefficient. Also, because the active regions of the device are aluminum-free, the growth of high efficiency devices is not affected by trace levels of $\mathrm{O}_{2}$ and $\mathrm{H}_{2} \mathrm{O}$ in the MOCVD growth system. Preliminary radiation resistance data for the tandem device are encouraging. It appears that the radiation damage coefficient for $\mathrm{GaInP}_{2}$ is less than that of GaAs (or AlGaAs). Furthermore, to achieve current matching, the top cell is thinned to a thickness of about $0.5 \mu \mathrm{m}$. Such thin cells are relatively resistant to $10^{15} \mathrm{~cm}^{-2}$ $1-\mathrm{MeV}$ electrons (end-of-life exposure) and the $\mathrm{J}_{\mathrm{sc}}$ of the top cell degrades by $2 \%$. Consequently, the degradation of the tandem cell is determined mainly by that of the GaAs bottom cell. With proper design of both the top and bottom cells, we have shown that it should be possible to achieve end-of-life AM0 efficiencies of $22 \%$ or greater. 
Quantitative Study of Atomic Ordering in $\mathrm{Ga}_{0.5} \mathrm{In}_{0.5} \mathrm{P}$ Thin Films by ${ }^{31} \mathrm{P}$ Nuclear Magnetic Resonance

We used ${ }^{31} \mathrm{P}$ Nuclear Magnetic Resonance (NMR) to measure the degree of cation ordering in thin films of $\mathrm{Ga}_{0.5} \mathrm{In}_{0.5} \mathrm{P}$ grown by MOCVD. We used magic-angle spinning to resolve the NMR lines in Figure 4-3 from ${ }^{31} \mathrm{P}$ nuclei in the five possible $\mathrm{Ga}_{\mathrm{n}} \mathrm{In}_{4-\mathrm{n}} \mathrm{P}$ clusters. The lines were assigned based on the spectrum's dependence on the stoichiometry of the alloy and based on transverse spin relaxation measurements. The populations of the different clusters, and hence the degree of cation ordering, are then given by the areas of the corresponding lines. The ordering is not strong (order parameter $\leq 0.6$ ) even in films that appear highly ordered in transmission microscopy.

\section{Effect of Base Doping on Radiation Damage in GaAs Single-Junction Solar Cells}

We studied effects of $1-\mathrm{MeV}$ electron irradiation to a fluence of $10^{15} \mathrm{~cm}^{-2}$ for 13 GaAs $n-p$ single-junction solar cells with base doping levels from $2 \times 10^{16}$ to $3 \times 10^{17} \mathrm{~cm}^{-3}$. Radiation damage in solar cells occurs primarily through the creation of deep traps within the energy band gap, which reduce the minority carrier lifetimes and hence the minority carrier diffusion lengths. The degradation is usually characterized by a radiation damage coefficient, $\kappa$, defined by the following equation:

$$
\kappa \Phi=1 / L^{2}-1 / L_{0}^{2},
$$

where $\Phi$ is the radiation fluence, and $L$ and $L_{0}$ are the post- and pre-irradiation minority carrier diffusion lengths, respectively. Two effects on the minority carrier diffusion length are seen as a function of doping. First, both the pre-irradiation and the post-irradiation diffusion lengths decrease with doping because the carrier mobility and radiative lifetimes follow that trend. Second, the degree of damage introduced by irradiation also increases as a function of doping. Therefore, the cells that had the highest base doping also experienced the greatest percentage loss in short-circuit current density, the device parameter that is most sensitive to degradation in the minority carrier diffusion length.

Although these trends in minority carrier diffusion length are qualitatively apparent in the short-circuit current densities, numerical values for the damage coefficients are most easily extracted from modeling of the external quantum efficiency of the cells. In Figure 4-4, the values so derived are seen to be about 4-10 times greater than values reported in earlier work, while agreeing qualitatively with trends as a function of material doping level. The discrepancies may arise from differences in material growth technique, measurement technique, or radiation exposure conditions.

Other radiation-induced effects include an increase in radiation resistance of the open-circuit voltage as base doping increases. This improved resistance effectively counteracts the short-circuit current degradation so as to produce efficiencies that are almost constant as a function of base doping. The base doping may still be relevant in the efficiency of tandem solar cells, where current-matching influences the overall device efficiency. An anomalous degradation in FF and $V_{o c}$ for cells with the highest base doping is also observed, and their unique dark IV features suggest that the degradation onset is caused by tunneling-assisted recombination through radiation-induced defect states in the depletion region. The primary evidence for the involvement of a tunneling mechanism is the persistence of the excess dark current to $77 \mathrm{~K}$.

\section{Publications and Presentations}

\section{Publications}

P. J. Faine, S. R. Kurtz, and J. M. Olson, "Modeling of Two-Junction, Series-Connected Tandem Solar Cells Using Top Cell and Coating Thicknesses as Adjustable Parameters," Proc. of the 21st IEEE PVSC, 1990, p. 339.

P. J. Faine, S. R. Kurtz, C. Riordan, and J. M. Olson, "The Influence of Spectral Solar Irradiance Variations on the Performance of Selected Single-Junction and Multijunction Solar Cells," Solar Cells 31, 1991, p. 259.

S. R. Kurtz, J. M. Olson, K. A. Bertness, D. J. Friedman, A. Kibbler, B. T. Cavicchi, and D. D. Krut, "Radiation Hardness of $\mathrm{Ga}_{0.5} \mathrm{In}_{0.5} \mathrm{P} / \mathrm{GaAs}$ Tandem Solar Cells," Space Photovoltaic Research and Technology 1991 (NASA Conference Publication 3121) p. 40-1.

S. R. Kurtz, J. M. Olson, and P. Faine, "The Difference Between Standard and Average Efficiencies of Multijunction Compared with Single-Junction Concentrator Cells," Solar Cells 30, 1991, p. 501.

S. R. Kurtz, J. M. Olson, and A. Kibbler, "Effect of Growth Rate on the Band Gap of $\mathrm{Ga}_{0.5} \mathrm{In}_{0.5} \mathrm{P}$;" Appl. Phys. Lett. 57, 1990, p. 1922.

S. R. Kurtz, J. M. Olson, and A. Kibbler, "High Efficiency GaAs Solar Cells Using GaIn $\mathrm{P}_{2}$ Window Layers," Proc. of the 21st IEEE PVSC, 1990. p. 138. 
Section 4 III-V High-Efficiency Photovoltaic Cells

TP-4961

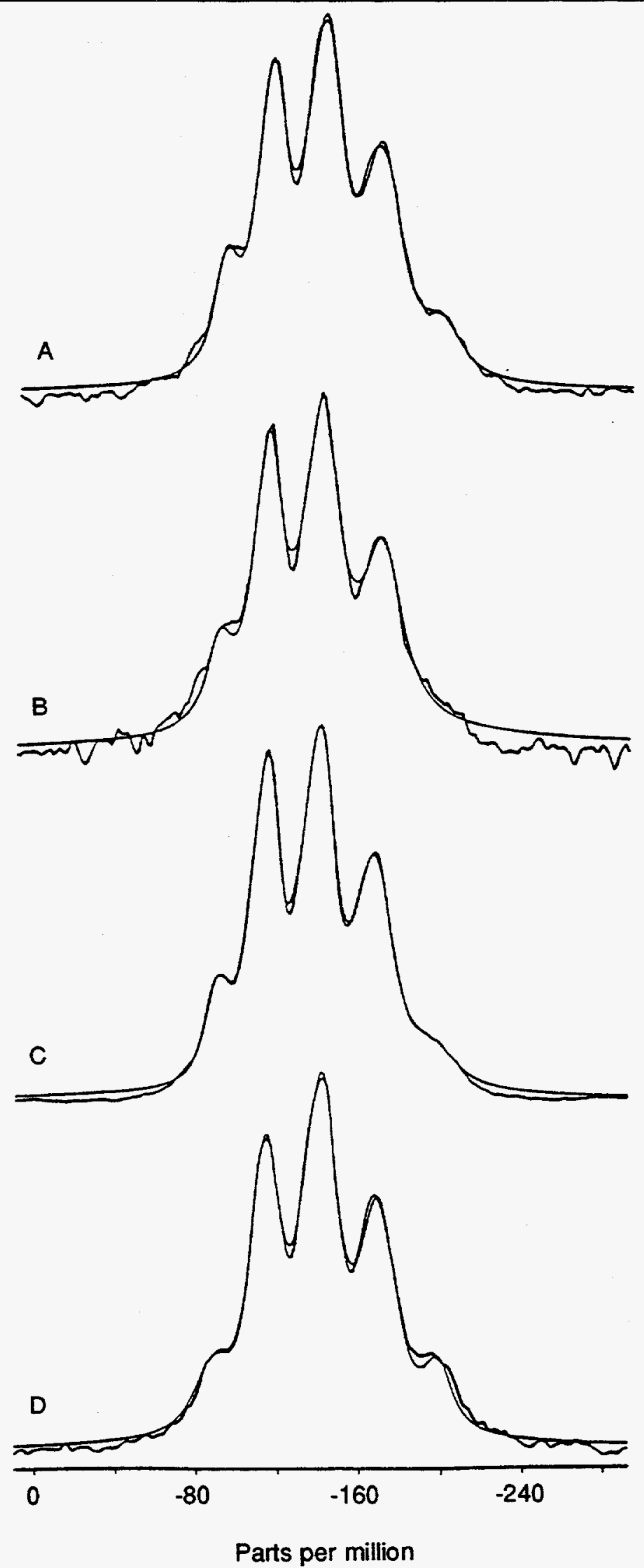

Figure 4-3. Effects of magic-angle spinning to resolve NMR lines from ${ }^{31} P$ nuclei in the five possible Ga ${ }_{n} \ln _{4-n} p$ clusters

32 


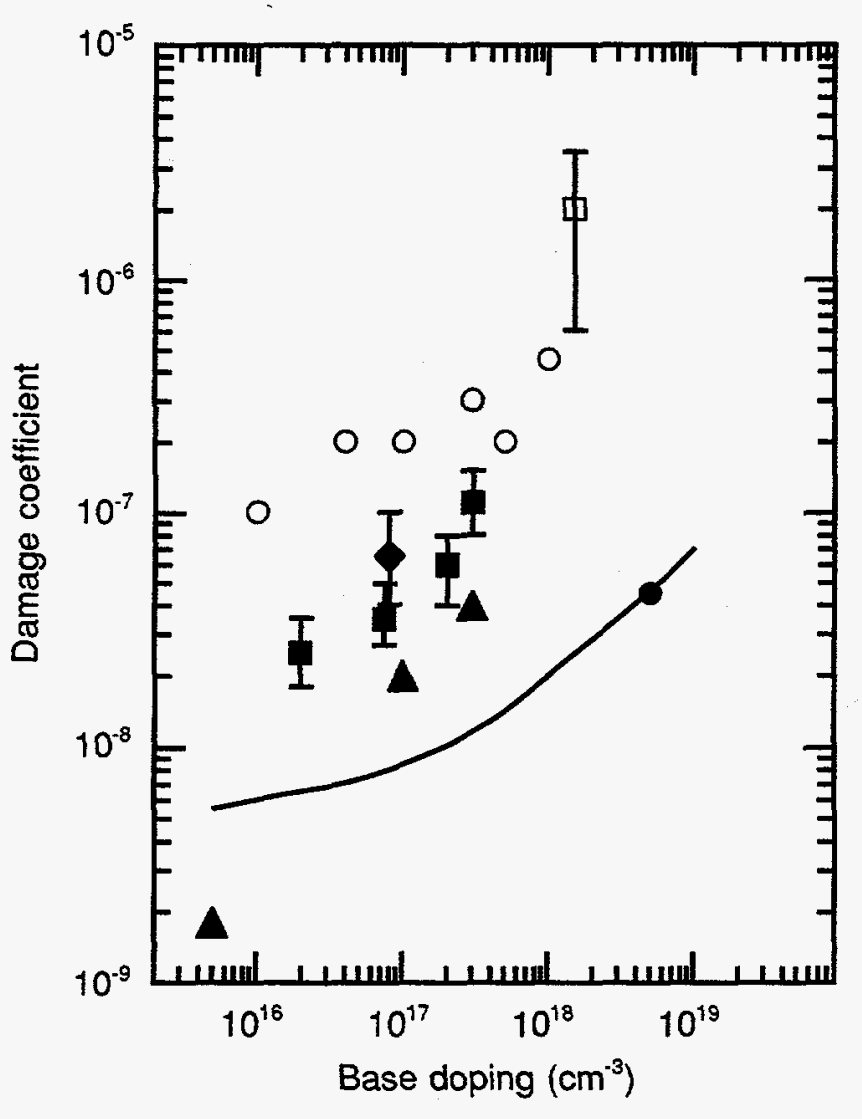

Figure 4-4. Damage coefficient values derived from modeling the external quantum efficiency of the cells. For $n$-type GaAs cells, values from this work (a) and Amano et al. (1) (0) are shown. For p-type GaAs cells, values from this work (a), a heterojunction cell ( $\downarrow)$, Amano et al. (1) ( $\bullet)$, Amano et al. (1) theory ( $\rightarrow$ ), and Fan (2) (4) are shown.

J. M. Olson, S. R. Kurtz, A. E. Kibbler, K. A. Bertness, and D. J. Friedman, "GaInP $\mathrm{P}_{2} / \mathrm{GaAs}$ Tandem Cells for Space Applications," Proc. of the ASME International Conference on Solar Energy, 1992.

R. Tycko, G. Dabbagh, S. R. Kurtz, and J. Goral, "Quantitative Study of Atomic Ordering in $\mathrm{Ga}_{0.5} \mathrm{In}_{0.5} \mathrm{P}$ Thin Films by ${ }^{31} \mathrm{P}$ Nuclear Magnetic Resonance," Phys. Rev. B 45, 1992, p. 13452.

\section{Presentations}

K. A. Bertness, "Growth of III-V Semiconductors Using Organometallic Vapor Phase Epitaxy (OMVPE)," guest lecture for undergraduate solid state physics course at University of Colorado at Boulder, Colorado, March 16, 1991.
K. A. Bertness, B. T. Cavicchi, S. R. Kurtz, J. M. Olson, A. E. Kibbler, and C. Kramer, "Effect of Base Doping on Radiation Damage in GaAs Single-Junction Solar Cells," presented at the 22nd IEEE PVSC, Las Vegas, Nevada, October 1991.

D. J. Friedman, A. E. Kibbler, and J. M. Olson, "Cation Site Ordering and Conduction Electron Scattering in GaInP ${ }_{2}$, Presented at the Branch 212 Seminar, Golden, Colorado, October 1991.

D. J. Friedman, A. E. Kibbler, and J. M. Olson, "Temperature-Dependent Electron Mobility and Clustering in GaInP $\mathrm{P}_{2}$, presented at the 18th International Symposium on GaAs and Related Compounds, Seattle, Washington, September 1991.

D. J. Friedman, S. R. Kurtz, A. E. Kibbler, and J. M. Olson, "Back Surface Fields for GaInP ${ }_{2}$ Solar Cells," presented at the 22nd IEEE Photovoltaic Specialists Conference, Las Vegas, Nevada, October 1991.

S. R. Kurtz, "High Efficiency $\mathrm{Ga}_{0.5} \mathrm{In}_{0.5} \mathrm{P} / \mathrm{GaAs}$ Cells and the Ordered Alloy $\mathrm{Ga}_{0.5} \mathrm{In}_{0.5} \mathrm{P}$," presented at Research Triangle Park, North Carolina, May 1991.

S. R. Kurtz, "The Ordered Alloy $\mathrm{Ga}_{0.5} \mathrm{I} \mathrm{n}_{0.5} \mathrm{P}$," presented at Emory University, Atlanta, Georgia, April 1991.

S. R. Kurtz, "The Ordered Alloy $\mathrm{Ga}_{0.5} \mathrm{In}_{0.5} \mathrm{P}$," presented at the University of North Carolina, Durham, May 1991.

S. R. Kurtz, J. M. Olson, K. A. Bertness, D. J. Friedman, A. Kibbler, B. T. Cavicchi, and D. D. Krut, "Radiation Hardness of $\mathrm{Ga}_{0.5} \mathrm{In}_{0.5} \mathrm{P} / \mathrm{GaAs}$ Tandem Solar Cells," presented at the NASA Space Photovoltaic Research and Technology Conference, Cleveland, Ohio, May 1991.

S. R. Kurtz, J. M. Olson, and P. Faine, "The Difference Between Standard and Average Efficiencies of Multijunction Compared with Single-Junction Concentrator Cells," presented at the PVAR\&D, Golden, Colorado, October 1990.

S. R. Kurtz, J. M. Olson, A. Kibbler, and D. Friedman, "The Importance of Fermi Level in Determining the Band Gap of $\mathrm{Ga}_{0.5} \mathrm{In}_{0.5} \mathrm{P}$," presented at the Electronic Materials Conference, Santa Barbara, California, June 1991. 


\section{References}

1. C. Amano, M. Yamaguchi, and A. Shibukawa, Technical Digest of the First Intl. Photovoltaic Science and Engineering Conf., Kobe, Japan, Nov. 1984, p. 845.

2. J. C. C. Fan, GaAs Shallow Homojunction Solar Cells, Final Report, NASA CR-165167, 1980. 


\section{Section 5 Solid-State Theory}

\section{Investigators}

\author{
A. Zunger, Research Fellow \\ and Group Leader \\ S. Froyen, Senior Scientist \\ S.-H. Wei, Senior Scientist \\ R. Osorio, OER/BES Senior Research \\ Associate \\ D. Laks, OER/BES Post-Doctoral \\ Scientist \\ Z. W. Lu, OER/BES Post-Doctoral \\ Scientist
}

\section{Objectives}

The past ten years have seen dramatic developments and breakthroughs in theoretical physics techniques aimed at understanding, on the atomic level, the electronic structure of superconductors, metals, clusters, alloys, and other quantum behaviors that underlie the properties of real materials. It is now possible to predict, from "first principles," the optical, magnetic, electrical, and thermodynamic properties of some simple materials even before measurements are performed. At the same time, equally dramatic developments occurred in the laboratory with our ability to grow "artificial" crystal structures through atomic-level control of the growth process (e.g., by molecular beam epitaxy [MBE] and organometallic vapor phase epitaxy [OMVPE]). Many crystal structures, consisting of particular architectures of atomic positions (even those not present in nature), can now be grown with reasonable perfection.

The Solid-State Theory Group's primary mission is to capitalize on these developments to (1) bring the state-of-the-art methods and ideas of condensed matter theory into the realm of PV materials, (2) develop a fundamental understanding of the elements that constitute and enhance solar cell performance, and (3) use this knowledge to design novel PV materials that could be grown and tested in the laboratory by modern crystal growth techniques.

A second mission of the group is to analyze the properties of existing materials. Unlike simple devices such as the transistor, solar cells are very complex in terms of their chemical constitution (containing pure layers and alloy layers of several different compounds), diverse atomic structures (i.e., dislocations, grain boundaries, and antiphase domains), and varying degrees of order. Because of this complexity, cell efficiency depends on a very large number of material parameters that are difficult to isolate. Our solid-state theory research attempts to address these problems by modeling the electronic structure of prototype systems that do isolate these effects. This modeling includes the following:

- Defects and impurities in bulk semiconductors

- Optical properties in alloys

- Stability and thermodynamics of superlattices

- Band gaps and optical properties of novel ternary semiconductors

- Surface and interfaces in semiconductors

- The properties of epitaxial thin films

A goal of this research is to ensure that PV technology continuously benefits from breakthroughs achieved in other areas of condensed matter physics. This approach supplements the more conventional trial-and-error approaches to designing PV systems.

\section{Major Accomplishments}

\section{Density of States of Disordered Transition Metal Alloys (OER-BES Work) $[1,2,3]$}

Most $A / B$ metal alloys are disordered at high temperatures, so that each lattice site of the crystal is randomly occupied by either an $A$ or a $B$ atom. Firstprinciples band-structure methods, which were designed for ordered, periodic structures, are poorly suited to calculate the electronic properties of random alloys. Instead, we often describe the electronic 
density of states and the mixing enthalpies of random substitutional $A_{1-x} B_{x}$ alloys within the single-site coherent potential approximation (SCPA). To do this, we assume that each atom interacts with a fictitious, highly symmetric, average medium and that, at a given composition $x$, all $A$ atoms (and separately, all $B$ atoms) are equivalent (e.g., they have the same charges and atomic sizes). In reality, however, a random alloy manifests a distribution of different, generally low-symmetry, local environments.

Concommitantly with this reduction in site symmetries, topologically different $A$ atoms (and separately, different $B$ atoms) can have different charges, and the various bonds need not be of equal average lengths $\left\langle R>\right.$ (i.e., $\left\langle R_{A-A}\right\rangle \neq\left\langle R_{A-B}\right\rangle \neq\left\langle R_{B-B}\right\rangle$ ). Furthermore, there can be a distribution of bond length values around $\left\langle R_{i j}\right\rangle$ for each of the three chemical bond types. Such "environmental effects," which are averaged out in the SCPA, were previously studied in terms of simple model Hamiltonians, while the lattice relaxation effects (e.g., different types of bond lengths and bond-length distributions) were neglected in the SPCA theory.

Our group developed an efficient method of describing these effects within first-principles self-consistent electronic structure theory. We used the "special quasirandom structures" (SQS) concept (Zunger et al., Phys. Rev. Lett. 65, 1990, p. 353), whereby the lattice sites of a periodic "supercell" are occupied by $A$ 's and B's in such a way that the structural correlation functions closely mimic those of a perfectly random infinite alloy. Instead of placing each atom in an identical, average medium, as is the case in the SCPA, we created a distribution of distinct local environments whose average corresponds to the random alloy.

The self-consistent charge density, total and local density of states, and mixing enthalpies were then obtained by applying band theory (here, the linearized augmented plane wave method) to the SQS. Application to $\mathrm{Ag}_{0.5} \mathrm{Pd}_{0.5}$ and $\mathrm{Ag}_{0.5} \mathrm{Au}_{0.5}$ alloys clearly reveals environmental effects. That is, the charge distribution and local density of states of a given atomic site depend not only on the composition and occupation of the site but also on the distribution of atoms around it. In the cases of $\mathrm{Cu}_{3} \mathrm{Au}$ and $\mathrm{Cu}_{3} \mathrm{Pd}$, we found that charge and relaxational fluctuations neglected in the SCPA lead to a significant stabilization of the alloy $(-30 \%$ lowering in mixing enthalpy) and to substantial $(\sim 1 \mathrm{eV})$ non-rigid shifts in the electronic energy levels.
First-Principles Calculation of the Order-Disorder Transition in Chalcopyrite Semiconductors [4]

Recent theory and observations of spontaneous long-range order in isovalent III-V semiconductor alloys created great interest in the theoretical study of self organization in random systems and in the possibility of changing the optical band gaps of random alloys at fixed composition through ordering. However, because of the relatively weak interactions between the isovalent atoms in such III-V alloys, the observed orderings are often imperfect and irreversible, which complicates the study of the transition. There is, however, a large class of tetrahedrally bounded semiconductors-the $A^{I} B^{I I I} C^{V I}$ chalcopyrites-where the strong interactions between the non-isovalent atoms lead to a reversible first-order phase transition between the disordered hightemperature sphalerite phase and the ordered lowtemperature chalcopyrite phase. Theoretical studies of the physical factors controlling the polymorphic order-disorder transition in chalcopyrites can be used to gain insights into the analogous transitions in isovalent alloys, as well as the physics of compensation in highly concentrated donor/acceptor systems.

We studied the order-disorder phase transition of the prototype chalcopyrite system $\mathrm{Cu}_{0.5} \mathrm{In}_{0.5}$ Se by combining highly accurate $a b$-initio total energy calculations with statistical mechanics. Our study consisted of three steps. First, we performed $T=0$ quantum-mechanical total-energy calculations on a variety of ordered superstructures of CuSe/InSe, mapping the results onto a generalized Ising Hamiltonian. In the second step, we used the Ising Hamiltonian to find the lowest energy at $T=0$ through a ground-state search. Finally, we solved the Ising Hamiltonian using the Monte-Carlo method, determining the various thermodynamic quantities of the different phases as a function of temperature. The basic difference between our approach and the more traditional phenomenological Ising models is that we defined the type of interactions, their range, and their magnitude directly in terms of the quantummechanical electronic structure. Our results are summarized below.

Our total energy calculations revealed that, in non-isovalent semiconductor alloys, electronic compensation is the dominant effect which determines the interactions between atoms and clusters. Indeed, the existence of such a strong electronic compensation is the main distinguishing feature between the order-disorder transition in non-isovalent versus isovalent ternary semiconductors. Our ground-state search found that the chalcopyrite structure has the lowest $\mathrm{T}=0$ energy of all possible face-centered cubic (fcc) configurations. However, the 
energy of the CuAu-I-like structure is only slightly above that of the chalcopyrite phase. This suggests that if the crystal is grown at low temperature, metastable phase or antiphase boundaries may occur. The calculated order-disorder transition temperature $T_{c}$ is $1125 \pm 20 \mathrm{~K}$, which is in good agreement with the experimentally observed $T_{c}=1083 \mathrm{~K}$, considering that the calculation is parameter-free. The disordered phase exhibits significant short-range order. The tetrahedron probabilities in the disordered phase are about $0 \%, 17 \%, 66 \%, 17 \%$, and $0 \%$ for $\mathrm{Cu}_{4}, \mathrm{Cu}_{3} \mathrm{In}$, $\mathrm{Cu}_{2} \mathrm{InB}_{2}, \mathrm{CuIn}_{3}$, and $\mathrm{In}_{4}$ clusters, respectively, compared with the ideal random probabilities of $6.25 \%, 25 \%, 37.5 \%, 25 \%$, and $6.25 \%$, respectively. This is consistent with the experimental NMR measurements. Upon ordering, the direct band gap increases by $0.35 \pm 0.1 \mathrm{eV}$. This is because the level repulsion in the ordered phase is smaller and because the donor-like and acceptor-like bands inside the band gap in the disordered phase are eliminated upon ordering.

We performed analogous calculations for $\mathrm{Zn}_{0.5} \mathrm{Sn}_{0.5} \mathrm{P}$, and obtained similar good agreement with experiments. We therefore conclude that the local density total energy calculation, in conjunction with the Monte-Carlo simulation, is able to provide a detailed description of "strong" order-disorder transitions in ternary chalcopyrites.

\section{Consequences of Interfacial Roughness in} Semiconductor Superlattices on Stability and Optical Properties (OER-BES Work) $[5,6]$

The quality of a semiconductor superlattice is partly determined by the abruptness of its interfaces. Superlattices made up of AlAs/GaAs, GaP/InP, and other III-V materials are grown at high temperatures (typically $500^{\circ} \mathrm{C}-700^{\circ} \mathrm{C}$ ), where atoms may diffuse during growth and degrade the quality of the superlattice.

We studied the stability of AlAs/GaAs and GaP/InP superlattices with respect to swapping atoms across the interfaces. Atom swaps spread the interface over a few layers of the superlattice. For example, in an AlAs/GaAs superlattice, half of the aluminum atoms on one side of an interface may be exchanged with half of the gallium atoms on the other side of the interface, creating two layers with equal concentrations of the two atoms. A large variety of swaps are possible, depending on the percentage of atoms swapped and the particular geometry of the swap. We examined hundreds of possible swaps for superlattices grown along the [001], [011], [111], and [201] directions. We calculated the formation energies of the abrupt (unswapped) and swapped superlattices using a combination of theoretical techniques: cluster expansions, valence force-field calculations, and first-principles pseudopotential calculations. We found that the abrupt superlattices are unstable with respect to swaps that have lower formation energies.

The AlAs/GaAs superlattices, which are lattice matched, are energetically stable against swapping, for periods greater than three. (However, at high temperatures, entropy may cause mixing in the superlattice.) Although swapping has a small effect on the AlAs/GaAs formation energy, it has a large effect on the electronic band structure. Indeed, the effects of atom-mixing swaps may help to identify the conduction band minimum in the monolayer

AlAs/GaAs superlattice. All first-principles theoretical calculations agree that the conduction band minimum in this superlattice lies along the [111] direction (in reciprocal space) and is located in the AlAs layers. Recent experiments, however, clearly show that the conduction band minimum lies along the [100] direction and is located in the GaAs layers. We have resolved this seeming contradiction by demonstrating that atomic swaps raise the energy of the [111] AlAs state relative to the [100] GaAs state. We found that a monolayer AlAs/GaAs superlattice with one-third of the atoms swapped across the interface has a band structure in full agreement with experiments. We conclude that even the best available experimental superlattices contain a substantial degree of intermixing.

For $\mathrm{GaP} / \mathrm{InP}$ superlattices, which are not lattice matched, atomic swaps can significantly lower the superlattice formation energy. The effect is particularly dramatic for very short-period structures. In one case, a monolayer superlattice along the [111] direction, the formation energy of the abrupt superlattice can be reduced by more than $50 \%$ by swapping one-third of the gallium and indium atoms. In general, the [201] and [001] superlattices are most stable with respect to swaps and the [111] are least stable.

The GaP/InP instabilities may be affected by the choice of substrate on which the superlattice is grown. Our results apply to superlattices grown on GaAs, which has a lattice constant equal to the average of the $\mathrm{GaP}$ and InP lattice constants. Superlattices grown on InP, which has the larger lattice constant, are even more unstable with respect to swaps, while those grown on GaP are the most stable.

Ordering Thermodynamics of Surface and
Subsurface Layers in GaInP Alloys $[7,8]$

$\mathrm{Ga}_{1-x} \mathrm{In}_{x} \mathrm{P}$ semiconductor alloys are frequently used in high-efficiency PV cells. These alloys show spontaneous ordering of gallium and indium into the 
[111]-oriented monolayer superlattice (the "CuPt" structure) when grown by vapor-phase epitaxy in a certain temperature range. Because the alloy band gap, and thus its PV properties, depends strongly on its degree of order, it is important to understand which physical mechanism produces ordering. Previous studies have shown that order cannot be explained by bulk equilibrium thermodynamics, even when coherent epitaxial effects are included. On the other hand, we previously studied the energetics of several atomic arrangements of a $\mathrm{Ga}_{0.5} \mathrm{In}_{0.5} \mathrm{P}$ relaxed (dimerized) surface and showed that the arrangement corresponding to a CuPt structure is the most stable. This finding suggests that surface effects can produce ordering. Studies of the energetics of subsurface layers show that only the third subsurface layer below the surface stabilizes CuPt order.

In exploring the thermodynamic consequences of these $T=0$ studies, we used the energies of about 3,000 surface and subsurface atomic arrangements of a four-layer $\mathrm{Ga}_{0.5} \mathrm{In}_{0.5} \mathrm{P}$ slab to extract effective atomic interaction parameters for surface, subsurface, and middle layers. We applied these interactions to a lattice statistical-mechanics theory, which consists of minimizing the free energy of each atomic layer at finite temperatures.

Our results indicate that a significant $\mathrm{CuPt}$ ordering persists at the dimerized cation-terminated surface at preparation temperatures $(\mathrm{T}-1000 \mathrm{~K})$. This occurs for the equimolar $\mathrm{Ga}_{0.5} \mathrm{In}_{0.5} \mathrm{P}$ alloy, as well as other compositions (e.g., $\mathrm{Ga}_{0.7} \mathrm{In}_{0.3} \mathrm{P}$ ) where ordering has been observed. A likely mechanism for the formation of macroscopic CuPt ordering involves equilibrating the cation-terminated layer and then freezing the cations as the surface is buried by newly deposited layers. The inter-layer couplings select the correct three-dimensional $\mathrm{CuPt}_{B}$ structure. We also showed that the CuPt surface and third subsurface layers are remarkably stable toward atomic swaps.

\section{Comparisons of Ab-Initio Charge Densities of Semiconductors with Experiment (OER/BES) $[9,10]$}

Silicon is the most important and most carefully studied material in modern semiconductor electronics. This makes silicon the ideal material for a highaccuracy comparison between the electronic charge density predicted by first-principles electronic structure calculations and the charge density deduced from experiment. Recent refinement of five data sets of silicon structure factors produced information on the silicon charge density with an unprecedented level of accuracy, unmatched by any other crystallographic study. We examined the extent to which an accurate implementation of the local density formalism can describe the charge distribution in silicon. Our method reproduces the measured structural factors of silicon to within very small deviations of $\sim 0.02 \mathrm{e} / \mathrm{cell}$ and shows a two- to five-fold improvement in the $R$-factor over previous calculations. We described, in detail, total, valence, and deformation charge density maps for silicon and analyzed the effects of high-momentum components (currently outside the range of the high-precision measurements) as well as dynamic structure factors on the maps.

Fox and Tabbernor (Acta Metall., 39, 1991, p. 669) recently measured the four lowest structure factors $F(G)$ of $\mathrm{NiAl}$ using highly accurate high-energy electron diffraction. They constructed a deformation electron density distribution (DEDD) map and discussed the bonding in this system. In a systematic comparison of their results with ab initio band theory, in the context of the local density formalism, we found very good agreement for three of the four lowest measured structure factors, while our $F(200)$ is $\sim 0.4 \mathrm{e} /$ cell higher. We tentatively attributed this difference to uncertainties in the treatment of the temperature factors. To examine the effect of the truncation of a few currently available high-precision structure factors on the ensuing DEDD maps, we extended the $\mathrm{NiAl}$ calculation to include high Fourier components (up to 164 reflections) that are not currently amenable to measurements. We found that the truncation of the Fourier series after four structure factors misses the directional, $d$-like charge lobes near the Ni sites. Our work shows that, relative to a superposition of neutral spherical ground-state atoms, the bonding in $\mathrm{NiAl}$ can be characterized as mixed ionic-covalent-metallic based on the following factors: (1) there is an overall depletion of charge from aluminum and deposition on nickel (ionic effect); (2) the charge depleted from aluminum has a nearly spherical character, while the charge deposited on nickel is preferentially oriented along the bonds (covalent effect); and (3) the small charge transfer in the interstitial regions is nearly uniform (metallic effect). Our study shows that static and dynamic DEDD give a similar picture of the bonding.

\section{An Efficient Method for Performing Large-Scale Pseudopotential Calculations on Complex Solids [11]}

Accurate first-principles modeling of novel semiconducting compounds for PV applications is central to the mission of the Solid-State Theory Group. Our current computer codes for pseudopotential calculations are based on designs more than ten years old, when "state of the art" problem sizes were typically smaller than a few atoms per unit cell. When these old algorithms are applied to the much larger unit cells we need to model today, they show signs of 
strain. With updated computer hardware, it should be possible to model systems containing a few hundred atoms per unit cell. Our current codes, however, restrict us to a few tens of atoms.

To overcome these limitations, we designed and implemented a new local-density pseudopotential code that uses conjugate-gradients for the total-energy minimization. This method avoids an instability associated with the traditional methods for solving the Schroedinger equation. Traditionally, the equation is linearized, the linear equation is solved (repeatedly) as a standard eigen-value problem, and the nonlinear part is solved iteratively until the linear solution achieves self consistency. In the old codes, the instability manifested itself as a basic lack of convergence and necessitated the incorporation of elaborate convergence accelerators (e.g., mixing schemes). As the problem size grows, these schemes are insufficient to obtain convergence and we observe the fundamental breakdown of the old algorithms. By directly dealing with the nonlinearities at the innermost iteration level, the new code is naturally convergent. A direct comparison for a 30-atom-unit cell shows that the new code (without mixing) converges slightly better than the old code with our most advanced mixing scheme. We believe that the new code can be further improved by the addition of mixing.

Some additional features of the conjugate gradient code are that the program is written in fweb and is modular (the fweb source is converted to standard Fortran by a preprocessor); the input data format is free-form, flexible, and easily extensible; and a dual, real-space/Fourier-space representation on a novel type of grid is used for all three-dimensional functions (fast Fourier-like transforms are used to convert between the two representations).

\section{Diamond-Like Order in Zinc-Blende Compounds (OER-BES Work) [12]}

In solar cell materials, defects and impurities degrade device performance. While foreign impurities can be eliminated by careful growth, native defects are intrinsic to the material. A native defect is anything that breaks the translational symmetry of the crystal without introducing foreign atoms. Point defects, which are limited to an atom of the crystal, have been studied for many years. We investigated a new form of defect that involves the chemical disorder of many atoms of a compound crystal.

Chemical disorder (i.e., switching the identity of atoms on fixed crystal sites) is common in many ternary semiconductor compounds, such as $\mathrm{Si}_{x} \mathrm{Ge}_{1-x}$ $\mathrm{Al}_{x} \mathrm{Ga}_{1-x} \mathrm{As}$, and $\mathrm{CuInSe}{ }_{2}$. We examined the possibility of chemical disorder in GaAs where, by randomizing the occupations of the gallium and arsenic sublattices, the diffraction pattern displayed by the crystal changes from a zinc-blende pattern to a diamond-like pattern. We calculated the energy of randomization of the GaAs lattice using firstprinciples local density theory and the special quasirandom structure technique, developed by the Solid State Theory Group. We found the energy of randomization to be surprisingly low at only $0.36 \mathrm{eV}$ per atom, compared with a simple estimate of $0.80 \mathrm{eV}$ per atom based on energies of antisite defects in GaAs. We also calculated the energy of randomization for ZnSe, which has twice the valence mismatch of $\mathrm{GaAs}$, and found $0.80 \mathrm{eV}$ per atom.

Although the energy of randomization of GaAs is very low, the macroscopic random phase is not thermodynamically stable below the melting point of the crystal. Nonetheless, microscopic random phase regions of about ten atoms may occur in GaAs. Such regions form a new class of defects in GaAs, which we call "random aggregates" (RAs). Our calculations of the energy of randomization provided a good estimate of the formation energies of RA defects. We found RAs with formation energies of $3-5 \mathrm{eV}$. Formation energies for RAs containing many atoms were in the same range as formation energies of native defects containing only a single atom. It follows that, under certain circumstances, RA concentrations in GaAs can be similar to native defect concentrations. RAs could introduce electronic levels in the band gap of the crystal, which could, in theory, be observed in optical experiments. We investigated the properties of RAs and showed how they may affect the doping and stoichiometry of the material.

\section{A New Method for Predicting Band Gaps of Arbitrary Substitutional Structures (OER-BES) [13]}

Substitutional $A / B$ crystal configurations can be obtained by having atoms $A$ and $B$ occupy the sites of a fixed (e.g., $\mathrm{fcc}$ ) lattice. These configurations contain ordered compounds, superlattices, and substitutionally disordered alloys. Considerable research on substitutional semiconductor systems has focused on "band-gap engineering," i.e., on attempts to identify atomic configurations that lead to prescribed band gaps. For example, we may ask (for $A=\mathrm{GaAs}$ and $B=\mathrm{AlAs}$ ) how the "building blocks" $A$ and $B$ should be positioned in space so that the resulting structure has a band gap of a given value. This is a difficult question; if there are $\mathrm{N}$ sites and on each site we can place either $A$ or $B$, then there are $2^{\mathrm{N}}$ different configurations. For $\mathbf{N}=35$, this gives approximately $34,000,000,000$ possible structures. Theoretical analysis of such problems has traditionally been based on band-structure techniques, whereby the 
dispersion of energy bands is mapped out in reciprocal space for a given real-space crystal configuration. Only five to ten configurations are tested, creating a huge potential for missing important ones. In such approaches, it has proved difficult to establish intuitive rules that relate band gaps to given motifs of atomic structure. Questions such as "what is the structure that, for a given composition, gives the largest direct band gap for AlAs/GaAs on a fcc lattice?" have to be addressed, in principle, by calculating the band structures of a large number of configurations and selecting the one with the largest gap.

We found a way to address this problem without having to do many calculations. First, we break the lattice into a set of "figures," i.e., pairs, triangles, and tetrahedra of atoms. We then find a way to decompose the band gap of any lattice configuration into "figure contributions," or J(figures), based on our calculations from first-principles pseudopotential theory. The band gap is expressed as a sum over $\mathrm{J}$ (figures) multiplied by the frequency of occurrence of each figure in the structure being studied. This linear form requires only multiplying a few numbers, permitting us to scan a huge number of structures in search of one with a desired value of band gap. This approach enables us to design substitutional systems with certain band-gap properties by assembling atomic figures. As an illustration, we predict that the [012]-oriented (AlAs) ${ }_{1} /(\mathrm{GaAs})_{4} /(\mathrm{AlAs})_{1} /(\mathrm{GaAs})_{2}$ superlattice has the largest band gap among all $\mathrm{Al}_{0.25} \mathrm{Ga}_{0.75}$ As lattices, with a maximum of ten cations per unit cell.

\section{Strain Energy and Stability of Si-Ge Compounds, Alloys, and Superlattices [14]}

Interest in alloys and superlattices of silicon and germanium has grown in recent years, driven partly by the discovery that their short-period superlattices can have a nearly direct band gap and by the discovery of spontaneous ordering in $\mathrm{Si}_{x} \mathrm{Ge}_{1-x}$ alloys. Ultrathin $\left(\mathrm{Si}_{2}\right)_{p}\left(\mathrm{Ge}_{2}\right)_{p}$ superlattices and $\mathrm{Si}_{x} \mathrm{Ge}_{1-x}$ films can be grown epitaxially in a variety of layer orientations, including (001), (110), and (111). Provided that the films are thin enough, they can be made coherent with substrates of different lattice constants, ranging from that of silicon to that of germanium. Recent theoretical and experimental work demonstrates how the choice of superlattice layer orientation, repeat period ( $4 p$ ), and substratelattice parameter sensitively affect the electronic properties. Little was known, however, about the way in which these affect the thermodynamic stability of the binary superlattices. While these parameters (along with growth conditions, surface steps, substrate misorientation, and surface reconstruction) can clearly affect growth kinetics and surface thermodynamics, we recently addressed the complementary question of the relative bulk thermodynamic stabilities of already-grown binary superlattices, e.g., short versus long, (001) versus (110) versus (111), and strained versus unstrained.

Total energies of superlattices with modestly small $p$ values can be obtained from first-principles total energy calculations. The advantage of this approach lies in the reliability with which these energies can be obtained; disadvantages are the substantial computational effort required for large unit cells and the fact that merely knowing the values of the total energies does not suggest the physical origins of stability or instability. Therefore, our main aim in this work was to use first-principles calculations to construct simple models of superlattice and alloy stability that are both numerically reliable and physically illuminating. In addition to general features of superlattice energetics, we calculated the formation enthalpy of the random alloy and the energies associated with a number of $\mathrm{Si} / \mathrm{Ge}, \mathrm{Si} / \mathrm{SiGe}, \mathrm{Ge} / \mathrm{SiGe}$, and $\mathrm{SiGe} / \mathrm{SiGe}$ interfaces. We also considered the implications of our results on the question of interdiffusion of $\mathrm{Si} / \mathrm{Ge}$ interfaces and on the interpretation of recent experiments in which spontaneous ordering of SiGe has been observed.

We decomposed the formation enthalpy of $\left(\mathrm{Si}_{2}\right)_{p}\left(\mathrm{Ge}_{2}\right)_{p}$ superlattices into "bulk" and "interfacial" terms and developed a method for efficiently calculating these energies even for very large unit cells. The strain-related parts are calculated via an anharmonic valence-force-field model, with force constants and equilibrium bond lengths determined from first-principles pseudopotential calculations; the chemical-energy-related part is calculated with a rapidly convergent cluster expansion, also based on first-principles results.

Considering the energetics of $\left(\mathrm{Si}_{2}\right)_{p}\left(\mathrm{Ge}_{2}\right)_{p}$ superlattices, we found the following: (1) for long-period superlattices, the stability sequence is the same as that in lattice-mismatched pseudobinary III-V superlattices-(001) $>(110)>(111)$-reflecting the orientationdependent strain of the constituents; (2) for shortperiod superlattices, the interfacial contribution to the formation energy stabilizes the (110) superlattice and one of the two distinct types of (111) superlattices (the type denoted RH1), but destabilizes the other type of (111) superlattice (the type denoted $\mathrm{RH} 2$ ) and slightly destabilizes the (001) superlattices; (3) only the (001) superlattice lies consistently below the energy of the random alloy, although the $(110)$ superlattice dips below the random alloy at $p=2$ and the (001) $p=1$ superlattice lies slightly above the random alloy; (4) straining the superlattices coherently on a substrate leads to an epitaxial stabilization [largest for 
(111)] through the strain that would be imposed on coherent, phase-separated constituents, thus hindering phase separation.

Considering the full range of interactions at a film-substrate interface showed that the film-substrate interface energy can safely be neglected for sufficiently thick films provided that the period of superlattices whose stacking direction is tilted with respect to the substrate plane is not too large.

For several types of isolated $\mathrm{Si} / \mathrm{SiGe}, \mathrm{Ge} / \mathrm{SiGe}$, and $\mathrm{SiGe} / \mathrm{SiGe}$ interfaces, we found negative (stabilizing) interface energies, particularly in those with $\mathrm{RH} 2 p=1$ as a constituent. The most stable interface among those we investigated is the (001) antiphase boundary in RH2 $p=1$. However, even a high density of these was not sufficient to stabilize that phase epitaxially or to reduce its energy below that of RH1 $p=1$. Our search for stable, thin, ordered regions of SiGe between (001)-oriented layers of silicon and germanium (a possibility that has been suggested in the literature) showed the abrupt (001) Si/Ge interface to be favored over the ordered interdiffused interface.

Our results led us to the following conclusions regarding spontaneous ordering of SiGe: (1) Because of its overwhelmingly higher strain energy, the $\mathrm{RH} 2$ superlattice has a higher formation enthalpy both in bulk and when strained coherently on (001) silicon than does the RH1 superlattice. This suggests that the ordered coherent epitaxial phase that is observed in strained $\mathrm{Si} / \mathrm{SiGe}$ superlattices after annealing is $\mathrm{RH} 1$ $p=1$, rather than RH2 (it was known to be one of the two, but the exact identity was not established experimentally until recently, when it was confirmed to be RH1). Because the reversibility of this ordering has now been substantiated experimentally, we can conclude that the post-growth ordering observed in these strained phases is not a result of the irreversible surface-induced ordering during growth that has been recently proposed as a general explanation of ordering in Si-Ge alloys. (2) Our results lend support to the proposal of a surface-induced ordering mechanism during growth that favors $\mathrm{RH} 2$. Such a mechanism would likely cause initial formation of $\mathrm{RH} 2$ in as-grown coherent samples as well, as has been confirmed experimentally; however, subsequent annealing for sufficient time at sufficiently high temperature results in the elimination of that highenergy phase. (3) Our calculations show that on a (001) silicon substrate, the RH1 $p=1$ superlattice is very slightly more stable than the random alloy, but the formation energies are still much too close to account for the order-disorder transition temperature observed in experiments. (4) The microscopic interactions at the interfaces of a $\mathrm{Si} / \mathrm{SiGe}$ superlattice do not significantly alter the predicted order-disorder transition temperature calculated on the basis of a "virtual" substrate (where only the biaxial-strain constraint is taken into account) of strained SiGe on a (001) silicon substrate. (5) Hence, the experimental observation of reversible RH1 $p=1$ ordering in strained SiGe alloys remains unexplained.

\section{Theory of Defects, Impurities, and Doping in ZnSe} $[15,16,17]$

ZnSe is an important wide-band-gap semiconductor. As a rule, wide-band-gap materials are much easier to dope one way than the other. In the case of $\mathrm{ZnSe}$, n-type doping is relatively easy, but p-type doping is extremely difficult. We have recently shown that, contrary to conventional wisdom, native-defect compensation is not responsible for doping problems in wide-band-gap semiconductors. We have now investigated the true cause of doping problems in p-type ZnSe, using first-principles theoretical techniques.

We examined acceptor-doping of ZnSe with lithium, sodium, and nitrogen. We used the first-principles methods to calculate the formation energies of these dopant impurities at various substitutional and interstitial sites in the ZnSe crystal. These energies were then combined with our calculated energies for the native defects in $\mathrm{ZnSe}$ to produce a comprehensive thermodynamic description of the concentrations and interactions of the dopant impurities and the native defects. The formation energies and concentrations depend, however, on the chemical potentials for zinc $\left(\mu_{Z n}\right)$ and $D\left(\mu_{D}\right)$, where $D$ is the dopant species. (The chemical potential of selenium is fixed by $\mu_{\mathrm{Zn}^{*}}$ ) Treating $\mu_{\mathrm{Zn}}$ and $\mu_{\mathrm{D}}$ as independent variables, we solved for the defect and dopant concentrations and the Fermi level as a function of both variables. The solution includes the effects of all possible reactions among the native defects and the dopants.

The problems with lithium doping are twofold. First, unwanted, interstitial lithium donors compensate the substitutional lithium acceptors. Interstitial lithium compensation may be eliminated by lowering $\mu_{\mathrm{Zn}}$ (thereby making the sample zinc-deficient) so that substitutional lithium on a zinc site is preferred to interstitial compensation. A second, and more important, limit to lithium doping comes from the solubility limits. The ranges of the chemical potentials are restricted by the free energies of other compounds of zinc, selenium, and lithium. The limits on $\mu_{\mathrm{Zn}}$ are imposed by bulk zinc and bulk selenium. The maximum value for the lithium chemical potential, $\mu_{\mathrm{L} i}$, is determined by $\mathrm{Li}_{2} \mathrm{Se}$. These chemical potential limits fix the maximum solubility of lithium in $\mathrm{ZnSe}$ at $10^{18}-10^{19} \mathrm{~cm}^{-3}$ for a temperature of $600 \mathrm{~K}$. 
Similar calculations show a much lower solubility for sodium and a somewhat higher solubility for nitrogen. Furthermore, nitrogen does not suffer from interstitial compensation. These results explain the failure of sodium doping of $\mathrm{ZnSe}$, the partial success of lithium doping, and the greater success of nitrogen doping.

\section{Publications}

\section{(Publications denoted by an asterisk represent work} supported by OER-BES)

1.* Z. W. Lu, S.-H. Wei, and A. Zunger, "Electronic Structure of Random $\mathrm{Ag}_{0.5} \mathrm{Pd}_{0.5}$ and $\mathrm{Ag}_{0.5} \mathrm{Au}_{0.5}$ Alloys," Phys. Rev. B 44, 1991, pp. 10470-10484.

2.* Z. W. Lu, S.-H. Wei, and A. Zunger, "Large Lattice-Relaxation-Induced Electronic Level Shifts in Random $\mathrm{Cu}_{1-\mathrm{x}} \mathrm{Pd}_{\mathrm{x}}$ Alloys," Phys. Rev. B 44 (Rapid Commun.), 1991, pp. 3387-3390.

3.* Z. W. Lu, S.-H. Wei, and A. Zunger, "Electronic Structure of Ordered and Disordered $\mathrm{Cu}_{3} \mathrm{Au}$ and $\mathrm{Cu}_{3} \mathrm{Pd}$," Phys. Rev. B 45, 1991, p. 10314.

4. S.-H. Wei, L. G. Ferreira, and A. Zunger, "FirstPrinciples Calculations of the Order-Disorder Transition in Chalcopyrite Semiconductors," Phys. Reo. B 45 (Rapid Commun.), 1992, p. 2533.

5.* D. B. Laks and A. Zunger, "Theory of Interfacial Stability of Semiconductor Superlattices," Phys. Rev. B 45, 1992, p. 14177.

6. D. B. Laks and A. Zunger, "The Identity of the Conduction Band Minimum in (AlAs) ${ }_{1}(\mathrm{GaAs})_{1}$ (001) Superlattices: Intermixing-Induced Reversal of States," Phys. Reo. B 45 (Rapid Commun.), 1992, p. 1141.

7. R. Osorio, J. E. Bernard, S. Froyen, and A. Zunger, "Ordering Thermodynamics of Surface and Subsurface Layers in the $\mathrm{Ga}_{1-x} \operatorname{In}_{x} \mathrm{P}$ Alloy", Phys. Rev. B 45, 1992.

8. R. Osorio, J. E. Bernard, S. Froyen, and A. Zunger, "Thermodynamics of Surface-Induced Ordering in the $\mathrm{Ga}_{0.5} \mathrm{In}_{0.5} \mathrm{P}$ Alloy," J. Vac. Sci. Tech. B 10, 1992.
9. Z. W. Lu and A. Zunger, "The Electronic Charge Distribution in Crystalline Silicon: Comparison of $A b$-Initio Theory and Experiment," Acta Cryst. A 48, 1992, pp. 545-554.

10.* Z. W. Lu, S.-H. Wei, and A. Zunger, "Theory of Bonding Charge Density in $\beta$ 's NiAl," Acta Metall. et Mat. 40, 1992, p. 2155.

11. S. Froyen, "Real-Space Grids and Fast-Fourier Transforms in Pseudopotential Solid-State Calculations," Phys. Reo. B 45, 1992, p. 3796.

12.* D. B. Laks, R. Magri, and A. Zunger, "Diamond-Like Order in Zinc-Blende Compounds," Solid State Communications, 83, 1992, p. 21.

13. R. Magri and A. Zunger, "Real-Space Description of Semiconducting Band Gaps in Substitutional Systems," Phys. Reo. B 44, 1991, p. 8672.

14. J. E. Bernard and A. Zunger, "Strain Energy and Stability of Si-Ge Compounds, Alloys, and Superlattices," Phys. Reo. B 44, 1991, p. 1663.

15. D. B. Laks, C. G. Van de Walle, G. F. Neumark and S. T. Pantelides, "First-principles Calculations of Solubilities and Doping Limits: $\mathrm{Li}, \mathrm{Na}$, and N in ZnSe," Physical Reoiew 45, 1992, p. 10965.

16. D. B. Laks and C. G. Van de Walle, "SelfCompensation and Doping Problems in ZnSe," Materials Research Society Conference Proceedings Vol. 242, December 1991, Boston, Massachusetts.

17. C. G. Van de Walle and D. B. Laks, "First-Principles Investigations of Acceptors in ZnSe," Materials Research Society Conference Proceedings Vol. 242, December 1991, Boston, Massachusetts. 


\section{Section 6 Solid-State Spectroscopy}

\section{Investigators}

A. Mascarenhas, Senior Scientist

G.S. Horner, Graduate Student

\section{Objective}

The goal of our research is to obtain an understanding of the fundamental opto-electronic properties of solid-state materials used for PV applications. We hope that this will provide clues to the intrinsic performance limitations of PV devices. In addition to investigating traditional PV semiconductor materials, an important aspect of this research is exploring the optical properties of novel semiconductor architectures that have potential for PV applications. During FY 1991, this research focused on the opto-electronic properties of an alloy system exhibiting the phenomenon of spontaneous lateral compositional modulation. We investigated the changes in the electronic band structure and the dielectric function caused by this phenomenon using polarized low-temperature photoluminescence and polarized modulation reflectance techniques.

\section{Major Accomplishments}

We successfully set up two new experiments. One experiment was to measure the symmetry of the dielectric function using polarized low-temperature modulation techniques; the other was to measure excited states using the technique of excitation spectroscopy. We used both these techniques in our experimental studies on the opto-electronic properties of samples exhibiting spontaneous lateral composition modulation. Because this was the focus of our research activities during FY 1991, it will be discussed in detail below. In setting up the experiments, we selected and installed a pump laser, a scanning dye laser, and a scanning Ti-Sapphire laser, and developed a high-precision scanning drive system. Both experiments were entirely computer automated. We were unable to conduct experiments for roughly a quarter of FY 1991 due to activities related to the Tiger Team visit to NREL.

\section{Spectroscopic Studies on Spontaneously Generated Lateral Superlattices}

In the FY 1990 Annual Report, we described our pioneering studies on the opto-electronic properties of samples of vertical bi-layer superlattices (BSLs) of $(\mathrm{GaP})_{2} /(\mathrm{InP})_{2}$, which exhibited the phenomenon of spontaneous lateral composition modulation. Our low-temperature polarized photoluminescence studies demonstrated for the first time that the optical properties of these structures were controlled not by the vertical BSL, but rather by the lateral composition modulation. This year, we performed polarized photoreflectance measurements to examine the symmetry of the dielectric function and thereby confirm that the symmetry of the electronic band structure in these samples was governed by the symmetry of the lateral superlattice. The polarized photoreflectance modulation spectra shown in Figure 6-1 are measured using the chopped 488-nm line of an Ar-ion laser as the modulating source, with the sample at room temperature. The dashed lines in Figures 6-1(a) and 6-1(b) show the measured change in reflectance $\Delta R / R$ as a function of photon energy for photons linearly polarized along the [110] and [110] directions, respectively. The strong inflections seen near $1.9 \mathrm{eV}$ originate from contributions to the dielectric function by the direct band edge $\left(M_{0}\right.$ critical point) of the buffer layer and show no anisotropy for incident light polarized along[110] or [110]. The inflections seen near $1.76 \mathrm{eV}$ originate from contributions to the dielectric function by critical points in the BSL's joint density of states and show a strong polarization anisotropy between the $[1 \overline{1} 0]$ and [110] directions.

An important observation in Figure 6-1 is that the [110] direction, in which the strongest contribution from the momentum matrix element to the dielectric function of the BSL occurs, is consistent with the direction in which the strongest contribution from the momentum matrix element to the interband electronic transitions in the BSL occurs (refer to Figure 6-1 of 


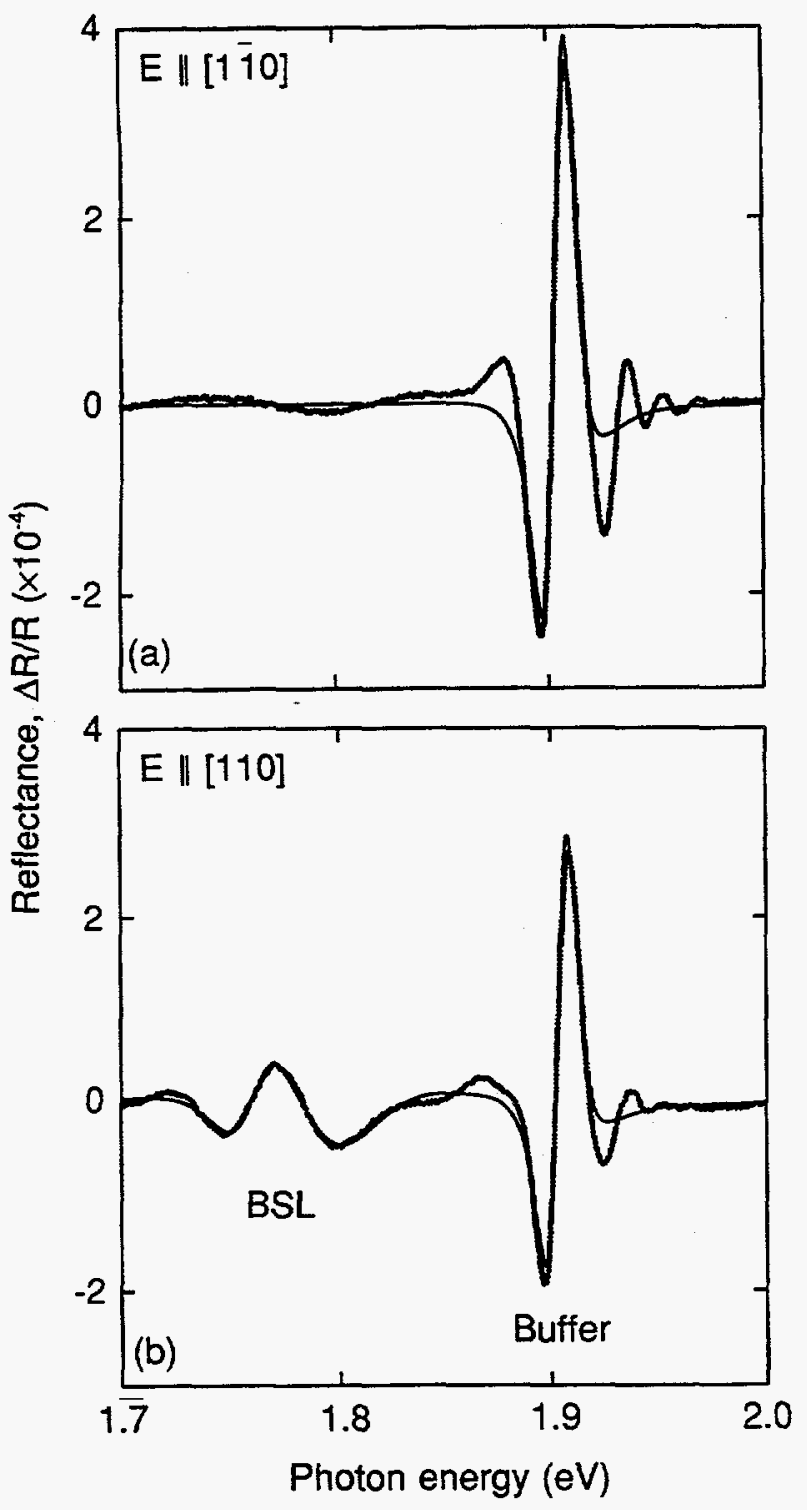

Figure 6-1. PR Spectra of the sample at room temperature with the polarization of the incident light E along (a) [110] and (b) (110). The experimental results are shown by the dashed lines; the solid lines represent the theoretical best fit.

FY 1990 Annual report). The solid lines in Figure 6-1 are generated using Aspnes' third-derivative functional form for $\Delta R / R$ at $M_{0}$ critical points to best fit the experimental data. The best fit to the spectra are obtained using a value of $1.905 \mathrm{eV}$ for the critical point of the buffer and values of $1.761 \mathrm{eV}$ and $1.798 \mathrm{eV}$ for critical points of the BSL. The values of $1.761 \mathrm{eV}$ and $1.905 \mathrm{eV}$ are consistent with the values of the transition energies of the BSL and buffer, respectively, measured using room-temperature photoluminescence.
To search for excited states and to profile the absorption edge of the lateral composition modulated structures, we performed excitation spectroscopy measurements. The excitation spectra are shown in Figure 6-2. Peaks 1, 2, and 3 are generated by Resonant Raman Scattering in the buffer. Peak 4 is attributed to excitonic absorption in the buffer. The characteristic shape of this spectral signature, which is associated with the density of states, provides evidence for reduced dimensionality in the buffer, caused by pattern transfer of the lateral coherency strain wave in the BSL. These results are consistent with those obtained by our photoluminescence measurements (refer to FY 1990 Annual Report) and confirm the existence of a strain-generated lateral superlattice in the buffer.

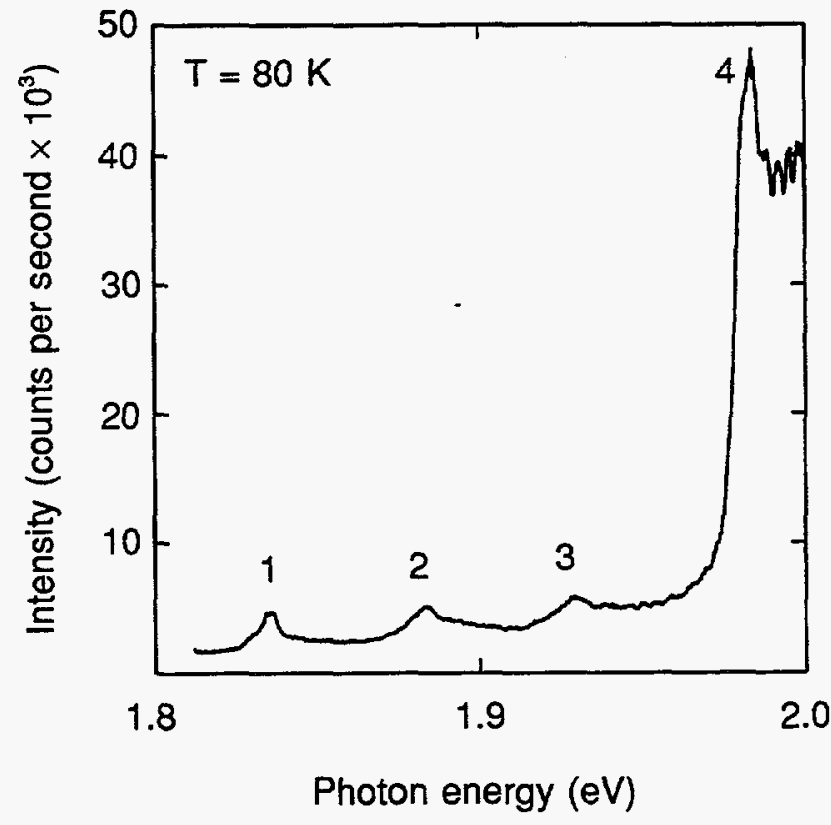

Figure 6-2. Photoluminescence excitation spectrum of the buffer layer

\section{Publications}

K. Y. Cheng, K. C. Hsieh, and J. N. Baillargeon, Proceedings of the 18th International Symposium of $\mathrm{GaAs}$ and Related Compounds 120, 1992, p. 589. London: Institute of Physics Series.

A. Mascarenhas, R. G. Alonso, G. S. Horner, S. Froyen, $\mathrm{K}$ C. Hsieh, and K. Y. Cheng, "Spontaneous Composition Modulation: A New Tool For Tailoring The Opto-electronic Properties Of Semiconductors," Proceedings of the 11th Photovoltaic Project Review Meeting, Denver, Colorado, 1992. New York: American Institute of Physics. 


\section{Section 7 Superconductivity}

\section{Investigators}

R. Blaugher, Principal Scientist and Task Leader

R. Noufi, Principal Scientist

R. N. Bhattacharya, Staff Scientist

P. A. Parilla, Staff Scientist

L. L. Roybal, Master Technician

\section{Objectives}

The electric power industry requires highly efficient conversion, storage, and transmission of energy. The installation of superconducting devices into existing electrical generation and transmission grids would yield significant energy savings with respect to fuel costs and overall electrical losses.

Superconducting power components would be more widely considered and accepted if these devices could be operated at liquid nitrogen $(77 \mathrm{~K})$ rather than the present liquid helium temperature $(4.2 \mathrm{~K})$ required by conventional superconductors. NREL is pursuing the development of the high-critical-temperature oxide materials in a viable conductor configuration suitable for operation at liquid nitrogen temperature.

The focus of our investigation is the thallium-oxide superconductors which presently offer the highest critical temperatures observed to date at $125 \mathrm{~K}$. NREL is studying a novel electrodeposition process that offers low cost and scalability to long-length conductor configurations such as wire or tape. We are concentrating on the demonstration of high electrical transport current in a mechanically rugged and flexible conductor that can be transitioned into high-temperature superconducting power applications. In addition, the processing approach and the thallium materials system can be applied to selected applications in the electronics area, such as back plane interconnects for multi-chip modules.

\section{Major Accomplishments}

\section{Technical Highlights}

The outstanding critical current densities measured to date for polycrystalline $\mathrm{Tl}-\mathrm{Ba}-\mathrm{Ca}-\mathrm{Cu}-\mathrm{O}$ (TBCCO) films

are as follows: (1) the critical current density at $77 \mathrm{~K}$ for a pulsed-potential TBCCO film on silver foil was $10,000 \mathrm{~A} / \mathrm{cm}^{2}$ in zero magnetic field, (2) the critical current density at $76 \mathrm{~K}$ for a TBCCO film deposited at constant potential on a silver-coated $\mathrm{SrTiO}_{3}$ substrate was $20,000 \mathrm{~A} / \mathrm{cm}^{2}$ in zero magnetic field and $5,000 \mathrm{~A} / \mathrm{cm}^{2}$ in a 1-tesla field parallel to the film plane, and (3) the critical current density of a pulsed-potential deposited TBCCO film on silvercoated $\mathrm{SrTiO}_{3}$ was $56,000 \mathrm{~A} / \mathrm{cm}^{2}$ at $76 \mathrm{~K}$ in zero magnetic field. These values represent some of the better results to date in this field, and we are very encouraged that some of the major stumbling blocks in realizing a viable high-temperature superconductor (HTSC) can be overcome.

\section{Subcontracts and Collaborations}

In 1989, NREL solicited letters of interest (LOI) for subcontracted research on oxide superconductor materials. As a result of this solicitation and subsequent review of proposals requested from the top six applicants, two subcontracts were awarded to General Electric Corporate Research and Development (GE-CRD) and Rutgers University.

The GE-CRD program, which concentrated on the bismuth oxide system, evaluated the introduction of artificial pinning centers produced by fission tracks to provide improved critical current density. This program was subsequently redirected to support NREL internal research on the thallium oxide electrodeposited films. GE-CRD provided an important collaboration in the high-temperature reaction of the thallium films. GE-CRD had pioneered a two-zone reaction process for the thallium superconductors that was used as an alternative method to the standard "pellet" process followed by other laboratories. This two-zone reaction process, coupled with the extensive GE background in reacting the thallium-based superconductors, quickly produced attractive results with 
current density $\sim 10^{4} \mathrm{~A} / \mathrm{cm}^{2}$ at $77 \mathrm{~K}$ in zero magnetic field for NREL's electrodeposited films on silver foil. This result represented the highest current density obtained for the thallium system on a flexible substrate.

The Rutgers program was successful in demonstrating a current density at $77 \mathrm{~K}$ greater than $10^{6} \mathrm{~A} / \mathrm{cm}^{2}$ for $\mathrm{Y}-\mathrm{Ba}-\mathrm{Cu}-\mathrm{O}$ (YBCO) films deposited on ceramic substrates using MOCVD deposition. A fine sub-micron dispersion of $\mathrm{Y}_{2} \mathrm{O}_{3}$ was produced that greatly enhanced the critical current density in applied magnetic fields.

In addition to the above subcontracts, collaborations continued with Sandia National Laboratories and Los Alamos National Laboratory. Both of these collaborations greatly extended the materials understanding of the thallium oxide system and provided independent reaction capability and corroboration of NREL results. As noted in the publications section, a number of joint papers were presented and published from this interaction.

\section{Development of Electrodeposition Processing}

The Superconductivity Group has spent considerable effort on understanding the critical electrodeposition parameters needed for the production of high-quality superconducting films. We have made much progress in expanding our knowledge base in this area, and we are continuing our research to further refine the processing procedure. Our research in FY 1991 included the following achievements:

- We empirically discovered the correct deposition potentials required for the simultaneous deposition of all the constituent metals in the respective oxide systems (TBCCO, BSCCO, and YBCO). This was achieved using a technique called cyclic voltammetry (see Figure 7-1).

- We empirically ascertained the correct concentrations of the constituents in the electrodeposition bath required to produce the proper stoichiometric films. This was done for the thallium-, bismuth-, and yttrium-based systems.

- We investigated the effect of different substrates on the electrodeposition process. Both singlecrystal and polycrystalline substrates were explored and include $\mathrm{MgO}$, yttria-stabilized zirconia, $\mathrm{SrTiO}_{3}$, nickel, silver, silver-palladium, Consil 995, and a General Atomic proprietary wire. For each of these substrates, an empirical adjustment of the elctrodeposition bath was needed to yield the proper stoichiometric films.

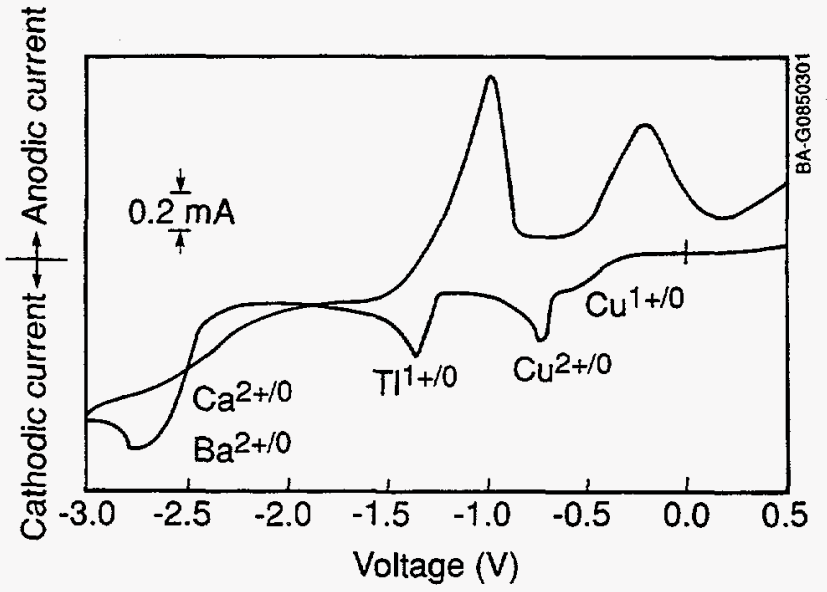

Figure 7-1. Cyclic voltammogram for a solution mixture of $\mathrm{TINO}_{3}, \mathrm{Ca}\left(\mathrm{NO}_{3}\right)_{2} 4 \mathrm{H}_{2} \mathrm{O}, \mathrm{Ba}\left(\mathrm{NO}_{3}\right)_{2}$, and $\mathrm{Cu}\left(\mathrm{NO}_{3}\right)_{2}$ dissolved in dimethyl sulfoxide

- We investigated the effect of silver on the electrodeposition process. A thin layer of silver is needed on the normally nonconductive substrates to electrodeposit films. We investigated the influence this thin layer has on the resultant film.

- We studied several issues related to the final morphology of the film. These include using a pulsed electric field instead of a steady-state field and stirring the electrochemical bath during deposition.

- We investigated the effect that different electrochemical cells have on the electrodeposition process with particular regard to the reproducibility from run to run and the uniformity on a given film.

-We installed a new electrodeposition system, which consists of a state-of-the-art potentiostat/ galvanostat (PAR 273A) interfaced to an IBM AT computer (see Figure 7-2) and provides improved control and monitoring of the electrodeposition process. The new system offers a number of advantages over more conventional systems: (1) it allows sophisticated current/voltage profiles to be run automatically, (2) it gives precise control and reproducibility of deposition parameters, and (3) it facilitates monitoring the processing parameters and archiving the numerous processing runs.

\section{Heat Treatment of Electrodeposited Films}

The three oxide superconductors, i.e., YBCO, BSCCO, and $\mathrm{TBCCO}$, are usually prepared by mixing the respective oxides and reacting at high temperature 


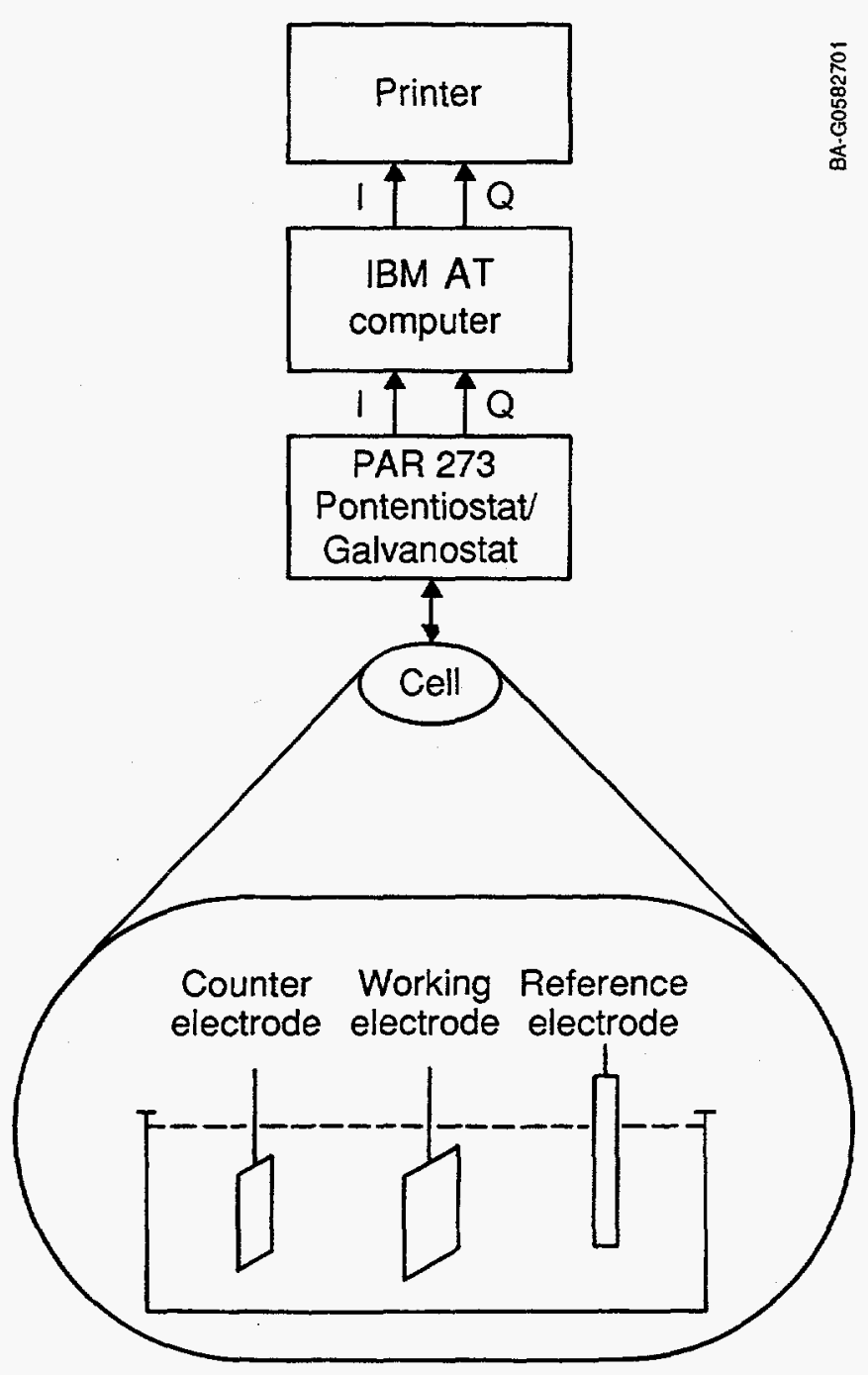

Figure 7-2. The electrodeposition schematic

$\left(800^{\circ} \mathrm{C}-1000^{\circ} \mathrm{C}\right)$ to form the proper compound. This process is repeated many times to produce the desired stoichiometry with acceptable superconducting properties.

The reaction of the bismuth and yttrium superconductors at NREL generally follows these procedures and presents no major difficulty in obtaining suitable superconducting properties. Moreover, the electrodeposited films produced at NREL provide a highly reactive mixture on an atomic scale, which markedly reduces the time and temperature compared to the usual powder calcining approach.

The thallium system, however, is compromised by the high volatility of the thallium, combined with its well known toxicity. Reactions of the thallium compounds are normally conducted in a sealed system using pellets prepared at the desired composition. These pellets maintain the thallium vapor pressure at the proper level to obtain the desired final composition following reaction. The pellet approach, however, does not lend itself to long-length conductor fabrication due to the limited content of thallium in the pellet.

NREL has adopted a procedure that was suggested by Oak Ridge National Laboratory and was implemented at GE-CRD. This "thallation" method uses a two-zone furnace that allows the sample and thallium source to be set at different temperatures. The mass for the thallium source can be much larger and easily replenished, which is essential for the continuous reaction process required for long-length conductors. NREL has constructed a two-zone reaction system as shown in Figure 7-3, which provides a 6-in $(15-\mathrm{cm})$ sample zone and a 4-in $(10-\mathrm{cm})$ thallium source region with temperature control to $\pm 2.0^{\circ} \mathrm{C}$ over the individual zones. The reaction can be conducted in either air or flowing $\mathrm{O}_{2}$. All reactions and effluents are contained in an ES\&H-approved system, which provides primary and secondary containment in the event of quartz tube failure and also provides complete gas clean-up of the thallium laden vapor.

\section{Microstructural Analysis}

Many aspects of the quality of the films have been studied to understand how changes in the processing affect the overall quality. These include structural, compositional, morphological, electrical, and magnetic properties of the films. X-ray analysis is used to determine the structure of the films, impurity phases, and the orientation of the film with respect to the substrate. Composition is determined by electron probe for microanalysis (EPMA), Auger electron spectroscopy (AES), and inductively coupled plasma (ICP). Morphology is routinely determined from optical and scanning electron microscopies. Electrical and magnetic characterization techniques are discussed in the following section.

\section{Superconductor Characterization}

To provide the necessary feedback to improve the characteristics of these HTSC films, routine characterization of the relevant properties is needed on a timely basis. NREL has numerous facilities that can perform many of these measurements, particularly with respect to the structural, compositional, and morphological makeup of the samples. However, there are many properties unique to superconductors, and NREL traditionally has not had the capability to characterize these properties. As a result, significant effort has been made to develop and expand the 


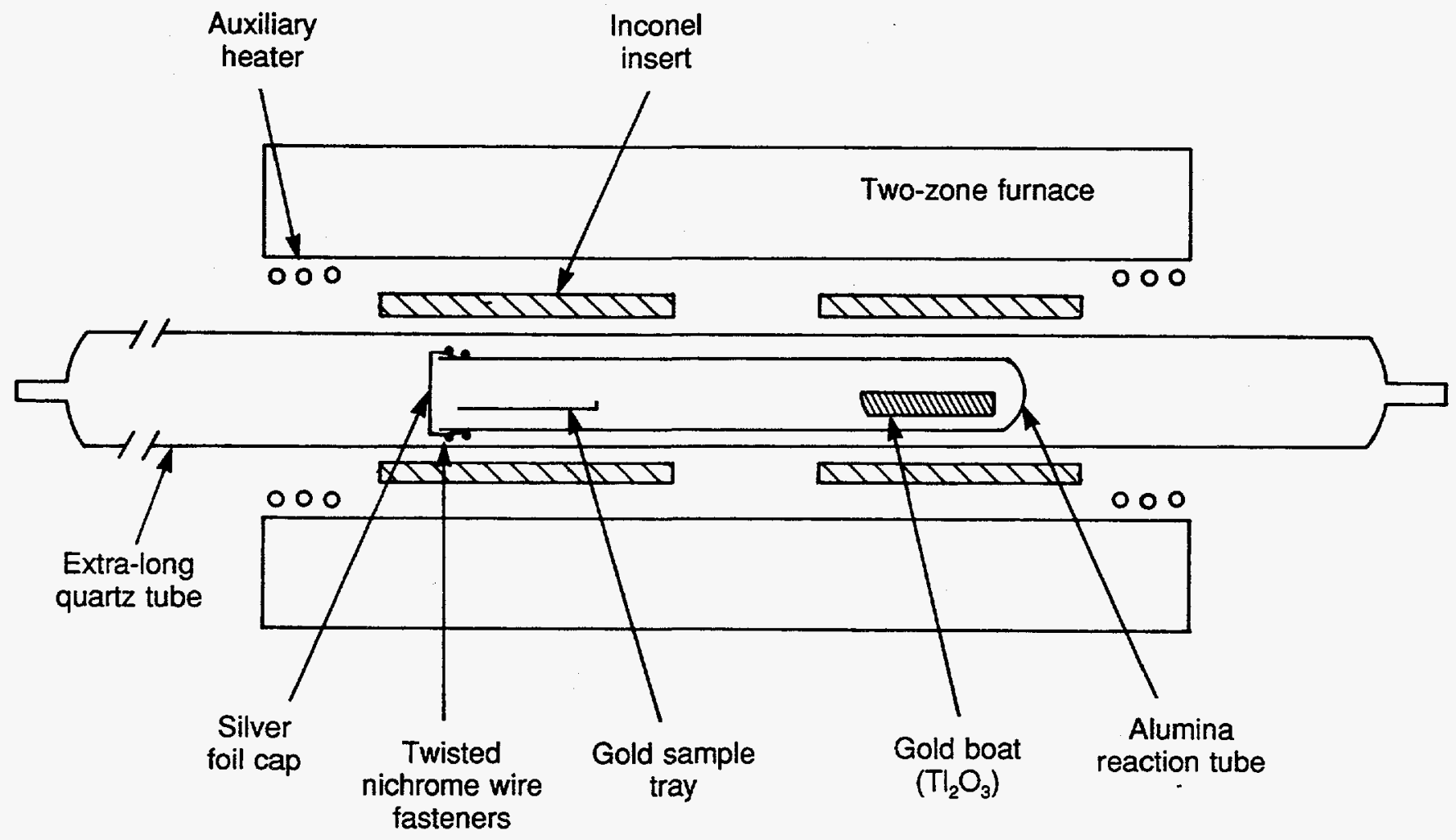

Figure 7-3. The two-zone furnace schematic

characterization capabilities for superconductors at NREL. A summary of these activities is provided below:

- Routine measurements of the critical current are now performed at NREL facilities. These facilities have the capability to measure the critical current of superconducting samples as a function of both temperature $(4-300 \mathrm{~K})$ and magnetic field $(0$ to - 1.0 tesla). Additionally, the sample's orientation to the magnetic field direction can be varied so that the zero-Lorentz force orientation may be compared to the non-zero one. Figure $7-4$ shows an example current-voltage curve from which the critical current is determined.

- NREL now has two resistance-versus-temperature measurement setups. One is used to quickly screen samples to see if they are of sufficient quality to warrant further investigation. This setup has a lower temperature range of $76 \mathrm{~K}$ (liquid nitrogen). The second setup uses the same apparatus as the critical current setup and has a lower temperature range of $4 \mathrm{~K}$ (liquid helium).
- For planar samples, the overall superconducting quality of the sample can be quickly and easily measured by a method called the mutual inductance measurement technique. A schematic of the technique is shown in Figure 7-5. It consists of two uniaxial coils separated by a short space where the sample is inserted. Passing an oscillating electric current through one of the coils (the "drive" coil) generates an oscillating magnetic field which, in turn, induces a signal in the second coil (the "pick-up" coil). This mutual inductor can be used to measure the superconducting properties of samples because superconductors can screen magnetic fields. The test sample is placed between the coils and the device is activated. When the sample is not superconducting, the magnetic field can pass through the sample, thereby inducing a strong signal in the pick-up coil. As the sample is cooled, it becomes superconducting and screens the magnetic field, reducing the ability of the drive coil to induce a signal in the pick-up coil. How well the sample screens the magnetic field and how this screening changes with temperature yield valuable information on the superconducting properties of the sample. 


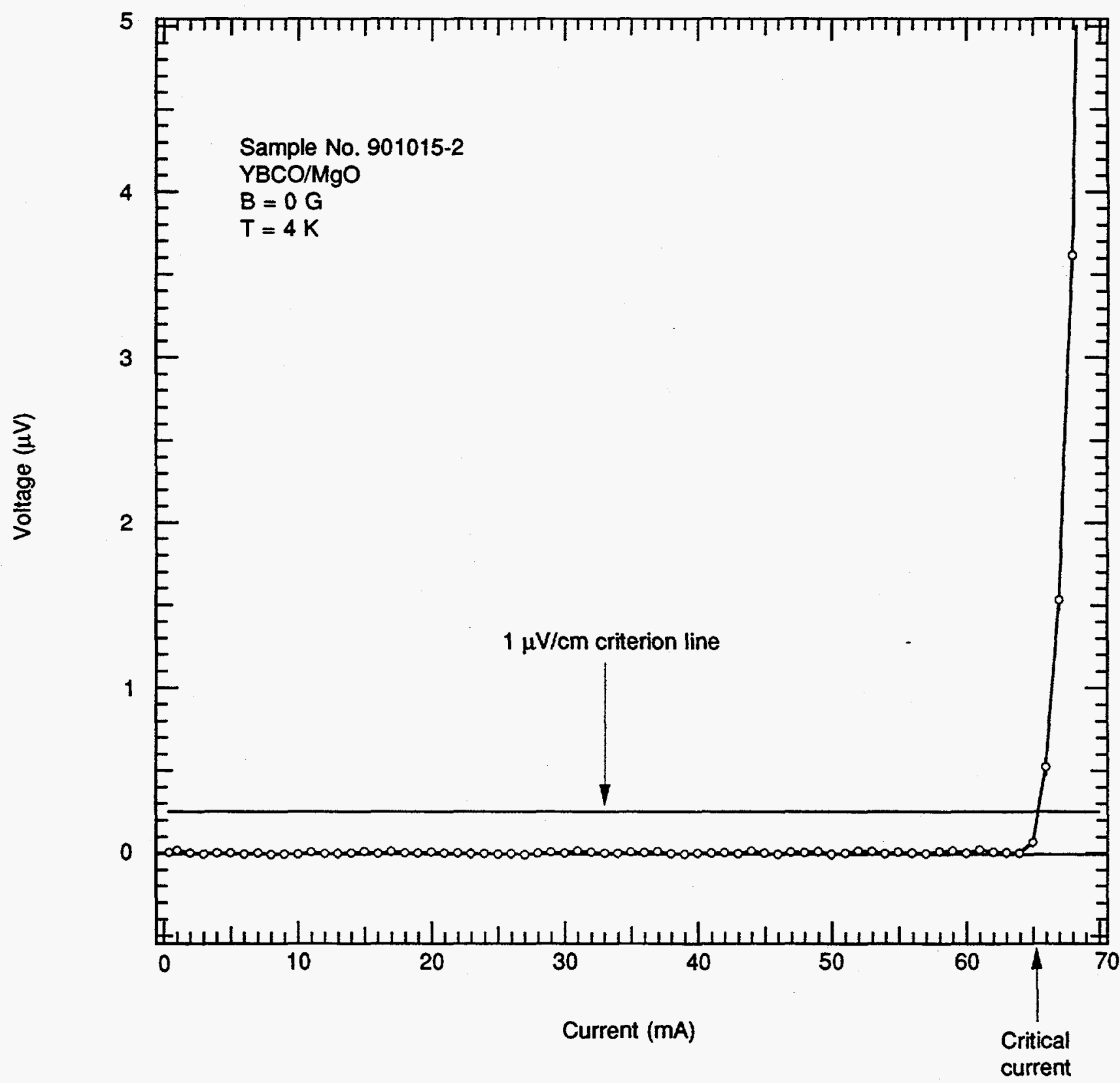

Figure 7-4. Typical current versus voltage for a YBCO film

\section{Publications and Presentations}

\section{Publications}

R. N. Bhattacharya, R. Noufi, L. L. Roybal, and R. K. Ahrenkiel, J. Electrochemical Soc. 138, 1991, p. 1643.

R. N. Bhattacharya, R. Noufi, L. L. Roybal, R. K. Ahrenkiel, P. Parilla, A. Mason, and D. Albin, in "Science and Technology of Thin Film Superconductors 2," 1991, p. 243.
R. N. Bhattacharya, P. A. Parilla, A. Mason, L. L. Roybal, R. K. Ahrenkiel, R. Noufi, R. P. Hellmer, J. F. Kwak, and D. S. Ginley, J. Mater. Res. 6, 1991, No. 7.

R. N. Bhattacharya, P. A. Parilla, R. Noufi, P. Arendt, and E. Elliot, J. Electrochem. Soc. 139, 1992, p. 67.

R. N. Bhattacharya, P. A. Parilla, L. L. Roybal, A. Mason, A. Swartzlander, R. K. Ahrenkiel, and R. Noufi, TMS Proceedings, High Temperature Superconducting Compounds III, 1991, p. 169. 


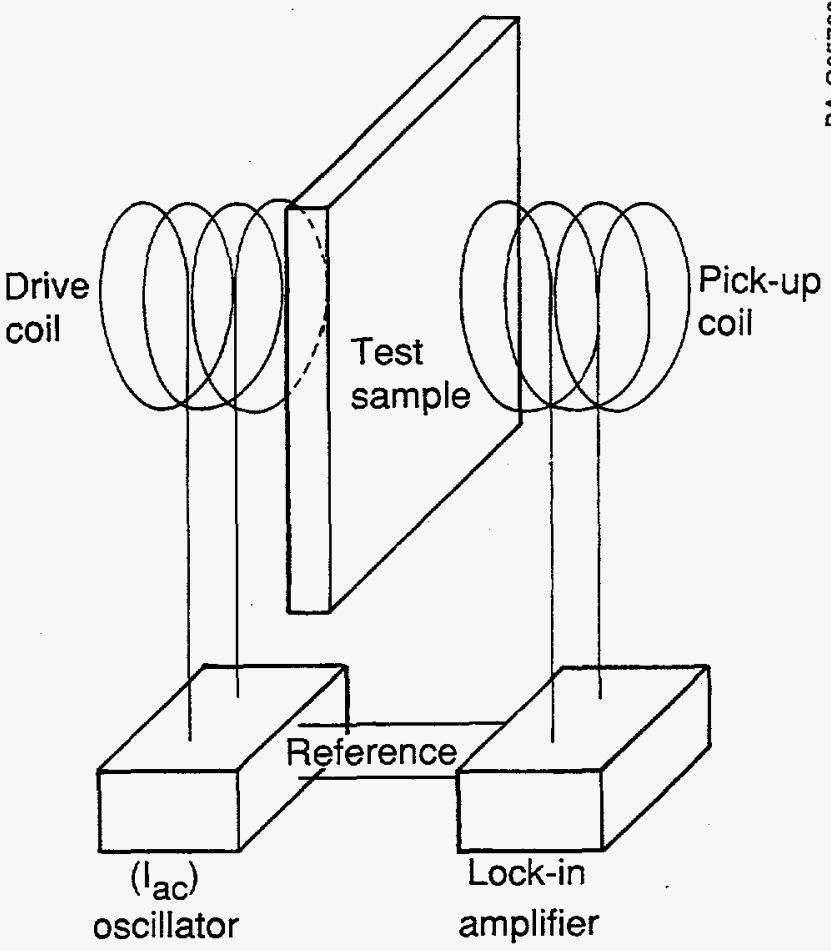

Figure 7-5. Schematic of the mutual inductance measurement selup

R. D. Blaugher, D. W. Hazelton, P. Haldar, J. A. Rise, J. G. Hoehn, and M. S. Walker, Conference on Superconductivity and Applications, Buffalo, NY. September 24-26, 1991.

L. R Motowidlo, E. Gregory, P. Haldan, J. A. Rice, and R. D. Blaugher, Appl. Phys. Lett. 59, 1991, pp. 736-738.

\section{Presentations}

R. Bhattacharya, "Oxide Superconductor Films via Electrodeposition," presented at the Materials

Research Society Fall Meeting, Boston, Massachusetts, December 1991.
R. Bhattacharya, "Electrodeposition of HighTemperature Superconductors," presented at the meeting of the Rocky Mountain Superconductivity Alliance, NREL, Golden, Colorado, August 1991.

R. Blaugher, "Design Aspects of HTS Power Transmission," presented at the Conference on Superconductivity and Applications, Buffalo, New York, September 1991.

R. Blaugher, "Electrodeposition of Oxide Superconductors," presented at the EPRI/DOE Coordinating Meeting on Power Applications, NST, Boulder, Colorado, October 1991.

R. Blaugher, "Electrodeposition of Tl-Oxide Superconductors," presented at the EPRI High Temperature Superconductor Workshop, Palo Alto, California, August 1991.

R. Blaugher, "HTS Conductor Meeting," presented at the Superconducting Technology Program for Electric Energy Systems, Washington, DC, July 1991.

R. Blaugher, "Melt-Processing of Oxide Superconductors," presented at the Defense Advanced Research Projects Administration (DARPA) Workshop on Power Applications, Santa Fe, New Mexico, February 1991.

R. Blaugher, "The Development of High-Temperature Superconductor Wires and Tapes," presented at the meeting of the Rocky Mountain Superconductivity Alliance, NREL, Golden, Colorado, August 1991.

R. Noufi, "Electrodeposition of Oxide Superconductors," presented at the TMS Annual Meeting, New Orleans, Louisiana, February 1991.

P. Parilla, "Superconductors," presented at the meeting of the Rocky Mountain Superconductivity Alliance, NREL, Golden, Colorado, August 1991. 


\begin{tabular}{|c|c|c|c|}
\hline $\begin{array}{l}\text { Document Control } \\
\text { Page }\end{array}$ & $\begin{array}{l}\text { 1. SERI Report No. } \\
\text { NREL/TP-451-4961 }\end{array}$ & $\begin{array}{l}\text { 2. NTIS Accession No. } \\
\text { DE93010012 }\end{array}$ & 3. Recipient's Accession No. \\
\hline \multirow{2}{*}{\multicolumn{3}{|c|}{$\begin{array}{l}\text { 4. Title and Subtitle } \\
\text { Annual Report, Basic Sciences Branch, FY } 1991\end{array}$}} & $\begin{array}{l}\text { 5. Publication Date } \\
\text { April } 1993\end{array}$ \\
\hline & & & 6. \\
\hline \multicolumn{3}{|c|}{$\begin{array}{l}\text { 7. Author(s) } \\
\text { Basic Sciences Branch }\end{array}$} & 8. Performing Organization Rept. No. \\
\hline \multirow{2}{*}{\multicolumn{3}{|c|}{$\begin{array}{l}\text { 9. Pertorming Organization Name and Address } \\
\text { National Renewable Energy Laboratory } \\
1617 \text { Cole Blvd. } \\
\text { Golden, Colorado } 80401-3393\end{array}$}} & $\begin{array}{l}\text { 10. Project/Task/Work Unit No. } \\
\text { PV314001 }\end{array}$ \\
\hline & & & $\begin{array}{l}\text { 11. Contract (C) or Grant (G) No. } \\
\text { (C) } \\
\text { (G) }\end{array}$ \\
\hline \multirow{2}{*}{\multicolumn{3}{|c|}{ 12. Sponsoring Organization Name and Address }} & $\begin{array}{l}\text { 13. Type of Report \& Period Covered } \\
\text { Progress Report }\end{array}$ \\
\hline & & & 14. \\
\hline \multicolumn{4}{|c|}{ 15. Supplementary Notes } \\
\hline \multicolumn{4}{|c|}{ 16. Abstract (Limit: 200 words) } \\
\hline \multicolumn{4}{|c|}{$\begin{array}{l}\text { This report summarizes the progress of the Basic Sciences Branch of the National Renewable Energy Laboratory } \\
\text { (NREL) from October 1, 1990, through September 30, 1991. Seven technical sections of the report cover these } \\
\text { main areas of NREL's in-house research: Semiconductor Crystal Growth, Amorphous Silicon Research, } \\
\text { Polycrystalline Thin Films, III-V High-Efficiency Photovoltaic Cells, Solid-State Theory, Solid-State } \\
\text { Spectroscopy, and Superconductivity. Each section explains the purpose and major accomplishments of the work } \\
\text { in the context of the U.S. Department of Energy's National Photovoltaic Research Program plans. }\end{array}$} \\
\hline \multicolumn{4}{|c|}{$\begin{array}{l}\text { 17. Document Analysis } \\
\text { a. Descriptors } \\
\text { solar cells ; semiconductors ; annual report ; research and development ; photovoltaics } \\
\text { b. Identifiers/Open-Ended Terms }\end{array}$} \\
\hline \multicolumn{4}{|l|}{$\begin{array}{l}\text { c. UC Categories } \\
270\end{array}$} \\
\hline \multirow{2}{*}{\multicolumn{2}{|c|}{$\begin{array}{l}\text { 18. Availability Statement } \\
\text { National Technical Information Service } \\
\text { U.S. Department of Commerce } \\
5285 \text { Port Royal Road } \\
\text { Springfield, VA } 22161\end{array}$}} & & $\begin{array}{l}\text { 19. No. of Pages } \\
61\end{array}$ \\
\hline & & & $\begin{array}{l}\text { 20. Price } \\
\text { A04 }\end{array}$ \\
\hline
\end{tabular}

Form No. 0069E (6-30-87) 